\title{
Sovereign contagion risk measure across financial markets in the eurozone: a bivariate copulas and Markov Regime Switching ARMA based approaches
}

\author{
Sawsen Bouker ${ }^{1}$ (D) Faysal Mansouri $^{1}$
}

Accepted: 31 August 2021 / Published online: 13 November 2021

(C) The Author(s) under exclusive licence to Kiel Institute for the World Economy 2021

\begin{abstract}
This paper analyzes sovereign risk contagion across financial markets in the eurozone during and after the European debt crisis. A particular focus is made on the causal impact of pre-Brexit and Covid-19 pandemic on the dependence between European markets. We use data set from 28 February 2008 to 11 March 2021 and combine copulas and MRS-ARMA techniques to measure dependence across financial markets and assessing asymmetric dependence structure and regime switching process. We develop a dynamic Kendall's tau correlation and provide evidence of time-varying dependence structure between several pairwise markets. The dependence structure shows a sharp rise on 23 June 2016, day of the referendum on Brexit. Results indicates that Covid-19 pandemic has intensified dependence and sovereign risk spillovers between sovereign CDS European markets. Significant time-varying characteristics of dynamic dependence structures suggests that fund managers and investors should consider in their investment strategies to manage systemic risk and high-risk investment. The identification of dependence structure regime between global financial markets would enhance response to major crises by investors and policy makers.
\end{abstract}

Keywords Pre-brexit · Covid-19 pandemic · Sovereign risk contagion · Copula's approach $\cdot$ Markov switching regime $\cdot$ ARMA models

Sawsen Bouker

saoussen22@hotmail.fr

1 IHEC Sousse, Research Laboratory LaREMFiQ Sousse, University of Sousse, Sousse, Tunisia 


\section{Introduction and related literature review}

The transmission of uncertainty from one market, region, country to another remains an important field of research in light of major global economic, financial, geopolitical and public health crises.

This research represents an attempt to study the causal impact on the dependence structure between financial markets by major events or shocks such as, Brexit, Sovereign debt crisis, Subprime crisis, and Covid-19 pandemics.

Indeed, the announcement of withdraw of UK from the European Union and the transitional phase, namely pre-Brexit, would have a substantial effect on the linkages between European financial markets. Using data from 28 February 2008 to 11 March 2021, this work takes advantage of the announcement of UK withdraw from the EU and the subsequent transition process to test the impact on the dependence structure between European financial markets.

Undoubtedly, Brexit is a major event in the history of EU. Since its announcement, Brexit has urged individuals, businesses, and policy makers to anticipate possible scenarios including threats, opportunities, exit strategies. Brexit is, indeed, associated with a high degree of financial, economic risks and uncertainties that would substantially affect UK, EU markets. The impact of pre-Brexit on the dependence structure of EU markets has received little or no attention of the literature. This work constitutes an attempt to provide findings that carry important implications for the post-Brexit UK in transition and for European countries.

COVID-19 global pandemic exponential spread around the world has caused overwhelming challenges to global public health and left households and businesses counting economic losses. Since its eruption, this global pandemic has increased tremendously uncertainty and fear of human and economic losses. Moreover, it is not clear how full social and economic recovery would take place. The analysis of potential effects of this major pandemic on various economic and financial markets around the globe has received little or no attention from the literature. Our work attempts to shed lights on these fundamental aspects by measuring risk transmission and global market linkages.

The analysis of the European sovereign debt crisis of 2009, a major economic event of the recent years, has been the subject of increasing interest in the academic literature. The study of the dependence between eurozone financial markets and in particular the analysis of dependence among sovereign CDS markets represent both a theoretical and an empirical framework that capture sovereign default risk transmission among sovereign European CDS markets.

Sovereign Credit Derivative Swap (CDS) is a derivative instrument that allow investors to swap credit risk that a country may go into default or experience substantial difficulties. Sovereign CDS spreads express default sovereign risk. In this regard, high sovereign default risks are expressed by large sovereign CDS spreads.

Debt crisis has major adverse effects not only on political stability but also on and economic and financial stability but more importantly on individual welfare and social cohesion. 
The Greek crisis spreads very quickly to Ireland, Spain, Italy and Portugal. As the turbulence spread over several euro-zone economies. Several reform programs and bailout plans have been proposed to rescue institutions and governments in particular for Greece (Fratzsher et al. 2016, Hryckiewicz 2014 and Kizys et al. 2016).

Nonetheless, linkages between financial markets have not received much attention as during the recent European debt crisis. Understanding the nature of linkages between markets and economies is fundamental for effective policy design and rational investment choices and it is not clear whether such model of uncertainty transmission exists or has been used.

Contagion is defined as the spread of a crisis from one market, region, or country to another. Because markets, regions or countries are interconnected, major events in one market region or country can impact others. Authors argue that contagion is characterized by an amplification and persistence of spillover effects (see Allen and Gale (2000), Dornbusch et al. (2000), Pericoli and Sbracia (2003) among others).

Potential effects of crisis transmission or contagion are measured based on historical data or information on existing relationships or linkages between financial markets. In assessing linkages between financial markets, authors distinguish between crisis period and tranquillity or calm period. In principle, during a crisis or stress period, transmission of uncertainty is supposed to increase in comparison to a calm or normal period. Links change depending upon the level of stress. Authors considers risk contagion is expressed by major co-movements and volatility spillovers (see, e.g., Sachs et al. (1996), Masson (1999a, b, c), Dornbusch et al. (2000), Pericoli and Sbracia (2003) and Dungey et al. (2006)).

One might argue that analysing the degree of the co-movement between financial markets during crisis periods, relative to that in calm periods may demonstrate the normal interdependence between financial markets and economies. Distinction is made between contagion and interdependence. Forbes and Rigobon (2002) define contagion as a significant increase in the cross-market linkages during a crisis or a common shock after controlling for fundamentals. Prior to Forbes and Rigobon (2002), authors chiefly address interdependence and not financial contagion. Since the publication of Forbes and Rigobon (2002), financial contagion has been examined mainly around the notion of "correlation breakdown". Financial contagion could be internal ,i.e., cross-markets but also global ,i.e., cross-borders. External shocks may affect any asset market in an economy, and then spread to asset markets in other countries as well. Internal shocks may spread out by inter-linkages to other domestic asset markets. If a crisis strikes a given financial market around the globe, negative shocks are transmitted from the source to other financial markets.

In the case of the European debt crisis, sovereign CDS were initially unaffected but as the crisis evolves the effect spread out to other financial markets. Most of the research studies financial contagion in the context of equity markets (Fry-McKibbin et al., 2021). Few existing empirical works focuses on contagion effect between sovereign CDS and commodity markets during a sovereign debt crisis. Research on sovereign CDS markets, analyses co-movement of sovereign CDS with other assets, mainly stocks and bonds. More recent studies analyse the development of correlations between commodities and financial assets in the aftermath of the global financial crisis (Sun et al., 2020). Authors focus more on contagion effect 
between commodity and other financial markets (see Sharpe (1964), Grubel and Fadner (1971), King and Wadhwani (1990), Engle et al. (1990), Bekaert and Hodrick (1992), and later from Forbes and Rigobon (2002), Barberis et al. (2005), Hwang et al. (2013), Aloui and Hkiri (2014), Alotaibi and Mishra (2015), Ji et al. (2018a, b, c), Chen et al. (2020)).

Most authors have mainly focused on the transmission mechanism of sovereign risk. However, there is absence of consensus on the transmission pattern among the European countries, see Louzis (2015), Alter and Beyer (2014), De Bruyckere et al. (2013), Alter and Schuler (2012), Barth et al. (2012), Arezki et al. (2011), Caceres et al. (2010). For example, Brutti and Saure (2015) find that the exposure to Greek government debt and Greek banks' assets are main sources of strengthening transmission's risk. Kohonon (2014) argues that sovereign default risk was transmitted from the Greek bonds markets only at the early stage of the crisis. Using VAR, Dieblod and Yilmaz $(2012,2014)$ examine financial spillovers effects between various economies and markets. Apostolakis and Papadopoulos (2015) analyse the effects between the G7 banking, securities and foreign exchange markets, identifying interactions between them. Grammatikos and Vermeulen (2012) find strong evidence of a crisis transmission from US non-financials to European non-financials.

The analysis of the relevant literature shows scarcity of research on sovereign contagion risk between sovereign CDS and financial markets during the European debt crisis. Moreover, the analysis of sovereign contagion between sovereign CDS and commodity markets are even more scarce. Several authors discuss the nature of the co-movement or correlation or time-varying correlation among different sovereign CDS markets or between sovereign CDS and stock markets. Nonetheless, there absence of research on contagion between sovereign CDS and commodity markets. Moreover, authors analyse more global financial contagion and not contagion across domestic financial markets.

On technical issues, authors have privileged linear correlations approach to examine the linkages between international financial markets. More recently, researchers have turned to use various techniques to examine the dependence structures between assets across markets and countries, see Chen et al. (2020), Zhang et al. (), Daehler et al. (2021). Indeed, most of the linear correlation analysis is not time varying. In addition, it is difficult to analyse the asymmetric dependency between various markets by applying linear correlation. Also, linear correlation does not capture extreme downside risk spillovers. In contrast, copula methods allow to describe the dynamic and asymmetric dependency structures. The copula approach provides a tool to isolate the dependence pattern from the marginal distributions, and it is possible to obtain more conveniently dependency structure and contagion effects. Durante and Jaworski (2010), use copula methods to show that dependency between financial markets in the crisis period is higher than that of the tranquillity period.

In this paper, we attempt to examine the impact of major global crises, preBrexit, Covid-19 pandemic, sovereign debt crisis, on the dependence structure between financial markets. A particular focus is given to sovereign risk contagion by providing an alternative measure to linear correlation that go beyond the specification of the crisis and non-crisis periods via suitable thresholds. This measure is computed by non-parametric methods. 
Also, we provide a detailed account of potential transmission channels sovereign default risk within the peripheral European countries, Ireland, Italy, Portugal and Spain. We use the Kendall's tau correlation instead of Pearson's correlation to detect the nonlinear dependency structure among financial markets and to examine Sovereign contagion risk during the European debt crisis. Using the Dynamic Conditional Kendall's tau correlation allow to study the dynamic dependency structure as well as the links between financial markets. Hence, we provide a dynamic dependence measure that shows the degree of dependence and exhibits associations between financial markets over time.

Financial contagion is detected when there is a change in the dependence structure between financial markets and not when there is persistent extreme dependence caused more by interdependence and not by contagion. The dependence between two markets is described by using the information contained in the copula and not by the means of the local correlation coefficients as in Bradley and Taqqu (2005) and Durante and Jaworski (2010).

First, we compute the daily conditional Kendall's tau correlation, using the information incorporated in copulas of couples' sovereign CDS indexes as proxy of sovereign default risk and various other financial markets indexes for stock, bonds, and commodity markets.

Second, we use Markov Regime Switching ARMA model for Daily conditional Kendall's tau correlation of different pairs to examine the changes in dependence structure during the European debt crisis. Dueker (1997), Hamilton and Susmel (1994), Lamoureux, and Lastrapes (1990) argue that Markov Regime Switching (MRS) model is a better to model time varying of the stock market return distribution.

We believe that modelling of dynamic daily conditional Kendall's tau correlation, using the MRS-ARMA model offer a novel approach to show the transmission of sovereign risk from the sovereign CDS markets to various financial markets (stock, government bonds and commodity markets) and indicate the presence of sovereign contagion risk during the European debt crisis.

This paper is structured as follows. The next section presents the methodology and describes the various copulas functions and Markov Switching Auto-Regressive Moving Average Model (MS-ARMA) model. Section 3 presents the estimation results. Section 4 provides conclusions.

\section{Methodology}

Our methodology is based on three important steps. In the first step, we select the proper copula family by goodness of fit tests. Various copula families have various characteristics of Kendall's tau correlation that allow identification of Kendall's Tau correlation between different pairs of data. In the second step, we compute the dynamic conditional Kendall's tau correlation by using the dynamic conditional linear correlation. DCC-GJR GARCH model allow to obtain the daily dynamic linear correlation. In the third step, we model the daily Kendall's tau correlation of different pairs, using Markov Switching Regime (MSR) model to show the dependence structure between financial markets movement over time in various markets. 


\subsection{Copula functions and dependence measures}

In the context of dependence between variables is measured by a dependence function or copula function.

Let $\mathbf{F}$ be the joint marginal distribution function (DF) of a random vector $\boldsymbol{X}=\left(\boldsymbol{X}_{1}, \boldsymbol{X}_{2}, \ldots, \boldsymbol{X}_{\boldsymbol{d}}\right) \in \mathbb{R}^{d}$. Let $\left(\boldsymbol{F}_{1}, \boldsymbol{F}_{2}, \ldots, \boldsymbol{F}_{\boldsymbol{d}}\right)$ be their marginal DFs and let $\boldsymbol{X}_{\boldsymbol{i}} \rightarrow \boldsymbol{F}_{\boldsymbol{i}}\left(\boldsymbol{X}_{\boldsymbol{i}}\right), \boldsymbol{i}=1, \ldots, \boldsymbol{d}$, be the probability integral transformation to the standard uniform distribution. Then, the copula function is given by the following formula:

$$
C\left(u_{1}, u_{2}, \ldots, u_{d}\right)=F\left(F_{1}^{-1}\left(u_{1}\right), F_{2}^{-1}\left(u_{2}\right), \ldots, F_{d}^{-1}\left(u_{d}\right)\right) \forall u=\left(u_{1}, \ldots, u_{d}\right) \in[0,1]^{d}
$$

where $\mathbf{F}_{i}^{-1}$ are the inverse distribution functions of the marginal and $\boldsymbol{u}_{\boldsymbol{i}}=\boldsymbol{F}_{\boldsymbol{i}}\left(\boldsymbol{x}_{\boldsymbol{i}}\right)$ for $\boldsymbol{i}=1, \ldots, \boldsymbol{d}$. Thus, the copula function is a multivariate distribution with uniform $[0,1]$ margins. The copula $\mathbf{C}$ completely identifies the distribution $\mathbf{F}$, Sklar (1959), $\forall\left(\boldsymbol{X}_{1}, \boldsymbol{X}_{2}, \ldots, \boldsymbol{X}_{\boldsymbol{d}}\right) \in \mathbb{R}^{d}$ :

$$
\boldsymbol{F}\left(\boldsymbol{x}_{1}, \boldsymbol{x}_{2}, \boldsymbol{x}_{3}, \ldots, \boldsymbol{x}_{\boldsymbol{n}}\right)=\boldsymbol{C}\left(\boldsymbol{F}_{1}\left(\boldsymbol{x}_{1}\right), \boldsymbol{F}_{2}\left(\boldsymbol{x}_{2}\right), \boldsymbol{F}_{3}\left(\boldsymbol{x}_{3}\right), \ldots, \boldsymbol{F}_{\boldsymbol{d}}\left(\boldsymbol{x}_{\boldsymbol{d}}\right)\right)
$$

Equations (1) and (2) show that the copula represents the multivariate dependence structure, which links the uniform marginal distributions. The copula of any $\mathbf{F}$ distribution captures and summarizes the different types of dependence between variables even when they are rescaled by strictly monotone transformations.

- The Gaussian copula (normal copula): $C_{\text {Gaussian }}^{\rho}$

$$
C_{\text {Gaussian }}^{\rho}\left(u_{1}, u_{2}, \ldots, u_{d}\right)=\int_{-\infty}^{\Phi^{-1}\left(u_{1}\right)} \ldots \int_{-\infty}^{\Phi^{-1}\left(u_{d}\right)} \frac{1}{(2 \pi)^{d / 2}|R|^{1 / 2}} \exp \left(\frac{-1}{2} y^{\prime} R^{-1} y\right) d y_{1} \ldots d y_{d}
$$

where $-1<\rho<1$ and $\Phi$ is the cumulative distribution function of a standard normal distribution, $\Phi_{\Sigma}$ is the multivariate normal cumulative distribution function with mean zero and $m \times m$ correlation matrix $\mathrm{R}, \Phi^{-1}$ is the inverse function of the standard univariate normal distribution, $|R|$ is the determinant of the correlation matrix $\mathrm{R}$ and $y=y_{1}, \ldots, y_{d}$.

In the case of Gaussian copula, the Kendall's tau correlation is computed as follows:

$$
\tau_{i, j}=\frac{2}{\pi} \arcsin \rho_{i, j}
$$

- The student-t copula: $C_{t}^{\rho, v}$

The d-dimensional student-t copula (or briefly t copula) function takes the form: 


$$
\begin{aligned}
C_{t}^{\rho, v}\left(u_{1}, u_{2}, \ldots, u_{d}\right) & =T_{R, v}\left(T^{-1}\left(u_{1}\right), T^{-1}\left(u_{2}\right), \ldots, T^{-1}\left(u_{d}\right)\right) \\
& =\int_{-\infty}^{T^{-1}\left(u_{1}\right)} \ldots \int_{-\infty}^{T^{-1}\left(u_{d}\right)} \frac{\Gamma\left(\frac{v+d}{2}\right)|R|^{-\frac{1}{2}}}{\Gamma\left(\frac{v}{2}\right)(v \pi)^{\frac{d}{2}}}\left(1+\frac{1}{v} y^{\prime} R^{-1} y\right)^{-\frac{v+d}{2}} d y_{1} \ldots d y_{d}
\end{aligned}
$$

where $T_{R, v}$ the standardized multivariate student-t distribution function with $m \times m$ correlation matrix $\mathrm{R}$ of $\mathrm{v}$ degrees of freedom and $T^{-1}$ is the inverse function of the standard univariate student-t distribution with $\mathrm{v}$ degrees of freedom. The Kendall's tau is the same as for the Gaussian copula.

- The Gumbel copula: $C_{G u}^{\theta}$

Gumbel (1960) proposes the Gumbel copula with the following generator:

$$
\varphi(u)=(-\ln (u))^{\theta} \text { where } \theta>1
$$

The d-dimensional Gumbel copula is defined as follows:

$$
C_{G u}^{\theta}\left(u_{1}, u_{2}, \ldots, u_{d} ; \theta\right)=\exp \left(-\left[\sum_{i=1}^{d}\left(-\ln u_{i}\right)^{\theta}\right]^{\frac{1}{\theta}}\right)
$$

The Kendall's tau formula is given by following expression:

$$
\tau_{k}=1-\frac{1}{\theta}
$$

- The Clayton copula: $C_{C l}^{\theta}$

Clayton (1978) develops the Clayton copula with the following generator:

$$
\varphi(u)=u^{-\theta}-1 \text { where } \theta>0
$$

The d-dimensional Clayton copula is defined as follows:

$$
C_{C l}^{\theta}\left(u_{1}, u_{2}, \ldots, u_{d} ; \theta\right)=\left(\sum_{i=1}^{d} u_{i}^{-\theta}-d+1\right)^{-\frac{1}{\theta}}
$$

The Kendall's tau formula is given by the following expression:

$$
\tau_{k}=\frac{\theta}{\theta+2}
$$

- The Frank copula: $C_{F}^{\theta}$ 
The Frank copula (1979) is characterized by the following generator:

$$
\left.\varphi(t)=-\ln \left(e^{-\theta t}-1 / e^{-\theta}-1\right) \text {, where } \theta \in\right]-\infty, 0[\cup] 0,+\infty[
$$

The Frank copula is defined by:

$$
C_{F}^{\theta}\left(u_{1}, u_{2} ; \theta\right)=\frac{-1}{\theta} \ln \left(1+\frac{\left(e^{-\theta u_{1}}-1\right)\left(e^{-\theta u_{2}}-1\right)}{\left(e^{-\theta}-1\right)}\right)
$$

The Kendall's tau: $\tau_{k}=1-\frac{4}{\boldsymbol{\theta}}\left(1-\boldsymbol{D}_{1}(\boldsymbol{\theta})\right)$

- The Placket copula: $C_{P}^{\theta}$

Plackett (1965) introduces Plackett's copula.

$$
C_{P}^{\theta}\left(u_{1}, u_{2} ; \theta\right)=\frac{1+(\theta-1)\left(u_{1}+u_{2}\right)-\sqrt{\left[1+(\theta-1)\left(u_{1}+u_{2}\right)\right]^{2}-4 \theta(\theta-1) u_{1} u_{2}}}{2(\theta-1)}
$$

If $\theta=1$, then $C\left(u_{1}, u_{2} ; \theta\right)=u_{1} u_{2}$ which correspond to independence case.

- The symmetrized Joe Clayton copula: $C_{S J C}^{\tau_{U}, \tau_{L}}$

The Joe-Clayton copula is given by:

$$
C_{J C}\left(u_{1}, u_{2} ; \tau_{U}, \tau_{L}\right)=1-\left(\left\{\left[1-\left(1-u_{1}\right)^{k}\right]^{-\delta}+\left[1-\left(1-u_{2}\right)^{k}\right]^{-\delta}-1\right\}^{\frac{-1}{\delta}}\right)^{\frac{1}{k}}
$$

where $k=\frac{1}{\log _{2}\left(2-\tau_{U}\right)}, \delta=\frac{-1}{\log _{2}\left(\tau_{L}\right)}$ and $\tau_{U}, \tau_{L} \in(0,1)$

This copula has two parameters $\tau_{U}$ and $\tau_{L}$, which are the coefficients of upper and lower tail dependence respectively, Patton (2004). The Joe-Clayton copula has a slight asymmetry when $\tau_{U}=\tau_{L}$, which is not convenient. To overcome this issue, the symmetrized Joe-Clayton copula (SJC) is introduced and defined as following:

$$
\begin{aligned}
C_{S J C}\left(u_{1}, u_{2} \backslash \tau_{U}, \tau_{L}\right)= & 0.5 C_{J C}\left(u_{1}, u_{2} \backslash \tau_{U}, \tau_{L}\right)+0.5 C_{J C}\left(1-u_{1}, 1-u_{2} \backslash \tau_{U}, \tau_{L}\right)+u_{1} \\
& +u_{2}-1
\end{aligned}
$$

Which is symmetric when $\tau_{U}=\tau_{L}$.

\subsection{Markov Switching Auto-Regressive Moving Average Model: MS-ARMA model}

Markov Switching ARMA (MS-ARMA) processes are extensions of the ARMA processes allowing for time dependent ARMA coefficients, modelled as a chain Markov. Next, we first present the essence of MS-ARMA models and then the estimation process using maximum likelihood. 
- MS-ARMA model:

MS-ARMA models provide an appropriate framework to analyse the representations with changes in regime. MS-ARMA allow to examine the dynamic structures, based on value of the state variable, St, that controls the varying mechanism between various states. Moreover, the underlying parameters may be varying in accordance with the regime prevailing at time $t$. The nonlinear and common factor structures of the cyclical processes are represented at the same time. We consider the following presentation of the MS-ARMA model:

$$
\Delta y_{t}=\alpha\left(s_{t}\right)+\sum_{i=1}^{p} A_{i}\left(s_{t}\right) \Delta y_{t-i}+\sum_{j=1}^{q} B_{j}\left(s_{t}\right) \varepsilon_{t-j}+\varepsilon_{t}\left(s_{t}\right)
$$

The MS-ARMA with regime switching in the conditional mean and variance are defined as a regime-switching model, Hamilton (1989), where an observed Markov chain governs the regime switchess $s_{t}$, with ns states number and Ps transition probability matrix. The model is completed by specifying dynamics of the unobservable state variable $s_{t}$.

We assume that the model has two states $(\mathrm{ns}=2)$. Therefore, $\alpha, A_{i}$ and $B_{j}$ depend on the state variable $s_{t}$, and the matrix Ps. The transition probabilities are collected in a $2 \times 2, P_{s}$ given by:

$$
\text { Ps }=\left(\begin{array}{ll}
P_{11} & P_{12} \\
P_{21} & P_{22}
\end{array}\right)
$$

The link between the two states of the market is provided by a first order Markov process with following transition probabilities.

$$
\begin{aligned}
& \operatorname{Pr}(S t=1 / S t-1=2)=P_{21} \text { and } \operatorname{Pr}(S t=2 / S t-1=1)=P_{12} \\
& \operatorname{Pr}(S t=1 / S t-1=1)=P_{11} \text { and } \operatorname{Pr}(S t=2 / S t-1=2)=P_{22}
\end{aligned}
$$

where $P_{12}\left(P_{21}\right)$ indicates the probability that state $1(2)$ will followed by state $2(1)$, and $P_{11}$ and $P_{22}$ determine probabilities of staying in same regime. Additionally, $P_{i j}$ controls the probability of transition from $i$ state to $j$ state at time $t+1$.

To estimate the parameters of the MS-ARMA model by MLE the density of $Y t$, given the past information of $\psi_{t-1}$ is:

$$
\begin{aligned}
f\left(y_{t} \backslash \psi_{t-1}, S_{t}\right) & \\
\quad= & \frac{1}{\sqrt{2 \pi \sigma_{S_{t}}^{2}}} \exp \left(\frac{\left(y_{t}-\left(\alpha_{s_{t}}+\alpha_{1}, s_{t} y_{t-1}+\cdots+\alpha_{p}, s_{t} y_{t-p}+b_{1}, s_{t} \varepsilon_{t-1}+\cdots+b_{q}, s_{t} \varepsilon_{t-q}\right)\right)^{2}}{2 \sigma_{s_{t}}^{2}}\right)
\end{aligned}
$$

The joint probability of $y_{t}$ and $S_{t}$ is then given by the product:

$$
f\left(y_{t}, S_{t}=j \backslash \psi_{t-1}\right)=f\left(y_{t} \backslash S_{t}=j, \psi_{t-1}\right) P\left(S_{t}=j \backslash \psi_{t-1}\right) ; \quad j=1,2
$$


The conditional density of the $t$ th observation is the sum of these terms over all values of $S_{\mathrm{t}}$ for a two state cases:

$$
f\left(y_{t} \backslash \psi_{t-1}\right)=\sum_{S_{t=1}}^{2} \sum_{S_{t-1}=1}^{2} f\left(y_{t} \backslash \psi_{t-1}, S_{t}\right) P\left(S_{t} \backslash \psi_{t-1}\right)
$$

Then, the log likelihood function is given by:

$$
\ln L=\sum_{t=1}^{T} \ln \left(\sum_{S_{t}=0}^{1} f\left(y_{t} \backslash \psi_{t-1}, S_{t}\right) P\left(S_{t} \backslash \psi_{t-1}\right)\right) \text { where } P\left(S_{t} \backslash \psi_{t-1}\right) \text { is filtered }
$$

probabilities, which these probabilities are computed using the filter introduced by Hamilton (1989) for $t=1 \ldots T$. these probabilities refer to inferences about $S_{\mathrm{t}}$ conditional on information up to $t, \psi_{t}$. So, the smoothed probabilities $P\left(S_{t} \backslash \psi_{t}\right)$ using all available information in the sample, $\psi_{t}$ for $t=t-1, t-2 \ldots 1$ and given $P\left(S_{t} \backslash \psi_{t}\right)$ at the last iteration of the filter.

\section{Empirical results}

\subsection{Data description}

We examine data of a set of countries from Asia, China and Japan, the USA, from Africa South Africa, eight eurozone core countries, Belgium, Denmark, Poland, France, Germany, Netherlands, UK, and Sweden, and five peripheral countries Ireland, Italy, Greece, Portugal and Spain. For each country, we consider daily data of sovereign CDS, sovereign bonds and stock market indexes and eight commodities Crude Oil, Energy, Foodstuffs, Gold, Industrial Metals, Natural Gas, Nickel and Silver.

Data series are retrieved from Thomson Reuters (DataStream), covering the period from 28 February 2008 to 11 March 2021 so a total of 3400 observations. The data relative to the Greek sovereign bond is available until 08 March 2012 (1100 observations). The sample data period covers a wide range of major events.

The description of the daily market indexes is illustrated in the next Fig. 1. Indeed, we note a similar fluctuation pattern between sovereign CDS, sovereign bond, commodity, and stock market indexes for the selected countries. All financial market indexes trend together for the entire sample period. Some historical periods appear more riskier than others. For example, we observe a significant increase in sovereign CDS spreads since the start of the Greek debt crisis in March 2009 to 2013, mid-2014 to March 2020. Indeed, these periods cover respectively the European debt crisis 2009-2013, Arab spring, collapse of oil price, UK announcement of withdrawal from EU or pre-Brexit and Covid-19 pandemic. Data indicates a decrease in prices of sovereign bonds, stock and commodity markets. Furthermore, there is some indication of the existence of sovereign contagion risk as characterized by markets movements.

Descriptive statistics of daily return data are reported in Table 1. For changes in sovereign CDS and sovereign bonds spreads, Greece maintains the highest daily mean and volatility levels. As for the stock returns, Greece has the maximum and minimum returns, which indicates that the volatility in Greece's stock market is relatively higher. 

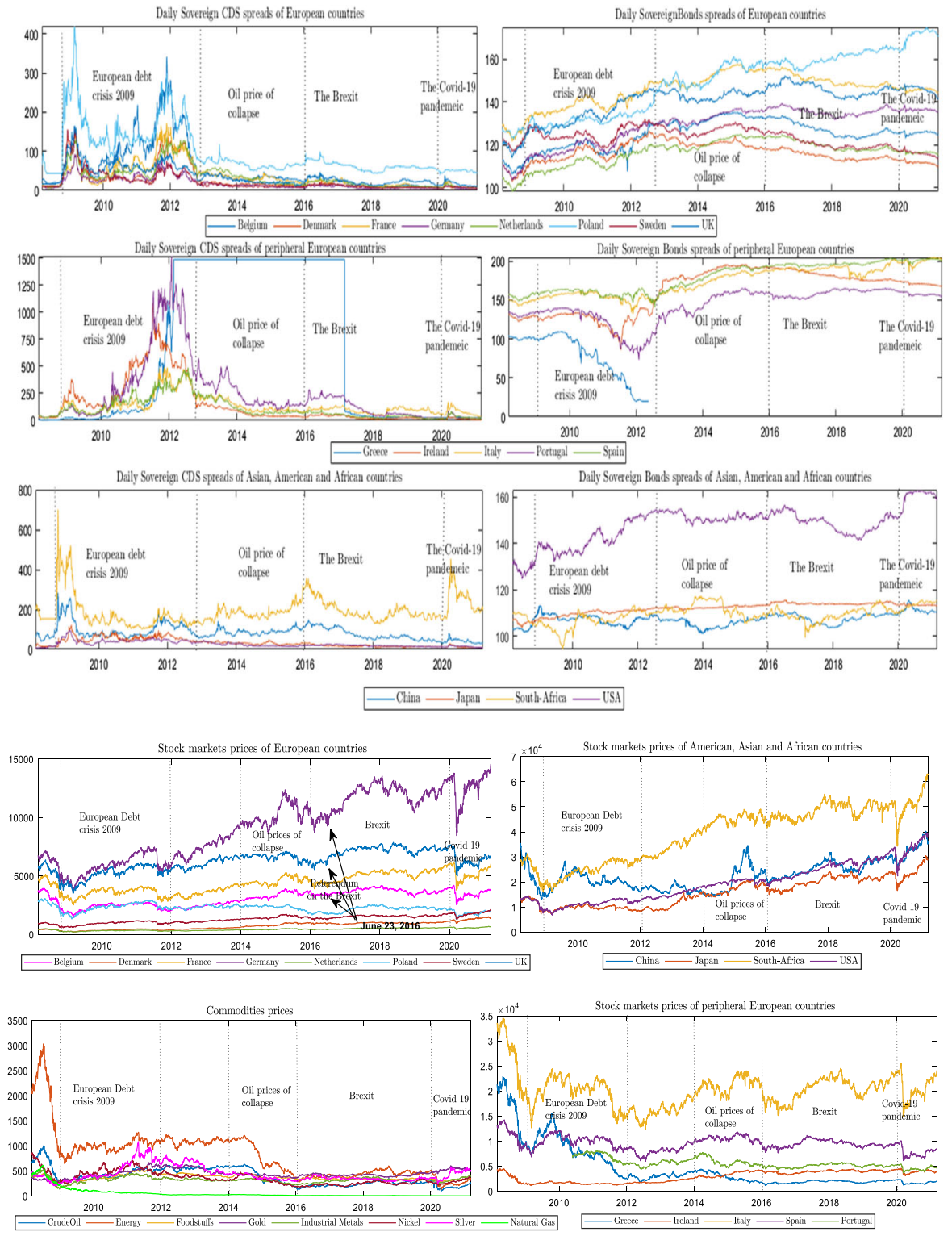

Fig. 1 Daily sovereign CDS spreads, sovereign bonds spreads, stock, and commodities prices

Moreover, the mean values are positive for all countries, except for Greece, Italy, Portugal, Spain, and Poland. For commodity returns, Crude-Oil, Energy, Natural Gaz, and Nickel have negative mean values. Nonetheless, standard deviation the Natural Gaz market is the highest, with the value of $2.61 \%$ followed by the CrudeOil (2.15\%). 


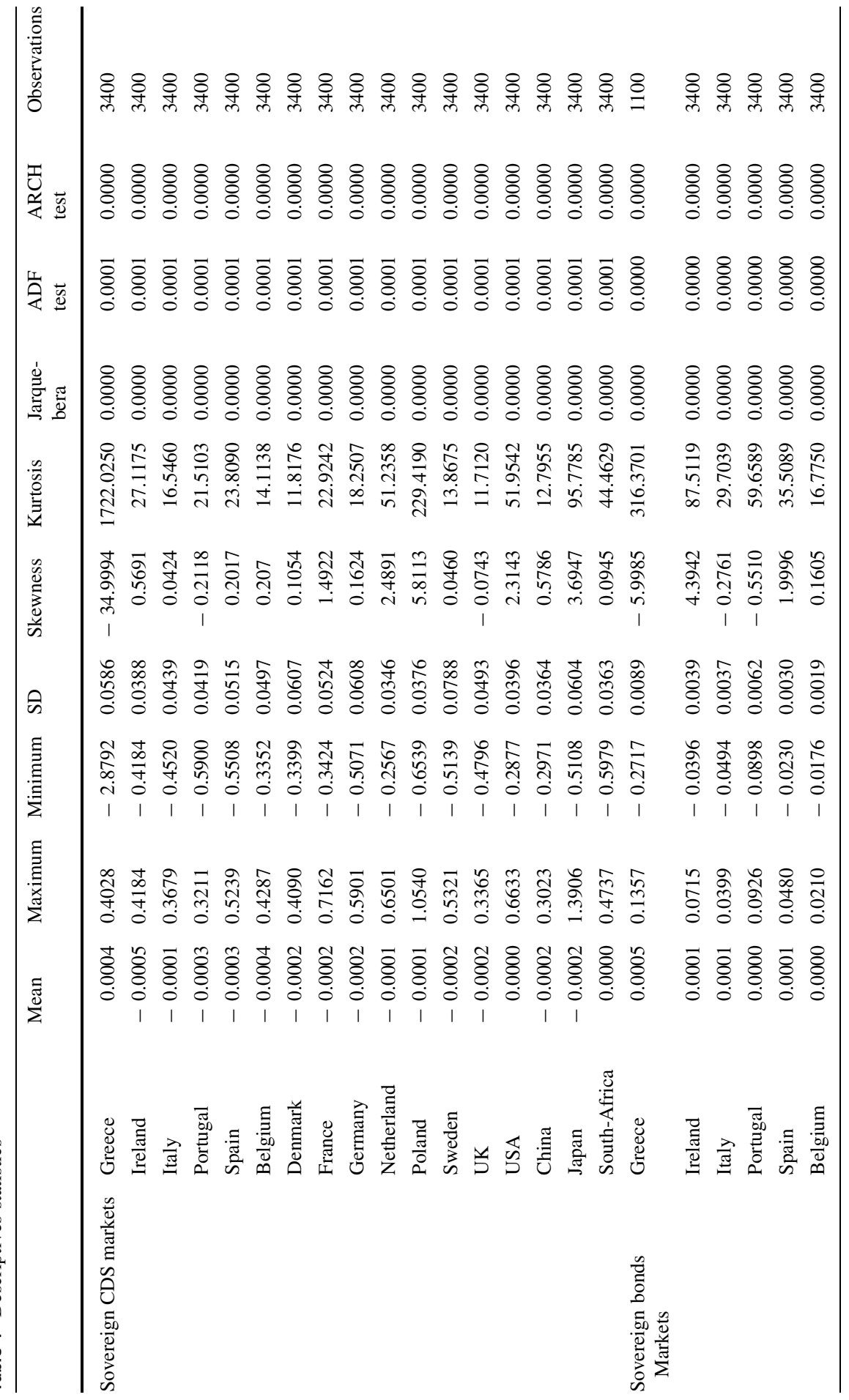




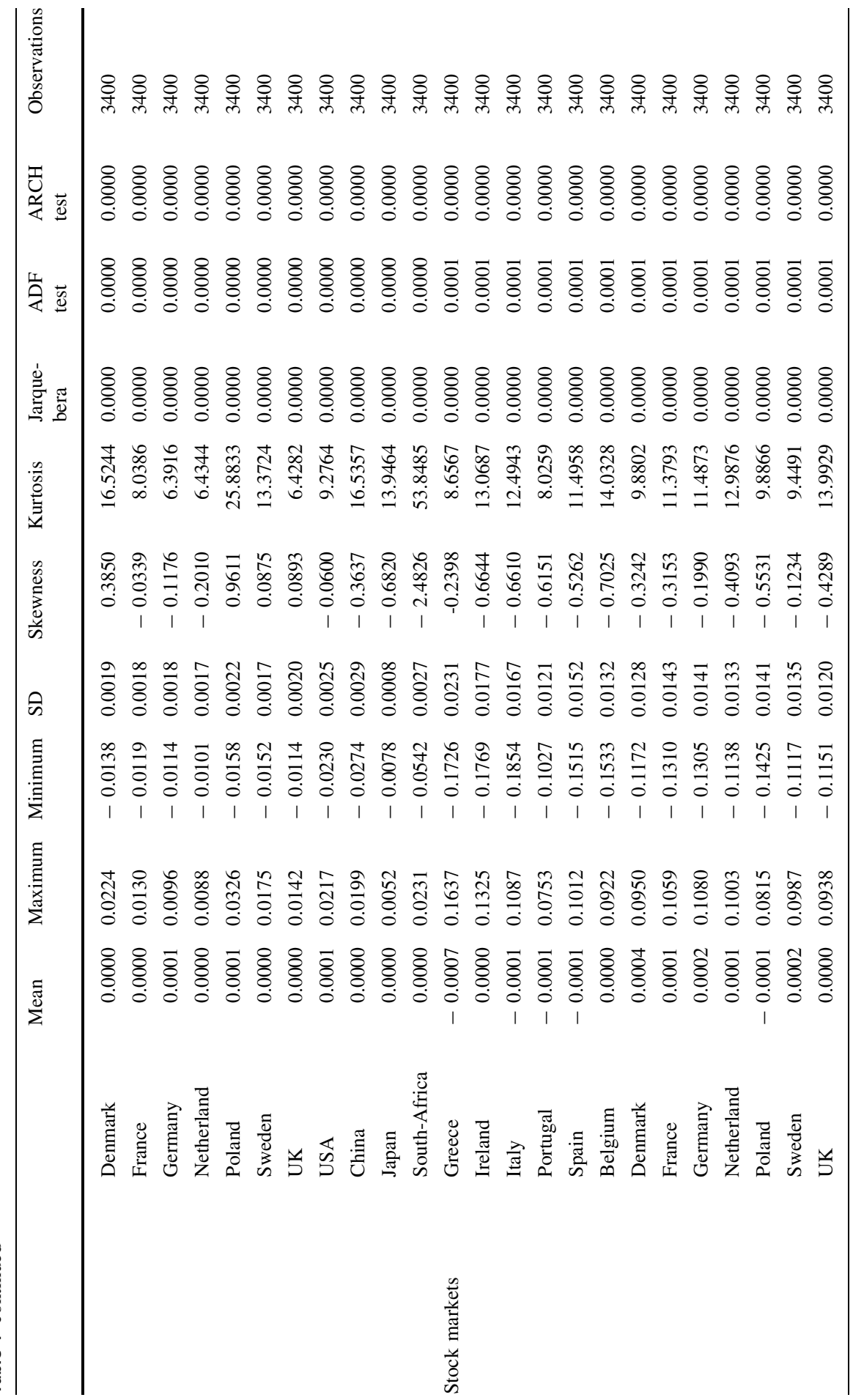




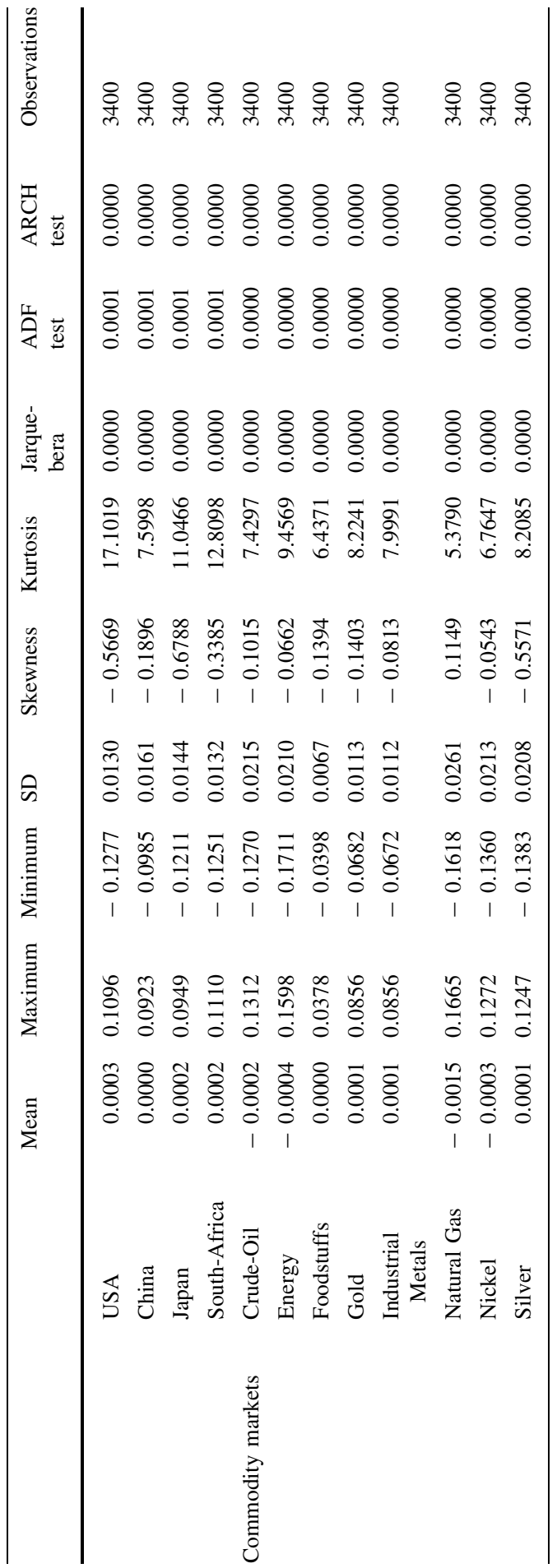


The time series are leptokurtic (Kurtosis statistic is greater than 3), indicating an asymmetric distribution. Jarque-Bera test reject the null hypothesis of normality of the entirety of return series, thus justifying an exploration of the correlations based on extreme dependence. Moreover, ADF tests indicate that all series are stationary and $\mathrm{ARCH}$ tests suggests the presence of heteroscedasticity phenomena, at significant level $1 \%$.

\subsection{Sovereign default risk proxy's analysis}

We examine the relationship between sovereign CDS spreads and sovereign bonds spreads of peripheral countries. First, results show how sovereign bonds changes correlate with sovereign CDS changes for peripheral eurozone countries. Pearson correlation coefficients are calculated and reported in Table 2. Regarding internal correlations within the sovereign bond markets, the highest correlation coefficient appears in Italy-Spain pair (0.7), while the Italy-Greece pair reveals the lowest correlation coefficient (0.18). As far as internal interactions within sovereign CDS markets, ItalySpain pair has the highest coefficient correlation (0.67), followed by Italy-Portugal pair (0.65). Finally, we focus on external interactions between sovereign bond and sovereign CDS markets. Results show that correlations are negative for all pairwise markets.

Second, we further explore the lead-lag relationships between sovereign CDS and sovereign bond markets and to identify the source of sovereign credit risk. Hence, we use the most widely utilized test that is the standard linear Granger-Causality test, Granger (1969), based on a vector autoregressive model VAR of order $\mathrm{p}$ $(\operatorname{VAR}(\mathrm{p}))$ that is given by the following equations:

$$
\begin{gathered}
X_{t}=\alpha_{X}+\sum_{i=1}^{k} \beta_{X, i} X_{t-i}+\sum_{j=1}^{k} \gamma_{X, j} Y_{t-j}+\varepsilon_{X, t} \\
Y_{t}=\alpha_{Y}+\sum_{i=1}^{k} \beta_{Y, i} Y_{t-i}+\sum_{i=1}^{k} \gamma_{X, j} X_{t-j}+\varepsilon_{Y, t}
\end{gathered}
$$

where $k$ represents the lag length set and the $X t$ and $Y t$ represent respectively the stationary variables. Furthermore, a variable $X$ Granger-cause another variable $Y$, if past values of $X$ help predict the current level of $Y$ better than past values of $Y$ alone, proving that past values of $X$ have some informational content that is not present in past values of $Y$. Using the VAR (1) model, we test for Granger-causality for all pairs. From the Table 3, we find 23 out of 25 causal relationships running from sovereign CDS markets to sovereign bond markets, while the number of causality linkages running from sovereign bond markets to sovereign CDS markets is 11 .

Moreover, we find evidence of bidirectional causality between sovereign CDS and sovereign bond markets for each peripheral country. These results indicate most likely the sovereign CDS markets is the source of sovereign credit risk is the. This finding supports the usefulness of sovereign CDS spread as proxy of sovereign credit risk when analyzing sovereign contagion risk of sovereign CDS markets from peripheral eurozone countries to other financial markets. 


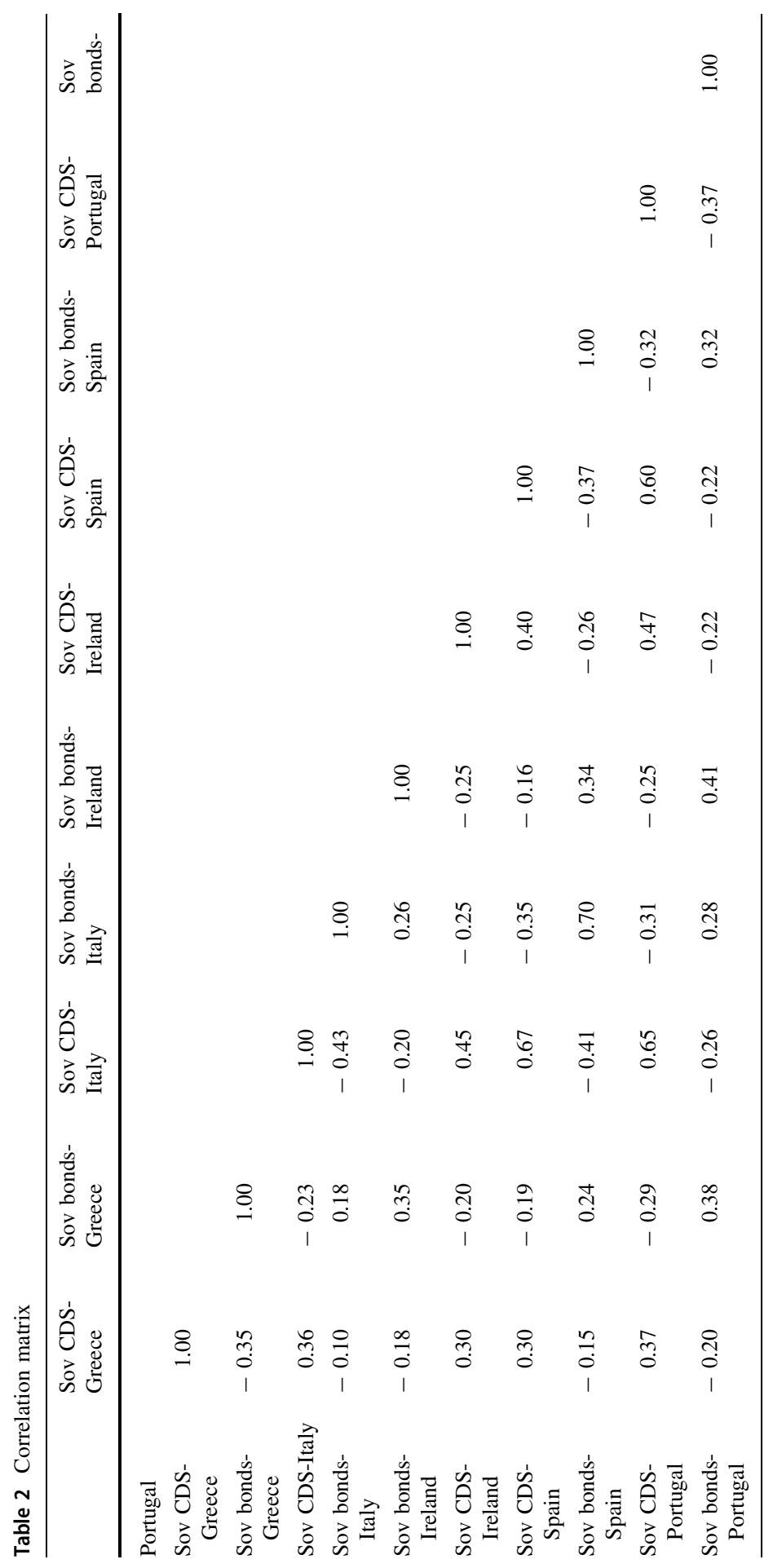


Table 3 Causal relationships

\begin{tabular}{|c|c|c|c|c|c|}
\hline \multicolumn{3}{|c|}{$\begin{array}{l}\text { Causality running from sovereign CDS markets to } \\
\text { sovereign bond markets }\end{array}$} & \multicolumn{3}{|c|}{$\begin{array}{l}\text { Causality running from sovereign bond } \\
\text { markets to sovereign CDS markets }\end{array}$} \\
\hline \multirow[t]{5}{*}{ CDS-Greece } & Bond-Greece & Yes & Bond-Greece & CDS-Greece & Yes \\
\hline & Bond-Ireland & Yes & & CDS-Ireland & No \\
\hline & Bond-Italy & No & & CDS-Italy & No \\
\hline & Bond-Spain & Yes & & CDS-Spain & No \\
\hline & Bond-Portugal & Yes & & CDS-Portugal & No \\
\hline \multirow[t]{5}{*}{ CDS-Ireland } & Bond-Greece & Yes & Bond-Ireland & CDS-Greece & No \\
\hline & Bond-Ireland & Yes & & CDS-Ireland & Yes \\
\hline & Bond-Italy & No & & CDS-Italy & No \\
\hline & Bond-Spain & Yes & & CDS-Spain & No \\
\hline & Bond-Portugal & Yes & & CDS-Portugal & No \\
\hline \multirow[t]{5}{*}{ CDS-Italy } & Bond-Greece & Yes & Bond-Italy & CDS-Greece & Yes \\
\hline & Bond-Ireland & Yes & & CDS-Ireland & Yes \\
\hline & Bond-Italy & Yes & & CDS-Italy & Yes \\
\hline & Bond-Spain & Yes & & CDS-Spain & Yes \\
\hline & Bond-Portugal & Yes & & CDS-Portugal & Yes \\
\hline \multirow[t]{5}{*}{ CDS-Portugal } & Bond-Greece & Yes & Bond-Portugal & CDS-Greece & Yes \\
\hline & Bond-Ireland & Yes & & CDS-Ireland & No \\
\hline & Bond-Italy & Yes & & CDS-Italy & No \\
\hline & Bond-Spain & Yes & & CDS-Spain & No \\
\hline & Bond-Portugal & Yes & & CDS-Portugal & Yes \\
\hline \multirow[t]{5}{*}{ CDS-Spain } & Bond-Greece & Yes & Bond-Spain & CDS-Greece & Yes \\
\hline & Bond-Ireland & Yes & & CDS-Ireland & No \\
\hline & Bond-Italy & Yes & & CDS-Italy & No \\
\hline & Bond-Spain & Yes & & CDS-Spain & Yes \\
\hline & Bond-Portugal & Yes & & CDS-Portugal & No \\
\hline
\end{tabular}

\subsection{Bivariate copulas and dependence measures}

To identify the presence of sovereign contagion risk, we analyse the interactions between sovereign CDS and other financial markets, among peripheral Eurozone countries and other selected countries, using static correlation measures such as Pearson, Spearman rho and Kendall's tau. Then, we examine the dependence structure using bivariate Copulas models.

\subsubsection{Correlation analysis}

In this section, we first examine how sovereign CDS market correlate to sovereign bond market and stock market in peripheral eurozone countries, as well as to commodity markets. Indeed, Pearson, Spearman rho and Kendall's tau correlation 
coefficients are computed and given in Tables 4, 5, 6, 7 (see "Appendix 1"). As for internal correlations within sovereign CDS market of peripheral eurozone countries, the coefficients of different correlations' measures are significant and negative for all pairwise markets. Furthermore, as for external interactions of sovereign CDS, namely interactions between sovereign CDS and sovereign bond markets, sovereign CDS and stock markets and sovereign CDS and commodity markets, results indicate that the coefficients of correlation are significant and negative for all pairwise markets. The exception is the correlation coefficients of sovereign CDS-Gold and sovereign CDS-Industrial Metals pairs, being positive. Next, we examine how sovereign CDS markets of core European, China and Japan, US, as well as South Africa correlate to sovereign CDS, sovereign bond and stock markets of periphery eurozone countries, as well as to commodity markets. First, correlations between sovereign CDS markets of peripheral countries and other selected countries are positive with significant and small coefficients. Second, correlations between sovereign bond market of peripheral eurozone countries and sovereign CDS market of other selected countries are negative for all pairwise markets. Third, all sovereign CDS markets are negatively and weakly correlated to the stock markets. Finally, when considering interactions between sovereign CDS and commodity markets, the correlation coefficients of all pairwise markets are negative, expect for sovereign CDS-Gold and sovereign CDS-industrial metals pairs. These findings indicate that sovereign CDS market are negatively correlated to all financial markets, expect the Gold and the Industrial metals. Negative correlation implies that sovereign CDS market is bull, while other financial market is bear, and vice versa.

\subsubsection{Fitting copulas results}

We use alternative bivariate copulas models with different features to assess the dependence structure among financial markets. These models include the normal copula, student-t copula, Placket, Frank, Gumbel, rotated Gumbel, and variants of Clayton copula. The parameter estimates of copulas models (see "Appendix 2") are all significant for all pairwise markets. In terms of goodness of fit, the student-t copula appears the most suited to examine the dependence structure between all pairwise markets. The bivariate copula parameter measures the strength of dependencies across different financial time series, in a positive or a negative single regime. However, the bivariate copula models do not allow us to see whether these markets have specific properties of risk during market stress or crash periods. This supports the importance of the time-varying dependence structure.

\subsubsection{Time-varying dependence structure}

Our study explores the time-varying dependence structure between sovereign CDS markets and other financial markets of selected countries. For this purpose, we compute daily Kendall's tau dynamic correlation of t-copula to examine timevarying dependence structure for all pairwise markets, using DCC-GARCH models. To capture the time varying dependence structure, we use the MRS-ARMA models 
to model the daily Kendall's tau correlations. This allows us to capture the dependence structure for different markets.

The Kendall's tau correlation coefficient is given by this following formula:

$$
\tau_{k}=2 \arcsin (\rho) / \pi
$$

The motivation uses the Dynamic Conditional Correlation (DCC) to calculate daily conditional Kendall's tau coefficient $\tau \mathrm{k}$ for each pair. In addition, Dynamic Conditional Kendall's tau correlation coefficient is given by the following formula:

$$
\tau_{D C K}=2 \arcsin (\rho \mathrm{DCC}) / \pi
$$

where $\rho \mathrm{DCC}$ is a $(1 * \mathrm{~N})$ dynamic conditional correlation coefficients vector. We compute DCC based on GARCH models. For this purpose, we consider three univariate models for the conditional variance process: a standard GARCH model, Bollerslev (1986), EGARCH model, Nelson (1991), and asymmetric GARCH model known as GJR-GARCH model, Glosten et al. (1993).

\section{- GARCH model}

The conditional variance following GARCH model of Bollerslev (1986) is assumed by this expression:

$$
h_{t}=\alpha_{0}+\sum_{i=1}^{p} \alpha \varepsilon_{t-i}^{2}+\sum_{j=1}^{q} \beta h_{t-j}
$$

In the conditional variance equation, $h_{t}$ is $2 \times 1$ vector of daily conditional variances of financial time series at time t, respectively, $\alpha$ is the $\mathrm{ARCH}$ term that measures the effect of past innovations on current variance, $\beta$ is the GARCH term, which measures the effect of past variances on current variance. The degree of persistence of the variance shock is measured by the sum of the ARCH and GARCH parameters $(\alpha+\beta)$. To ensure the stationary and the stability, the standard GARCH process must respect following requirements: $\alpha_{0} \geq 0 ; \alpha>0 ; \beta>0 ; \alpha+\beta<1$.

\section{- EGARCH model}

Nelson (1991) introduces the exponential GARCH model where the logarithm of the conditional variance is given by:

$$
\ln h_{t}=\alpha_{0}+\sum_{i=1}^{p} \alpha_{i}\left(\left|\varepsilon_{t-i}\right|+\gamma_{i} \varepsilon_{t-i}\right)+\sum_{j=1}^{q} \beta_{j} \ln h_{t-j}
$$

This specification considers that the leverage effect where past negative observations have a larger influence on the conditional volatility than past positive observations of the same magnitude, Black (1976), Christie (1982). Covariancestationary is obtained by requiring that $\beta_{j}<1$.

- GJR-GARCH model 
Glosten et al. (1993) modified GARCH model considering the leverage effect. The GJR model is able to capture the asymmetry in the conditional variance process. This model is defined as follows:

$$
h_{t}=\alpha_{0}+\sum_{i=1}^{p} \alpha \varepsilon_{t-i}^{2}+\sum_{j=1}^{q} \beta h_{t-j}+\sum_{j=1}^{q} d \varepsilon_{t-j}^{2} \mathrm{I}_{\varepsilon<0}\left(\varepsilon_{t-j}\right)
$$

In the case of asymmetric GJR-GARCH process, I represents a dummy variable the asymmetric response of the conditional variance to unexpected price decrease. $\mathrm{I}=0$ in response to positive shocks and $\mathrm{I}=1$ in response to negative shocks. A positive and significant value of $d$ indicates shocks indicating increase in future conditional variance more than a positive shock at the same magnitude. The stability and stationarity of the asymmetric process are obtained by requiring that: $\alpha_{0}>0 ; \alpha \geq 0 ; \beta \geq 0 ; \beta+d \geq 0 ; \alpha+\beta+0.5 d<1$.

The estimation of DCC consist of two steps: First is estimation of a univariate GARCH model, second is estimation of time-varying conditional correlations. The multivariate DCC-GARCH is defined as follows:

$$
\left\{\begin{array}{l}
H_{t}=D_{t} R_{t} D_{t} \\
D_{t}=\operatorname{diag}\left(\sqrt{h_{11 t}}, \sqrt{h_{22 t}}, \ldots, \sqrt{h_{N N t}}\right) \\
R_{t}=\left(\operatorname{diag} Q_{t}\right)^{-1 / 2} Q_{t}\left(\operatorname{diag} Q_{t}\right)^{-1 / 2}
\end{array}\right.
$$

where $H_{t}$ is the multivariate conditional variance, and $D_{t}$ is a diagonal matrix of conditional standard deviations obtained from estimating univariate GARCH. The different elements contained in $D_{t}$ are generated by a GJR-GARCH $(\mathrm{p}, \mathrm{q})$, given by:

$$
H_{t}=\left(\begin{array}{cc}
\sqrt{h_{i t}} & 0 \\
0 & \sqrt{h_{0 t}}
\end{array}\right)\left(\begin{array}{cc}
1 & \rho_{i 0, t} \\
\rho_{i 0, t} & 1
\end{array}\right)\left(\begin{array}{cc}
\sqrt{h_{i t}} & 0 \\
0 & \sqrt{h_{0 t}}
\end{array}\right)
$$

where $h_{i t}=c_{i}+\sum_{p=1}^{P_{i}}\left(\alpha_{i p} \varepsilon_{i t-p}^{2}+\lambda \mathrm{I}_{\left[\varepsilon_{t-1<0}\right]} \varepsilon_{t-i}^{2}\right)+\beta_{j} \sum_{q=1}^{Q} \beta_{i q} h_{i t-q}$; and $\mathrm{i}=1,2 \ldots$, $\mathrm{N}$. where $\mathrm{Rt}=\left[\rho_{i j, t}\right]$ represents the matrix of constant conditional correlation coefficients,

$\mathrm{Q}_{\mathrm{t}}=\left[\mathrm{q}_{\mathrm{ij}, \mathrm{t}}\right]$ is the covariance matrix of standardized residuals, of $(\mathrm{N} X \mathrm{~N})$ dimension, symmetric and positive definite.

$$
q_{i j, t}=\bar{\rho}_{i, j}+\alpha\left(Z_{i, t-1} Z_{j, t-1}-\bar{\rho}_{i, j}\right)+\beta\left(q_{i j, t-1}-\bar{\rho}_{i, j}\right)
$$

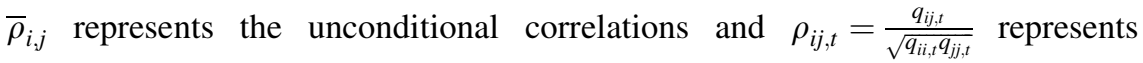
dynamic conditional correlations. The parameters are estimated using quasimaximum likelihood method (QMLE) introduced by Bollerselv et al., (1992). Under the Gaussian assumption, the log-likelihood of the estimators is: 


$$
l(\vartheta)=-\frac{1}{2} \sum_{t=1}^{T}\left[\left(n \log (2 \pi)+\log \left|D_{t}\right|^{2}+\varepsilon_{t}^{\prime} D_{t}^{-1} D_{t}^{-1} \varepsilon_{t}\right)+\left(\log \left|R_{t}\right|+\delta_{t}^{\prime} R_{t}^{-1} \delta_{t}-\delta_{t}^{\prime} \delta_{t}\right)\right]
$$

where $n$ is the number of equations, $T$ is the number of observations, $\vartheta$ is the vector of parameters to be estimated.

The first step of the DCC-GJRGARCH estimation process is to fit the univariate GARCH specification for sovereign CDS spreads, sovereign bond spreads, stock market and commodities returns. We estimate the univariate GARCH, EGARCH and GJR-GARCH models. We find evidence of asymmetry in the conditional variance of all financial market indexes. The results (see "Appendix 3") highlight the autoregressive conditional heteroscedasticity effects and the persistence of volatility through the significance of variance equations' parameters ( $\alpha$ and $\beta$ ). Moreover, the parameter of asymmetry $\lambda$ is also significant for all financial market indexes, providing evidence of asymmetry in conditional volatility. Consequently, the parameters are statistically significant and log-likelihood values suggest that the GJR-GARCH $(1,1)$ model is appropriate for sovereign CDS indexes, while the $\operatorname{EGARCH}(1,1)$ is adequate to model sovereign bond, stock market and commodities indexes.

In the second stage, the DCC specification is modified to account for the structural breaks in unconditional correlations.

\subsubsection{Analysis of dynamic conditional Kendall's tau}

Figures 2, 3 and 4 show the pairwise daily Kendall's tau correlations among sovereign CDS markets and sovereign bond, stock, and commodities markets. As for the dependence structure within the sovereign CDS market of peripheral countries, the coefficients of daily Kendall's tau correlations are significant and positive for all pairwise markets, implying that sovereign CDS markets are highly interdependent and move in the same direction. This indicates that the dependence structure is not static but changes over time. Moreover, Fig. 2 reports how dependence structure among sovereign CDS markets of peripheral EU countries has changed, especially during the global financial crisis 2008 (GFC), the European debt crisis 2009-2012, oil price crisis 2014-2016, pre-Brexit period 2016-2020 and Covid-19 pandemic. We find that most peaks are associated with the emergence of major economic, financial, political, or public health events or crisis, enhancing the linkages between these peripheral European countries. As shown in Fig. 2, we notice that dependence between sovereign CDS and sovereign bonds within peripheral European countries is low before the global financial crisis 2008, however a gradual uptrend is taking place post 2008, suggesting that the various financial, economic, political and public health events have intensified this dependence.

The dynamic Kendall' tau correlation allows us to capture the dependence over time between all pairwise markets. Results show that, the dependence between sovereign CDS and sovereign bonds is negative. A bear sovereign bond market condition is associated with a bull sovereign CDS market. As shown in Fig. 3, the dependence structure between sovereign CDS markets of peripheral countries and the other countries present significant time-varying behavior during the sample 

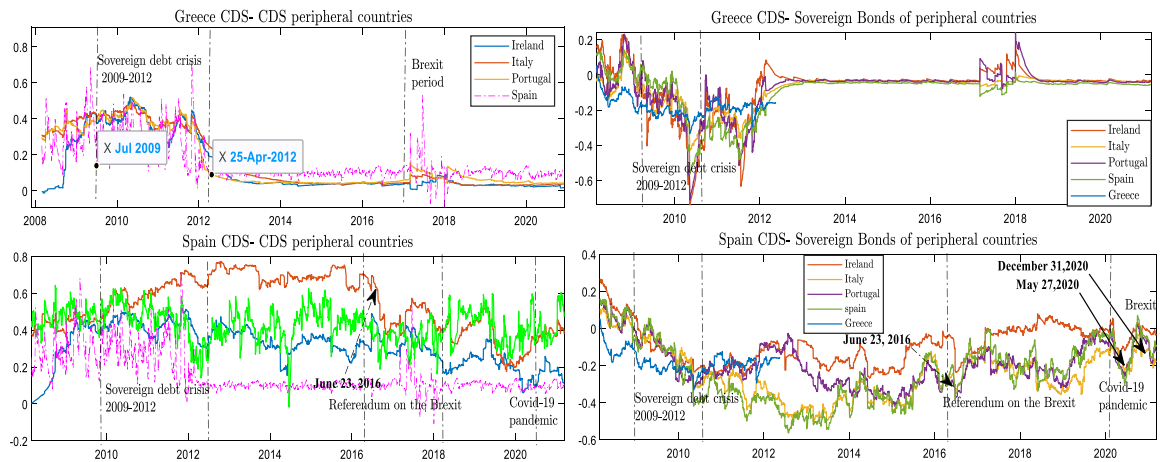

Ireland CDS- CDS peripheral countries
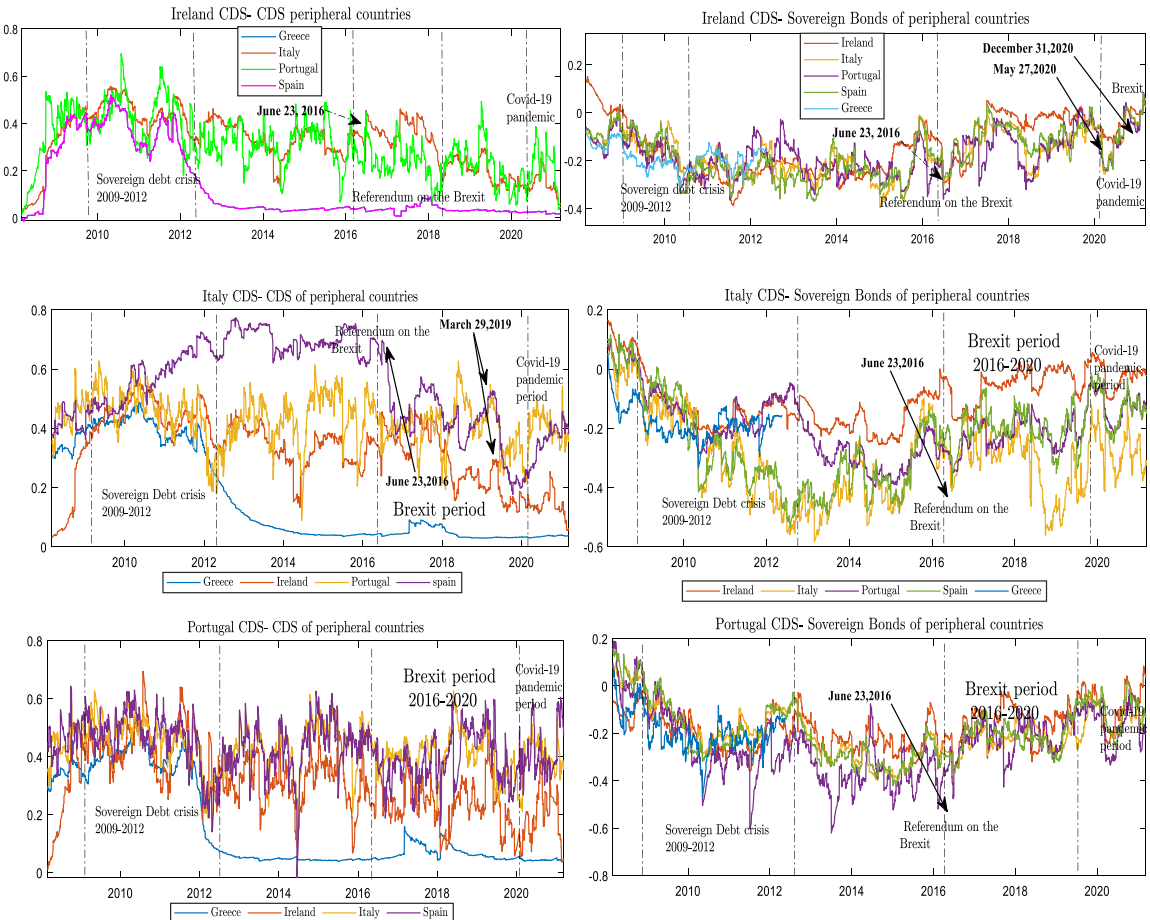

Fig. 2 Daily Kendall's tau correlations within sovereign CDS and sovereign bonds of peripheral European countries

period and a sharp rise during the GFC 2008, European debt crisis 2009-2014, 2016-2020 pre-Brexit and Covid-19 pandemic period. This suggests that major crisis events have a significant enhancement effect on the interdependence among sovereign CDS markets. Nevertheless, the US sovereign CDS and Portuguese sovereign CDS markets exhibits relatively very low dependence, almost zero, indicating an absence of sovereign risk spillovers between these markets. As per the dependence structure between peripheral's sovereign bond markets and sovereign CDS markets of other selected countries, we find that the dependence between all the pairwise markets are significantly negative, presents time-varying characteristics 

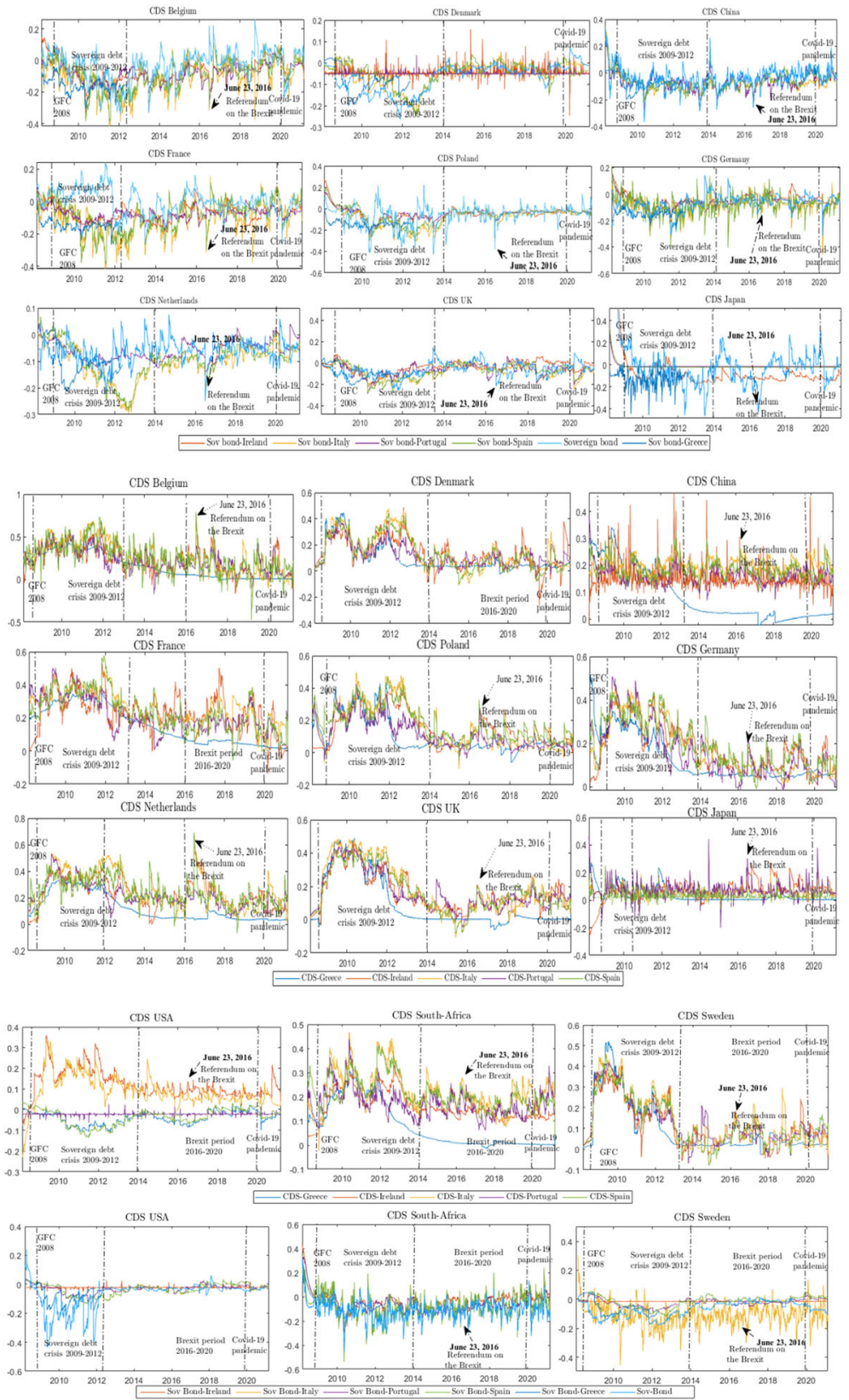

Fig. 3 Daily Kendall's tau correlations among sovereign CDS of European, American, Asian, and African countries and sovereign CDS and sovereign bonds of peripheral European countries 

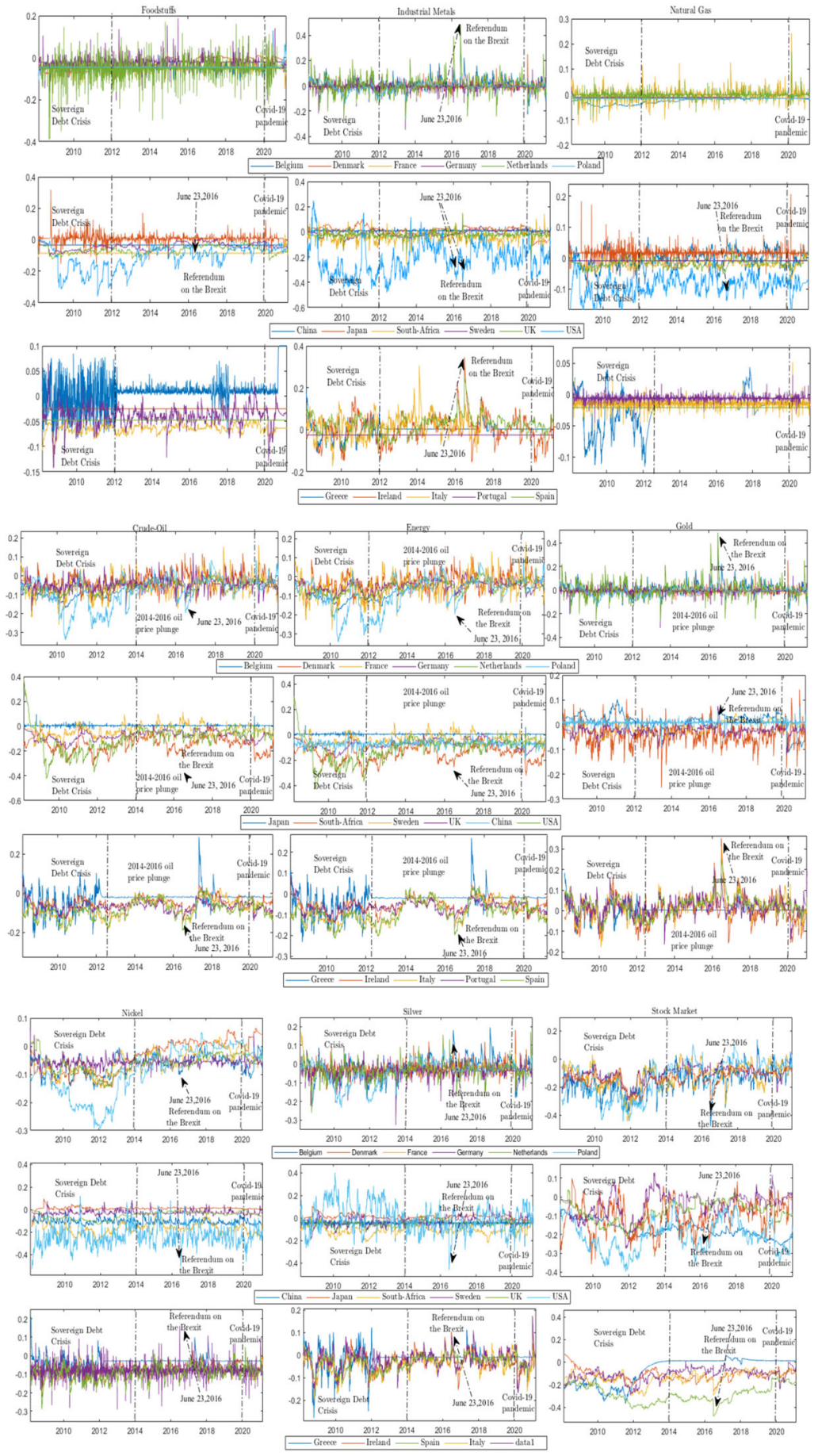

Fig. 4 Daily Kendall's tau correlations between sovereign CDS markets, stock, and commodity markets 

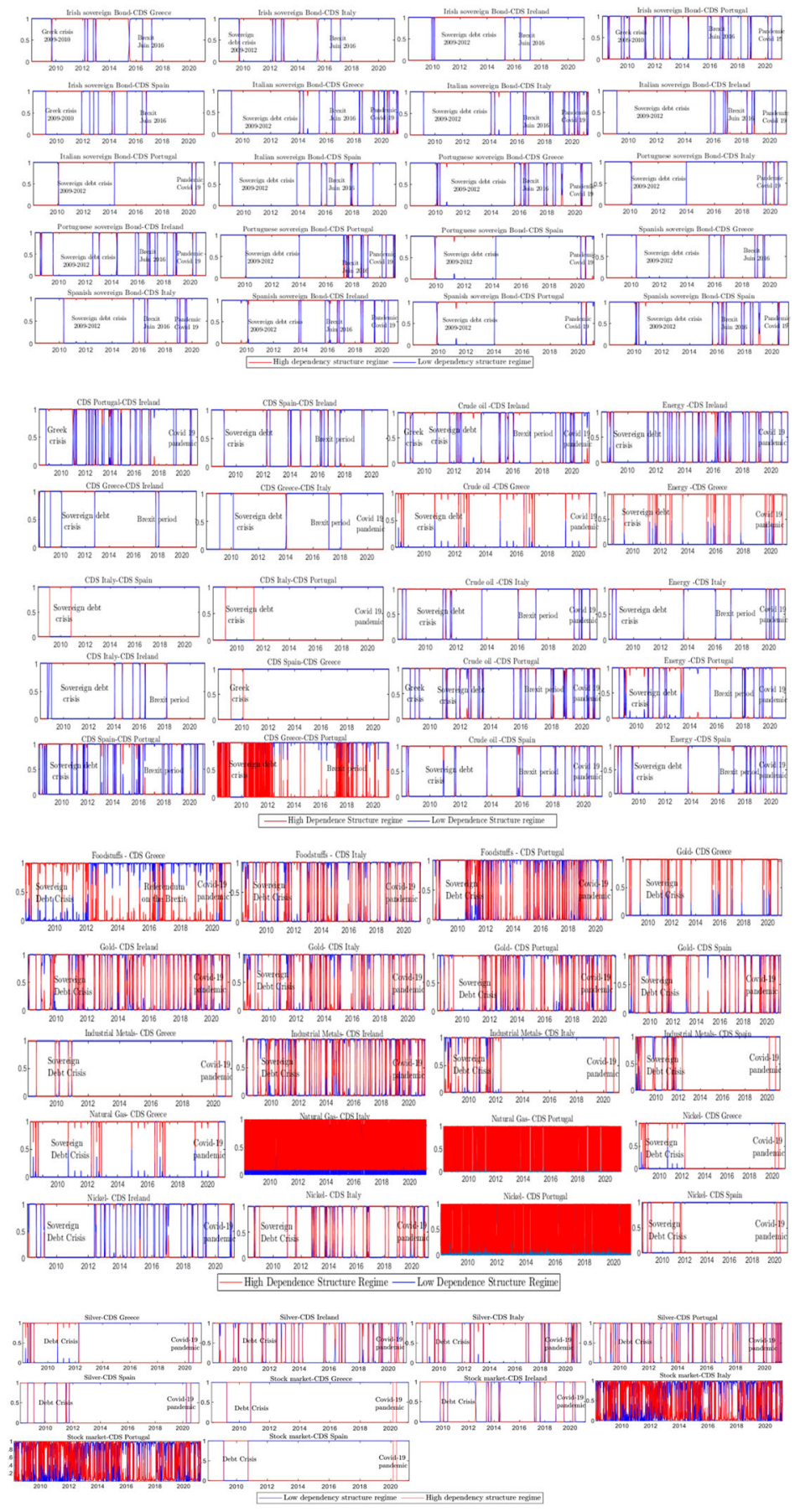

Fig. 5 Plots of switching regime of Kendall's tau correlations between peripheral European sovereign CDS markets with other financial markets 

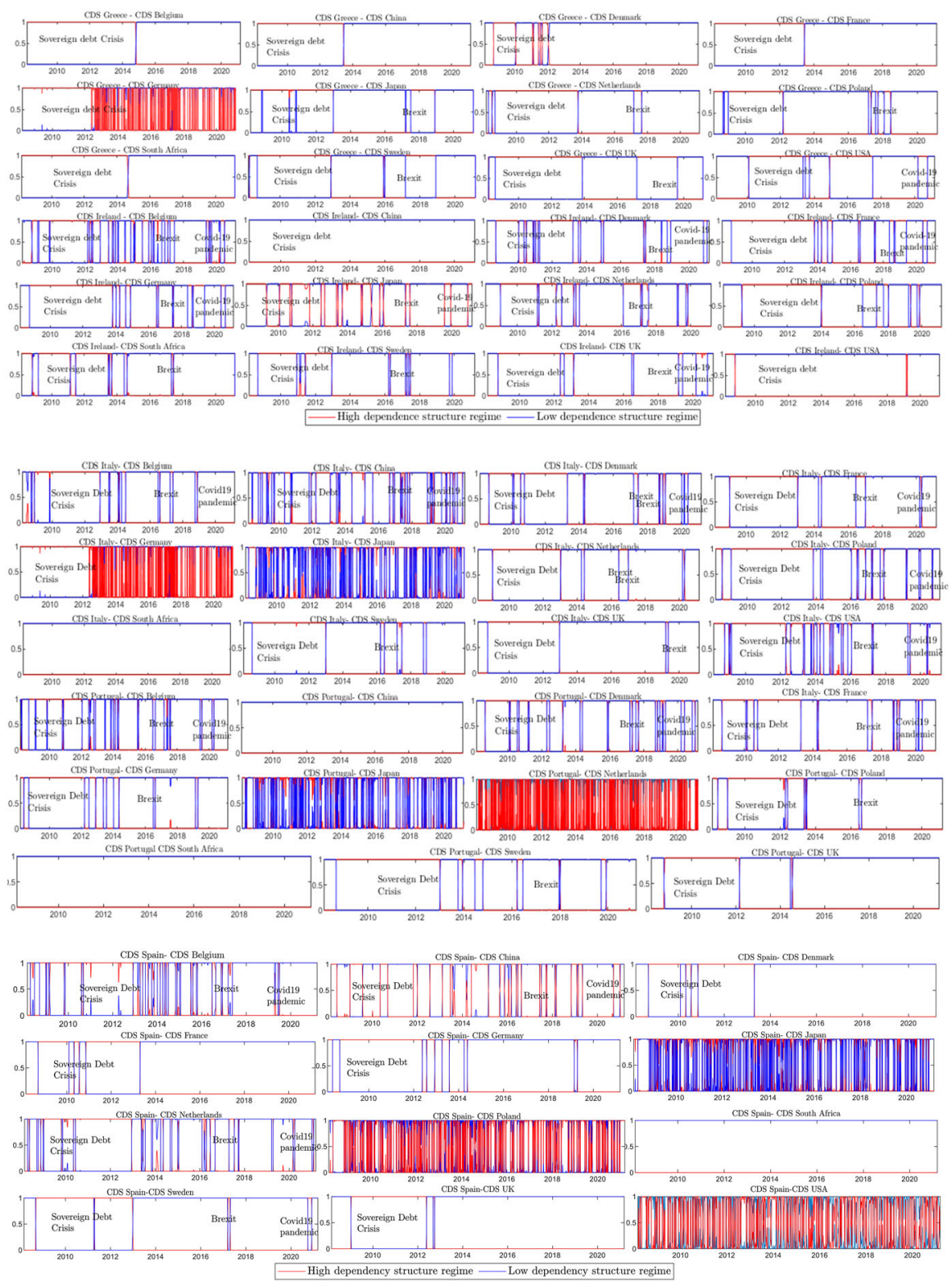

Fig. 6 Plots of switching regime of Kendall's tau correlations within sovereign CDS markets of peripheral European countries and other countries

with a sharp rise during the GFC 2008, sovereign debt crisis 2009-2014, 2016-2020 pre-Brexit and Covid-19 pandemic period, suggesting that sovereign risk spillovers between these markets has been amplified by these global events. However, the coefficients of daily Kendall's tau correlations for American sovereign CDS- Irish sovereign bond, Swedish sovereign CDS-Irish sovereign bond, Japanese sovereign 

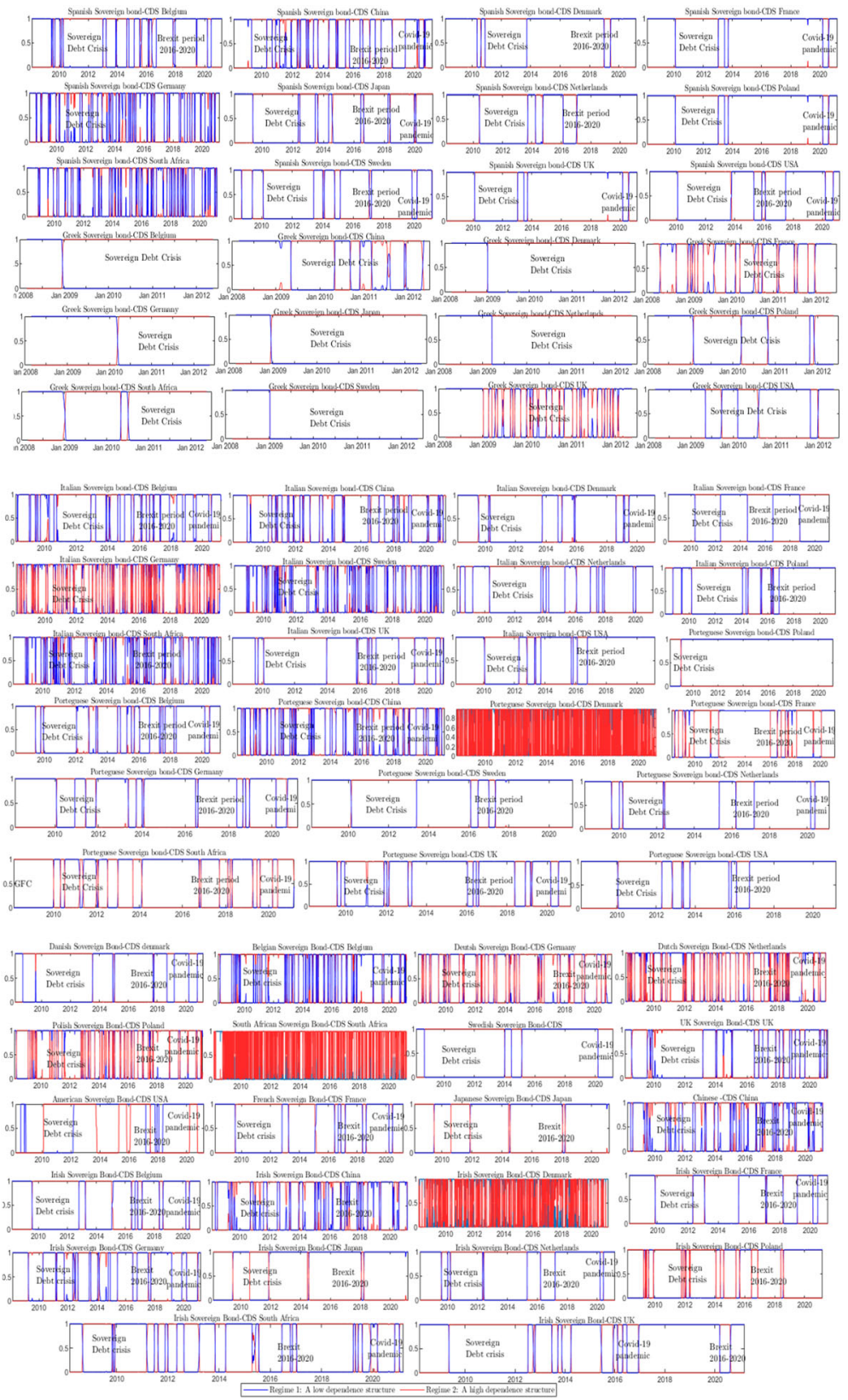

Fig. 7 Plots of Switching regime of Kendall's tau correlations between sovereign CDS markets of European, Asian, American, and African countries and sovereign bond markets of peripheral European countries 

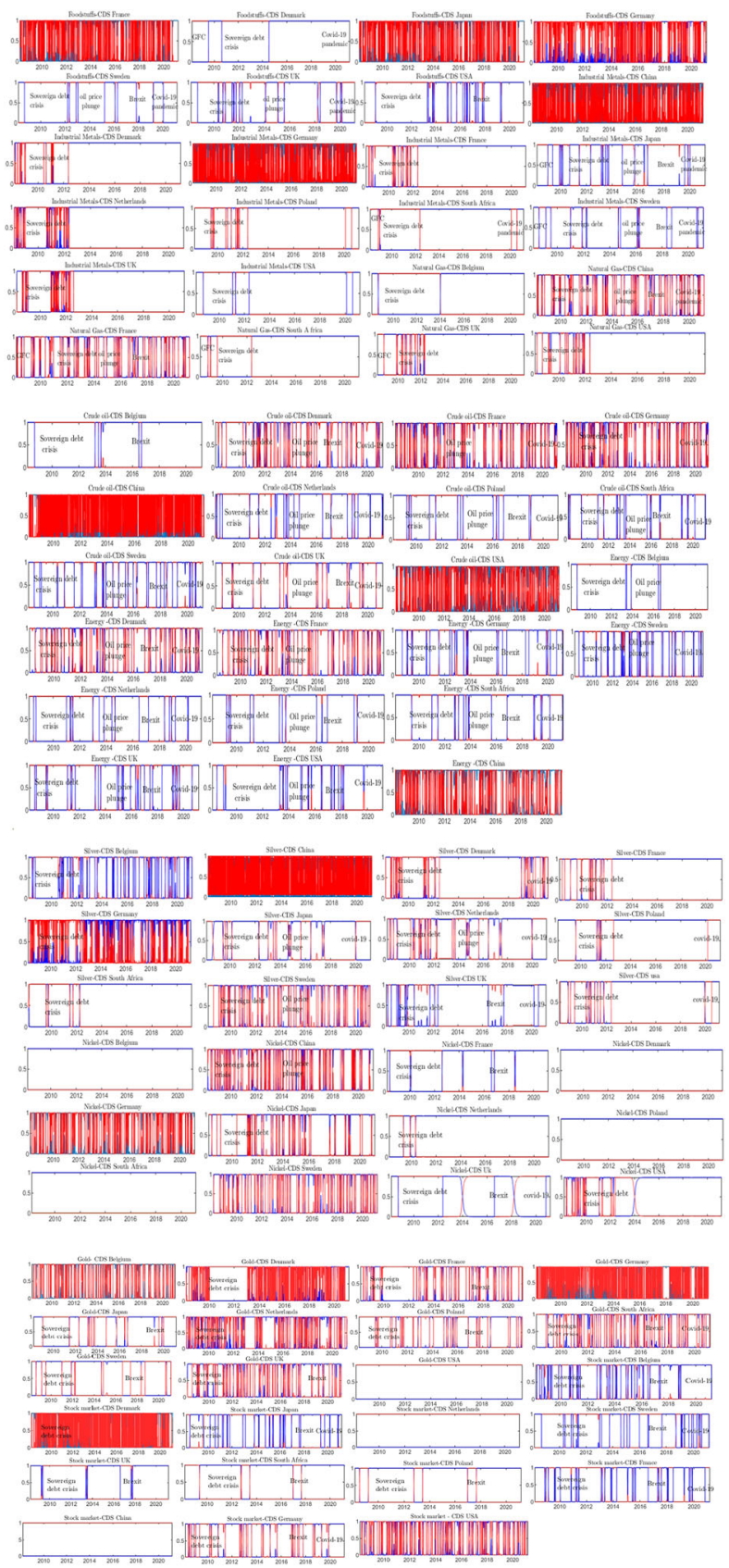

Fig. 8 Plots of switching regime of Kendall's tau correlations between sovereign CDS markets of European, Asian, American, and African countries and commodity and stock markets 
CDS-Italian sovereign bond and Japanese sovereign CDS-Portuguese sovereign bond are significant and equal to zero, indicating the absence of sovereign risk spillover effects among these markets.

We observe that crude-oil and energy markets illustrate negative and significant time-varying dependence with all sovereign CDS markets of both peripheral and nonperipheral countries, with a steady dependence with Japanese sovereign CDS market (see Fig. 4), Moreover, the level of dependence is initially low before mid-2008 but has been followed by a gradual uptrend after the GFC 2008. Some positive and negative jumps of the dynamic dependence are observed during the turmoil periods. This finding supports the presence of sovereign risk spillover effects between these markets. As per the natural gas market, we find that the dependence present significant time-varying feature only with sovereign CDS markets of Greece, Italy, Portugal, Belgium, France, Uk, USA, South-Africa and China. Besides, the natural gas market illustrates higher dependence with US sovereign CDS market while exhibits a relatively low dependence with others sovereign CDS markets.

Similarly, the foodstuffs market exhibits a relatively higher dependence with the US sovereign CDS market than with the sovereign CDS markets of Greece, Italy, Portugal, France, Denmark, Germany, Sweden, UK, and Japan. Furthermore, we find that the dependence structure between industrial-metals market and sovereign CDS markets present dynamic feature. Portugal is an exception with a weak and static dependence. For the metals markets, we find that dependence structure between sovereign CDS-Gold, Sovereign CDS-Silver and sovereign CDS-Nickel pairs swing to either positive or negative directions, except the Chinese sovereign CDS-Gold pair. Similarly, the coefficients of daily Kendall's tau correlations of all sovereign CDS-stock market pairs are significant and negative, revealing that these markets move in opposite direction. During 2009, sovereign CDS markets reveal a turbulent rise. Stock market prices has experienced a sharp decline, indicating a negative dependence among these markets. More interestingly, as shown in Fig. 4, the dependence structure experienced a sharp rise on 23 June 2016, which is the day of UK referendum on Brexit, as well as during the Covid-19 pandemic period. This indicates that major geopolitical and public health events intensify dependence among sovereign CDS markets and other financial markets. This clearly suggests the presence of sovereign risk spillover effects during these stress periods.

\subsection{Sovereign contagion risk analysis}

To determine whether there is interdependence or contagion between the markets, we model the dynamic Kendall's tau correlations time series using MRS-ARMA modelling. We consider time series of daily Kendall's tau correlations with a timevarying characteristics and exclude series that have a steady feature over-time from this analysis. We summarize in "Appendix 4" the MRS-ARMA findings and showing the estimated transition probabilities (P11 and P22) being all significant and different from zero. This indicates that the dependence of different pairwise markets switches between two regimes: a low and a high dependence structure regime. We define the regime 1 with a low volatility as regime of a low dependence structure and the regime 2 with a high volatility as the regime of a high dependence structure. 
To assess sovereign contagion risk, we first test if the dependence structure switches from a low dependence structure regime to a high dependence structure regime and if all pairwise markets remain in the same regime of a high dependence structure during the major events chronologically the GFC 2008, European debt crisis 2009, pre-Brexit 20,016-2020 and Covid-19 pandemic period. The results support the evidence of sovereign risk contagion during these major events.

Regarding the dependence structure within peripheral's sovereign CDS markets, the results reported in the "Appendix 4", show that all series are modelled by a MRS model. The exceptions are Italian CDS-Portuguese CDS pair and Italian CDS-Spanish CDS pair modelled respectively by MRS-ARMA (1,1) and MRS-MA (1). The estimated parameters values are all significant at $1 \%$ significance level and estimated transition probabilities $\left(\mathrm{P}_{11}\right.$ and $\left.\mathrm{P}_{22}\right)$ are all high enough and close to one. This implies that the dependence structure differs greatly between the two regimes. As shown Fig. 5, we observe that the dependence structure remains in the regime 1 of a low dependence structure until last quarter of 2008 for all pairwise markets, then changes take place in joint probabilities and the dependence structure switches to regime 2 from mid-2009. Furthermore, we observe that all pairwise markets remain in the same regime of high dependence structure during the European debt crisis 2009-2012, indicating the presence of sovereign risk contagion. In addition, we find out that the dependence structure moves from regime 1 to regime 2 during the pre-Brexit period, with less persistence in regime 2 of high dependence structure. Also, we notice that the date of switching of regimes is far apart among pairwise markets.

The dependence of Italian CDS-Portuguese CDS, Italian CDS-Spanish CDS and Spanish CDS-Greek CDS pairs remain in the same regime of low dependence structure till the end of sample period. This allow us to conclude that there is strong interdependence between peripheral's sovereign CDS markets during pre-Brexit and Covid-19 pandemic events. As per the dependence structure between sovereign CDS and sovereign bond markets within peripheral European countries, the results depicted in (see "Appendix 4"), we find that all estimated parameters values are significant at $1 \%$ significance level and the estimated transition probabilities P11 and P22 are all high and close to one. This implies that if the sovereign CDS and sovereign bond markets are highly dependent, it is more likely to be persistent (99\%) and there is small probability to $1 \%$ of moving to low dependent regime 1. So, there is indication that the dependence structure of all pairwise markets is characterized by two separate regimes.

As seen in Fig. 5, the dependence structure for all pairwise move from low to high dependence structure regime, and then remain in high regime during the European debt crisis, pre-Brexit, Covid-19 pandemic events. These results confirm the presence of sovereign risk spillovers running from sovereign CDS to sovereign bonds markets within peripheral European countries, providing evidence of sovereign risk contagion during these crises. The results regarding the dependence structure between sovereign CDS markets of peripherals European countries and other countries, are included in (see "Appendix 4"). For the eurozone countries, we find that the estimated transition probabilities are all high and close to one, implying that the dependence structure switches among the two regimes. The exceptions are the German sovereign CDS-Italian sovereign CDS dependence structure and 
Spanish sovereign CDS-Polish sovereign CDS dependence structure, which have low probabilities of being in regime1 during our sample period, respectively 0.41 and 0.47 . We observe that regime 2 of high dependence structure is more persistent for all pairwise markets. In addition, we note from Fig. 6 that the dependence structure moves from low to high dependence structure regime, and then stabilize in high dependence during the European debt crisis, indicating that all sovereign CDS markets have been impacted by this major event. We note that there is a regime switch due to pre-Brexit for most pairwise markets, supporting that sovereign CDS markets of core and non-core countries are highly dependent with at least a peripheral country during the pre-Brexit. Therefore, these dependencies confirm the strong interlinkages between core and peripheral countries in the eurozone and support the presence of sovereign risk contagion during pre-Brexit. Moreover, the dependence structure moves from regime 1 to regime 2 during Covid-19 pandemic period suggesting that there is sovereign risk spillovers among sovereign CDS markets which provides evidence of sovereign risk contagion. In the case of US, we note changes of dependence regime with Italy and Ireland to high dependence structure until last quarter of 2008 and a switch to regime of low dependence, and thus indicating a sovereign risk contagion during the GFC. More interestingly, we observe that the dependence structure with Greece remains in the regime of high dependence structure during the period from the first quarter of 2010 until the last quarter of 2013, the sovereign debt crisis, during the last quarter of 2014 to last quarter of 2017, the oil price crisis 2014-2016, pre-Brexit 2016-2020, and finally during the Covid-19 pandemic period. Obviously, these findings provide some evidence major events have caused sovereign risk contagion across sovereign CDS markets of USA and Greece. In the South African case, we observe that dependence structure with Greece remains in the regime of high dependence structure until the first quarter of 2014 and a move to regime of low dependence structure implying the presence of sovereign contagion. Moreover, the dependence structure with Ireland, initially remain in regime 2 until the last quarter of 2008 (GFC 2008), then moves to regime 2 starting the first quarter of 2009 till the last quarter of 2013 in concomitance with the sovereign debt crisis. This regime change reveals strong linkages with Irish sovereign risk, and evidence of sovereign risk contagion. For the dependence structure with Italy, Portugal, and Spain, we find that it remains in the regime of low dependence during the entire sample period, and thus indicating a weak interdependence and not a contagion phenomenon. For Japan, we find no sovereign risk contagion with Italy, Portugal, and Spain. However, the dependence structure with Greece remains in regime 2 until the last quarter of 2012 and then moves to regime of low dependence, revealing sovereign risk contagion during the GFC 2008 and the European debt crisis 2009-2012. In addition, we find evidence of contagion since the dependence structure with Ireland remains at regime 2 during the sovereign debt crisis, oil prices crisis, pre-Brexit, and Covid-19 pandemic period. For China, the Chinese sovereign risk is highly dependent with Greek sovereign risk during the GFC and European debt crisis. Furthermore, we observe also that there is strong interdependence with sovereign risk of Italy and Spain, while a weak interdependence with sovereign risks of Portugal and Ireland. Hence contagion took place only with Greece and Ireland. 
Regarding the dependence structure among sovereign bond and sovereign CDS markets, we find, as included in (see "Appendix 4"), that the estimations values of all parameters are significant at $1 \%$ significance level. The estimated transition probabilities $\left(\mathrm{P}_{11}\right.$ and $\left.\mathrm{P}_{22}\right)$ are all high and close to one, implying that the occurrence of switches between low and high dependence regimes are infrequent. For the CDSBond of South Africa and Irish sovereign bond-Danish sovereign CDS, where the probabilities of being is regime $1\left(\mathrm{P}_{11}\right)$ are respectively 0.5 and 0.47 , indicating that regime 2 is more persistent than regime 1 during our sample period, and thus, we have no contagion. Figure 7 , indicates that dependency structure of all pairwise markets remain in high regime during the sovereign debt crisis, showing that the sovereign debt crisis has contagious feature and is transmitted from peripheral European countries to other countries. Moreover, results confirm that sovereign risk. In addition, we note the US sovereign risk is highly dependent with the sovereign risk in EU peripherical countries. In China case, we find evidence of sovereign risk contagion during the following periods: the sovereign debt crisis, the collapse of oil price, the Brexit and the Covid pandemic, where there is switching of dependence structure from a low to high regimes. In Japan's case, we confirm that there is strong sovereign risk contagion from peripheral's countries Spain, Greece, and Ireland during the European debt crisis, but weak sovereign contagion during the following periods: collapse of oil price, the GFC, the Brexit and the Covid-19 pandemic.

Regarding the dependence structure between sovereign CDS and commodity markets, we find that all estimation parameters values are significant at $1 \%$ significance level. As per the dependence structure between the sovereign CDS and foodstuffs markets, the estimated transition probabilities $\left(\mathrm{P}_{11}\right.$ and $\left.\mathrm{P}_{22}\right)$ are all significantly high, indicating that the dependence structure moves greatly among two regimes. the figures depict that the regime 2 of high dependence structure is more persistent and all pairwise markets remain in regime 2, during the European debt crisis, thus there is strong sovereign risk contagion with sovereign CDS markets of Denmark, Sweden, UK, USA, Greece, Italy, and Portugal, and simply strong interdependence with France, Germany, Japan. Interestingly, there is no contagion effect in the case of dependence between foodstuffs- sovereign CDS of UK and USA since it remains in the regime of low dependency structure, respectively during the Brexit and GFC periods.

For Energy markets, we find a strong interdependence between Natural gas market and peripheral countries sovereign CDS markets. The dependence structure remains in regime of high dependence structure during the entire sample period. For natural gas markets, we note a sovereign contagion effect from sovereign CDS markets of France and China during the oil price collapse, pre-Brexit, and Covid-19 pandemic. Regarding the dependence structure between sovereign CDS and crude oil markets, we find evidence of contagion for all countries during the sovereign debt crisis 2009-2012, Brexit period and Covid-19 pandemic period, except the Poland and Belgium. Furthermore, we observe again a contagion effect during the collapse of oil price for all countries, except peripheral's European countries, Belgium, Poland, and South Africa.

As for the internal dependence structure, we consider the dependence between sovereign CDS and stock markets for various countries. Figures 5 and 8 depict that sovereign CDS markets have strong linkages with stock markets, especially in Italy, 
Portugal, Denmark, Netherlands, China, and USA, where we observe that the regime of high dependence structure is more persistent. indicating strong interdependence between sovereign CDS and stock markets in these countries.

\section{Conclusion}

In this paper, we explore the impact of major crises on the dependence structure between financial markets. A particular focus is made on sovereign risk contagion and transmission across financial markets during major crisis, Sovereign debt crisis, pre-Brexit and Covid-19 pandemic. Using a methodology that test for the existence of possible time-varying dependence among sovereign CDS, stock markets, as well as commodity markets, using a dynamic Kendall's tau correlation that is developed using the copula and the DCC-GARCH models. We identify breakpoints of the daily Kendall's tau correlations series and dependence structure, using Markov Regime-Switching ARMA models. We identify the presence of sovereign risk contagion by testing whether there is a switching of dependence from low to high dependence structure regimes. Results indicate that sovereign CDS indexes can serve as hedge assets against risks in various markets. Moreover, there is evidence of time-varying dependence structure among all pairwise markets, implying that investors and portfolio managers should frequently revise their investment strategies. Using MRS-ARMA modelling, we find that the dependence structure switches regimes from low dependence structure, or weak interdependence, to regime of high dependence structure, or strong interdependence. Moreover, we find that there is switching of regimes, and the dependence structure moves to a high regime during major crisis events, such as pre-Brexit, the European debt crisis 2009-2012, and Covid-19 pandemic. This indicates that the major global crisis events have intensified the sovereign risk spillovers effects among financial markets of the peripheral's European countries and other countries.

An accurate modelling of dependence structure between financial markets is major importance for investors and policy makers and supports hedging strategies and public policy design. Investors ought to be aware of the type of regime change and the duration of the dependence during different market states. This methodology would help to determining the appropriate assets to manage extreme risks. Significant time-varying characteristics of dynamic dependence structures suggests that fund managers and investors should take into account in their investment strategies to manage systemic risk estimation and high-risk investment. Enhancing the mechanism of response to major crisis is of fundamental importance allowing market participants to properly react to global crisis in a timely manner and take appropriate strategies, to minimize risk and losses. Indeed, our methodology offers a proper tool to provide information regarding time-varying characteristics of dependence structure between sovereign CDS markets and other financial markets. 


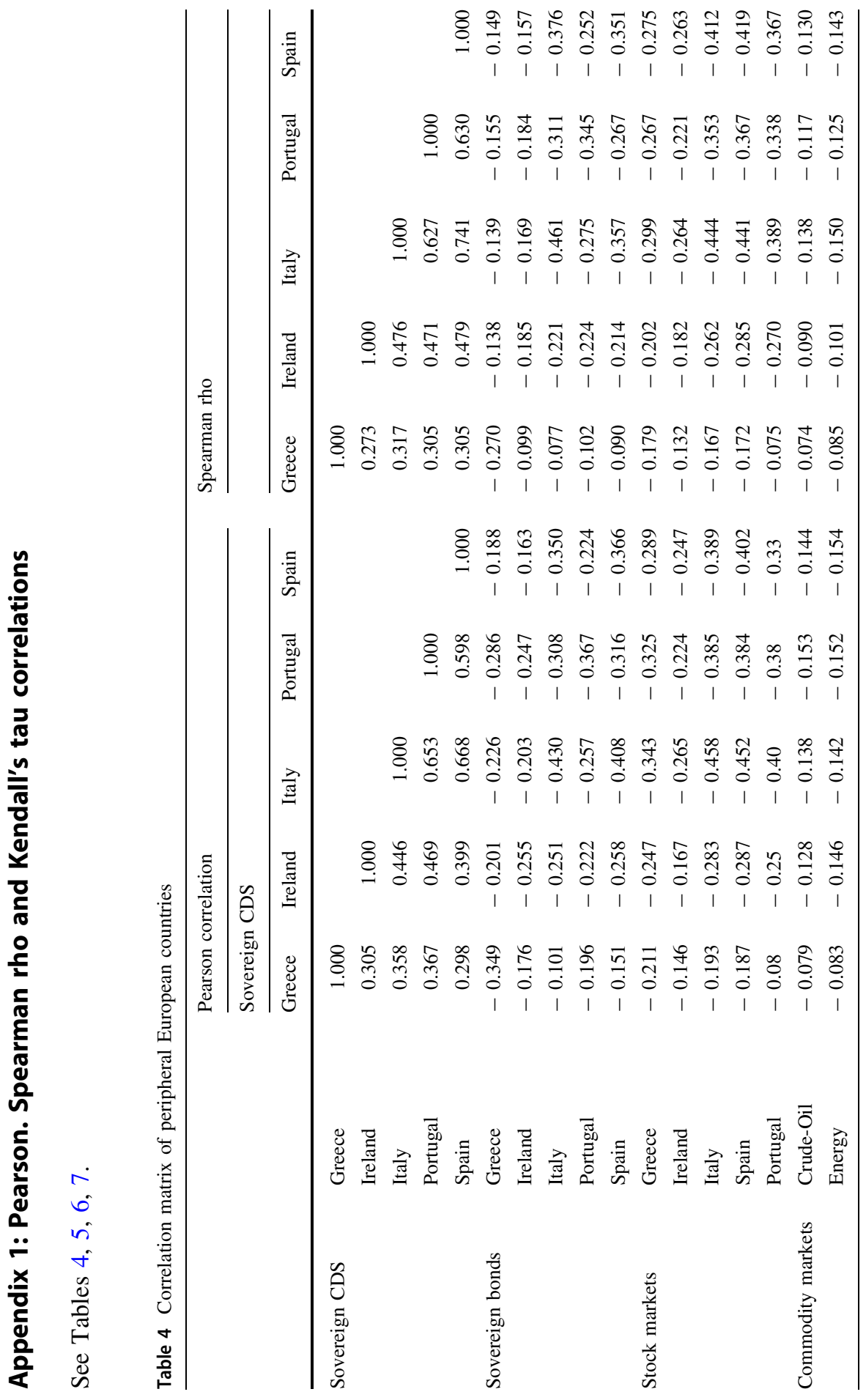




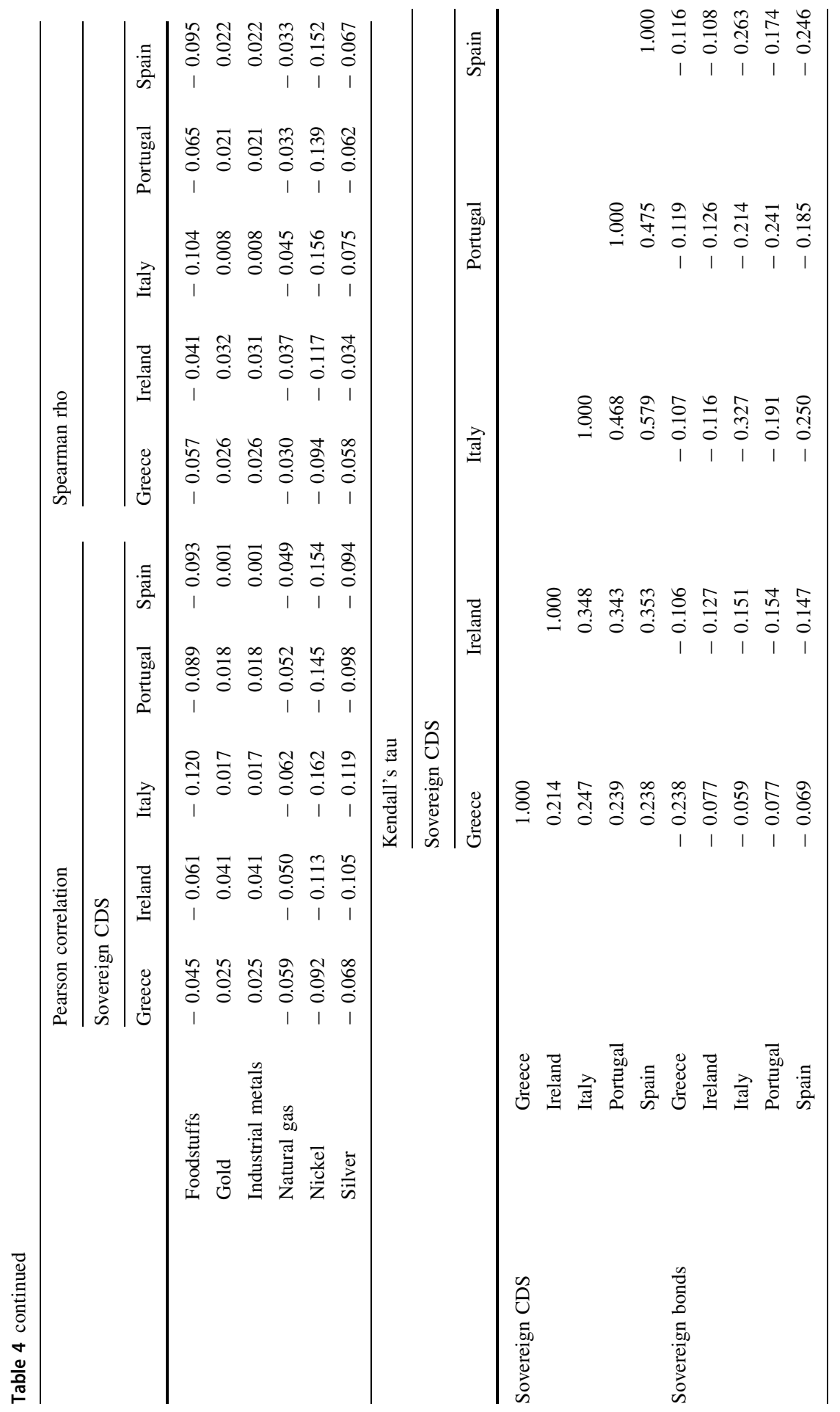




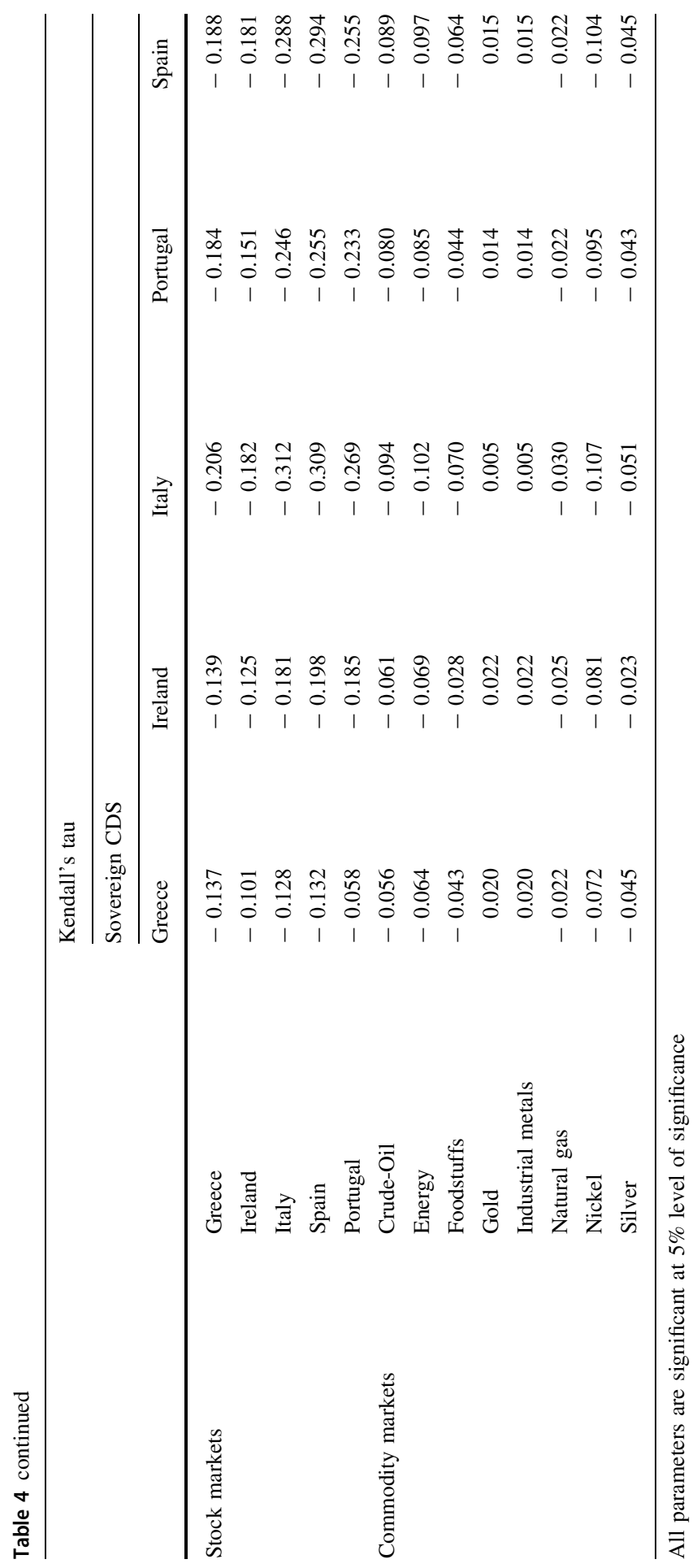




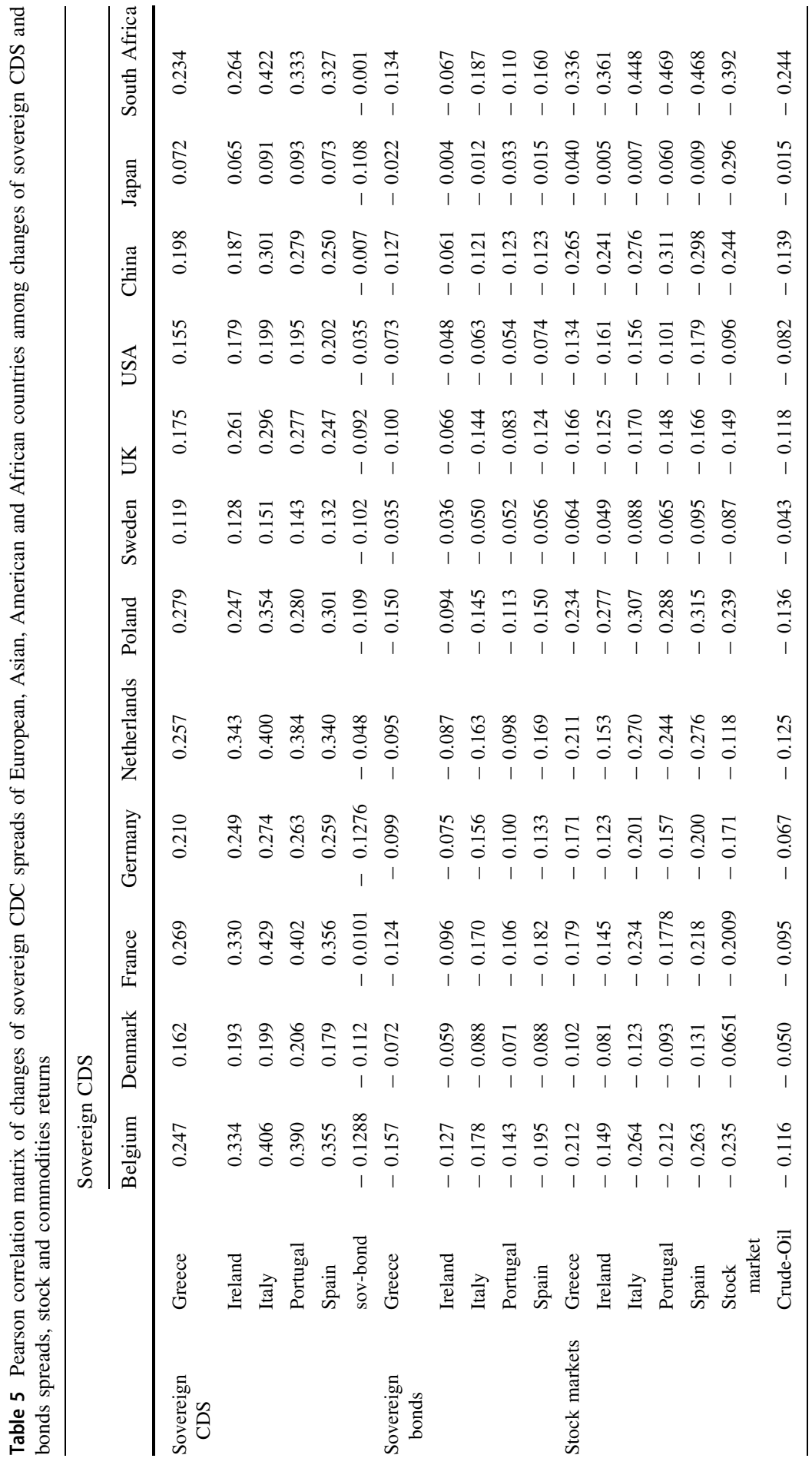




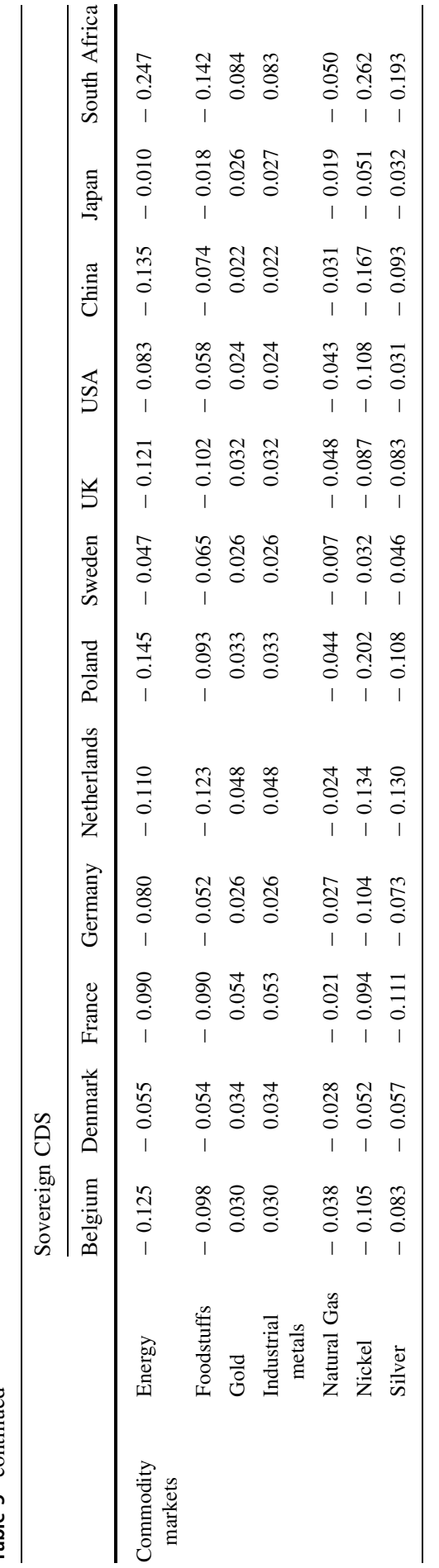




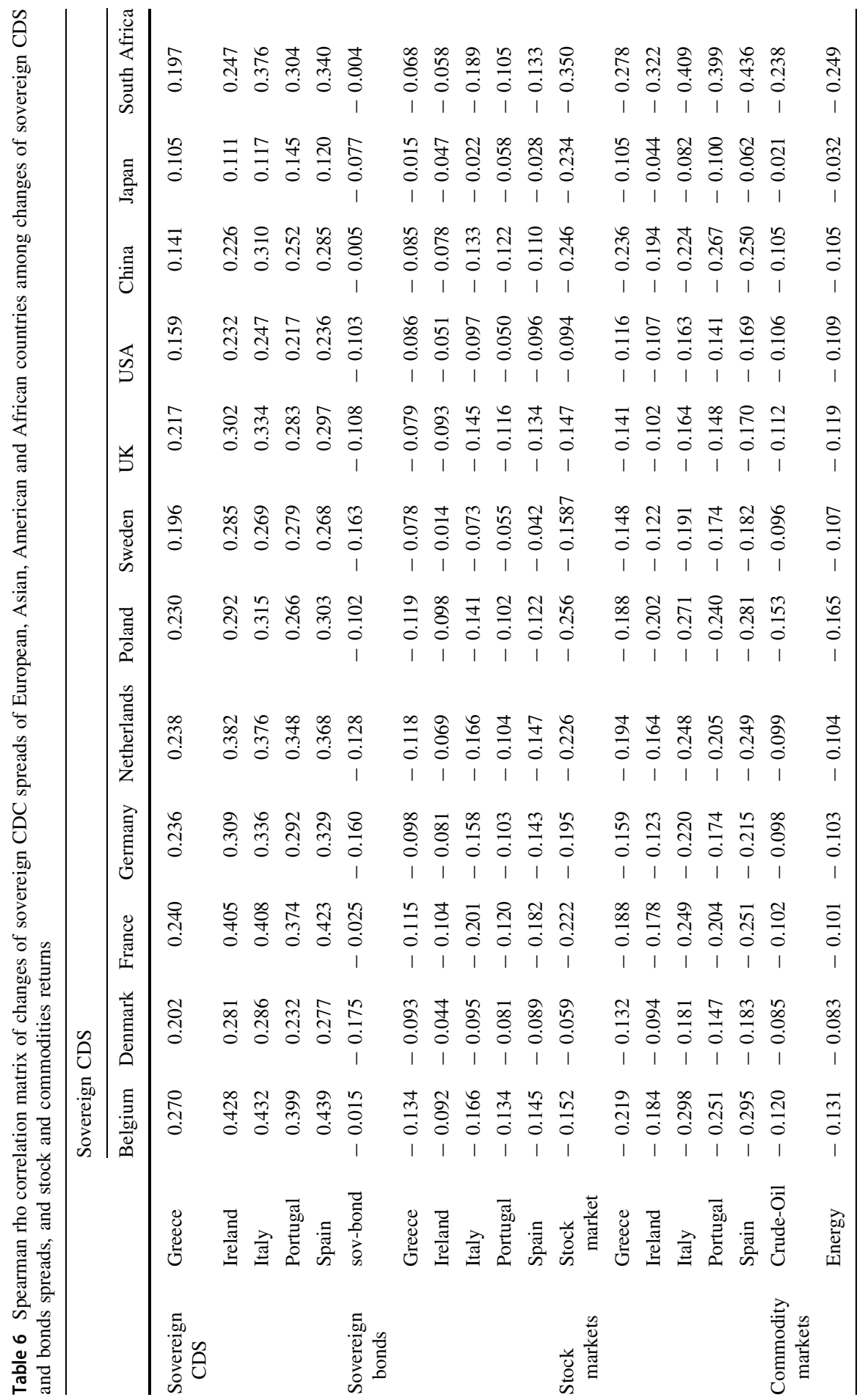




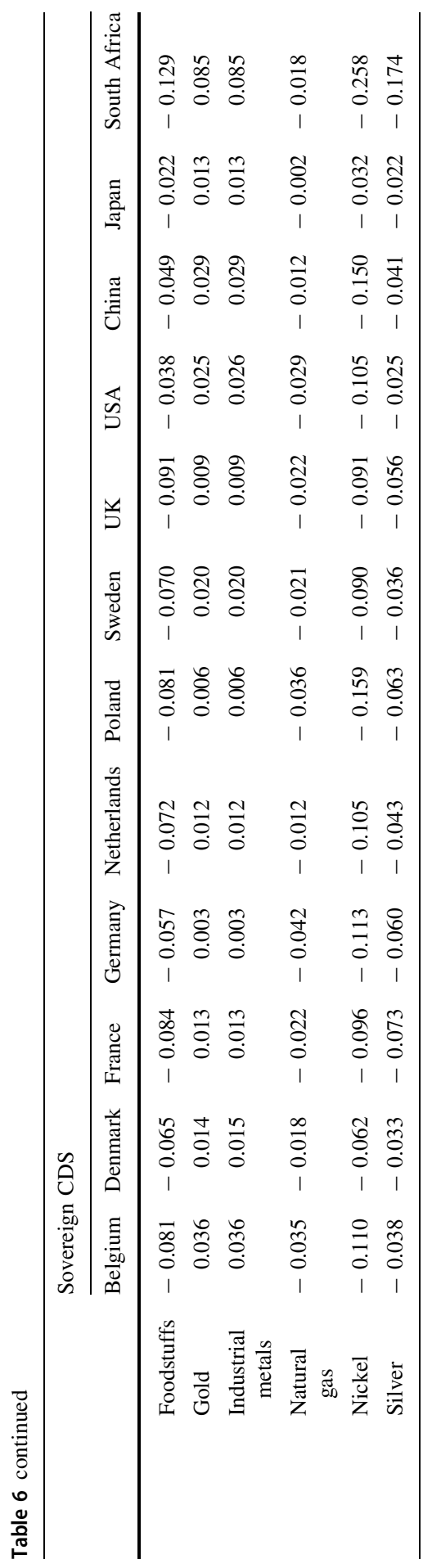




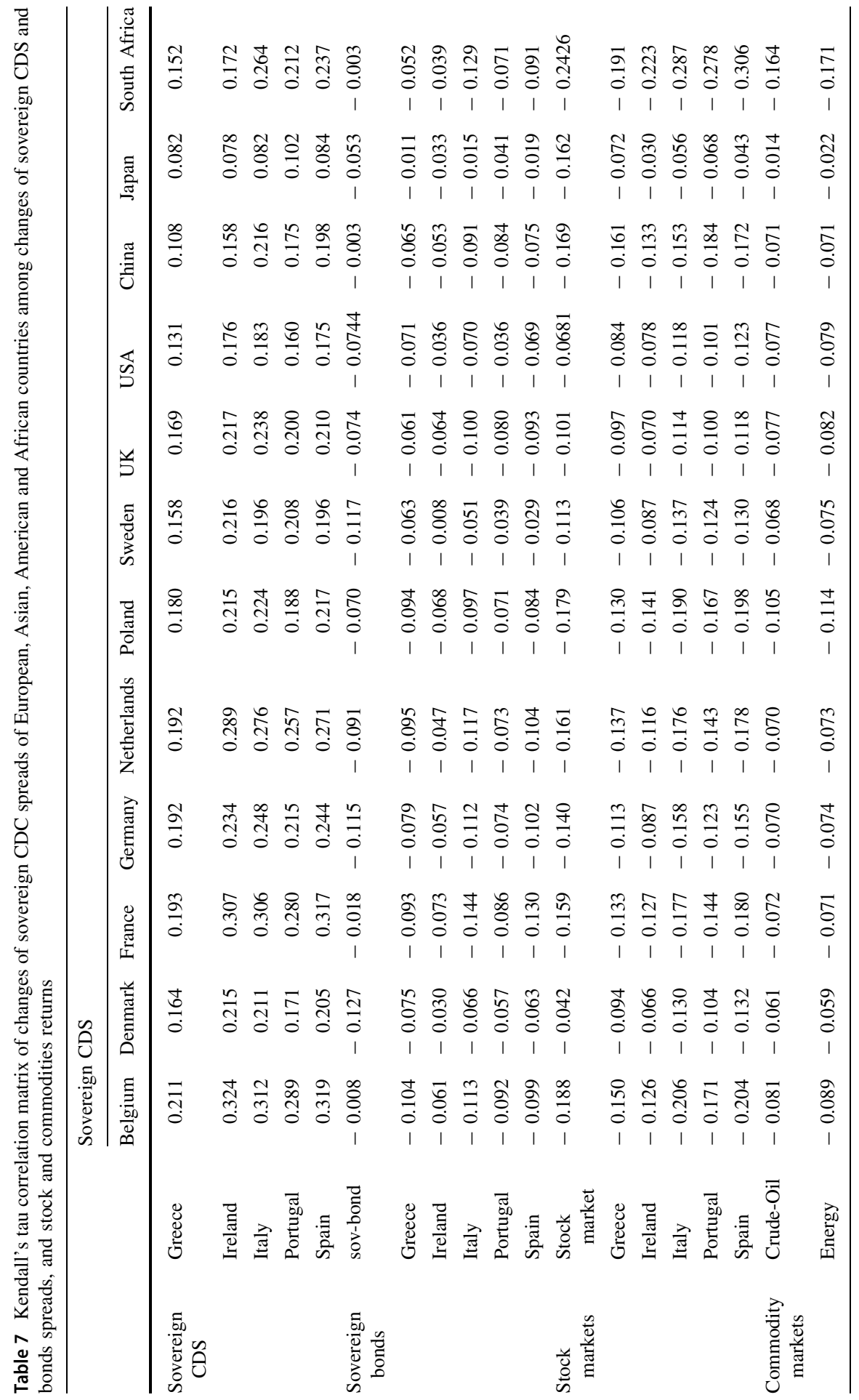




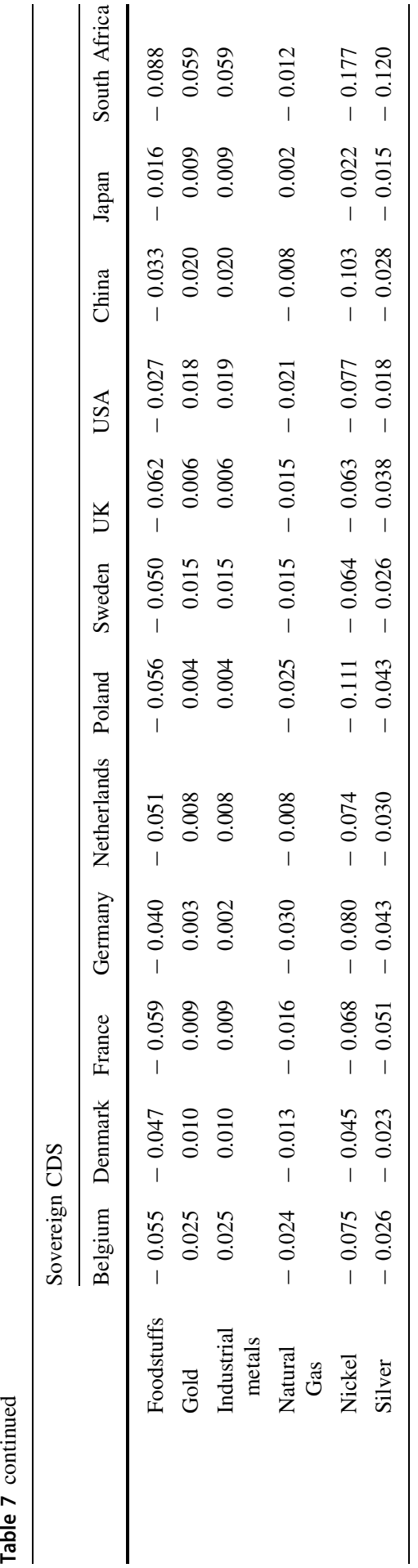




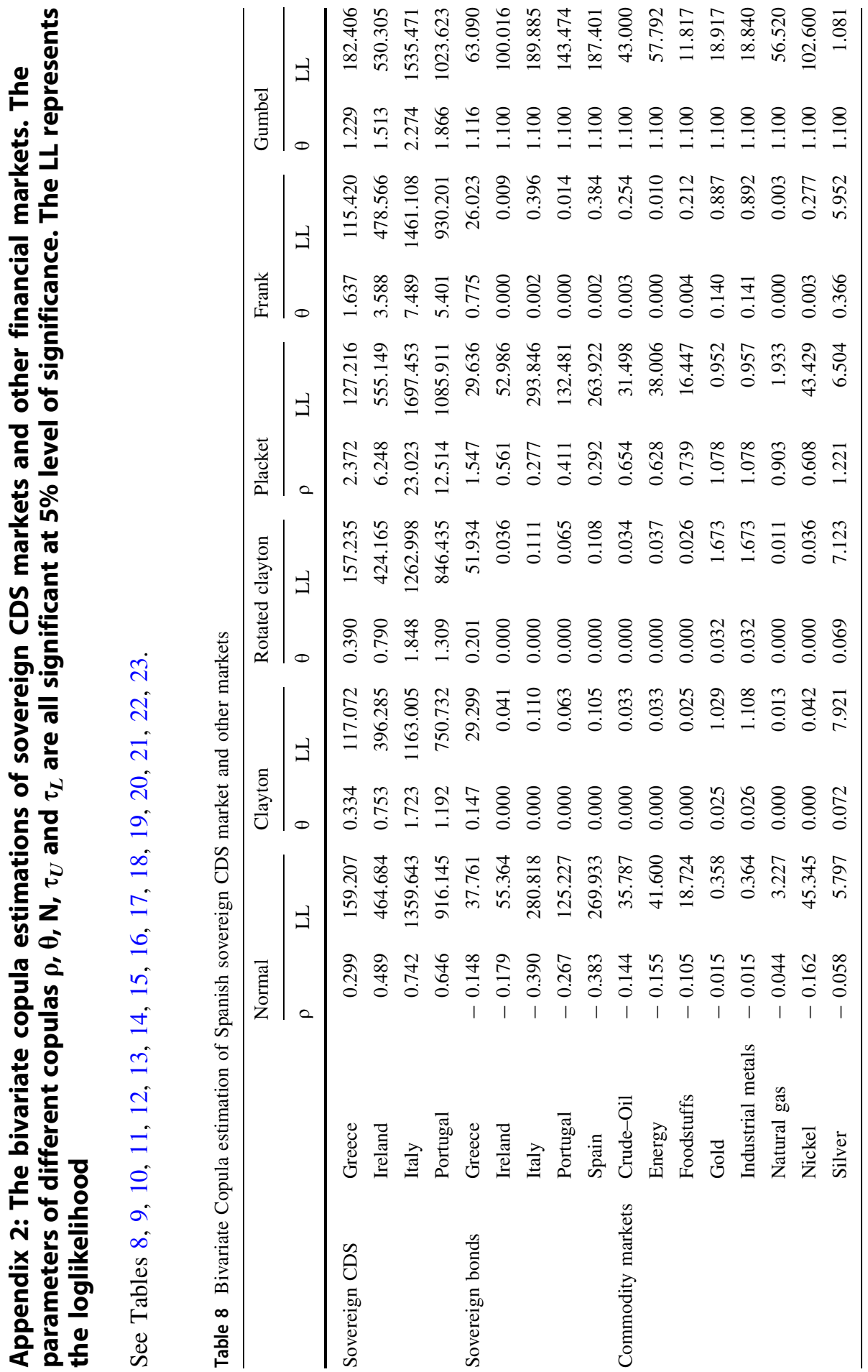




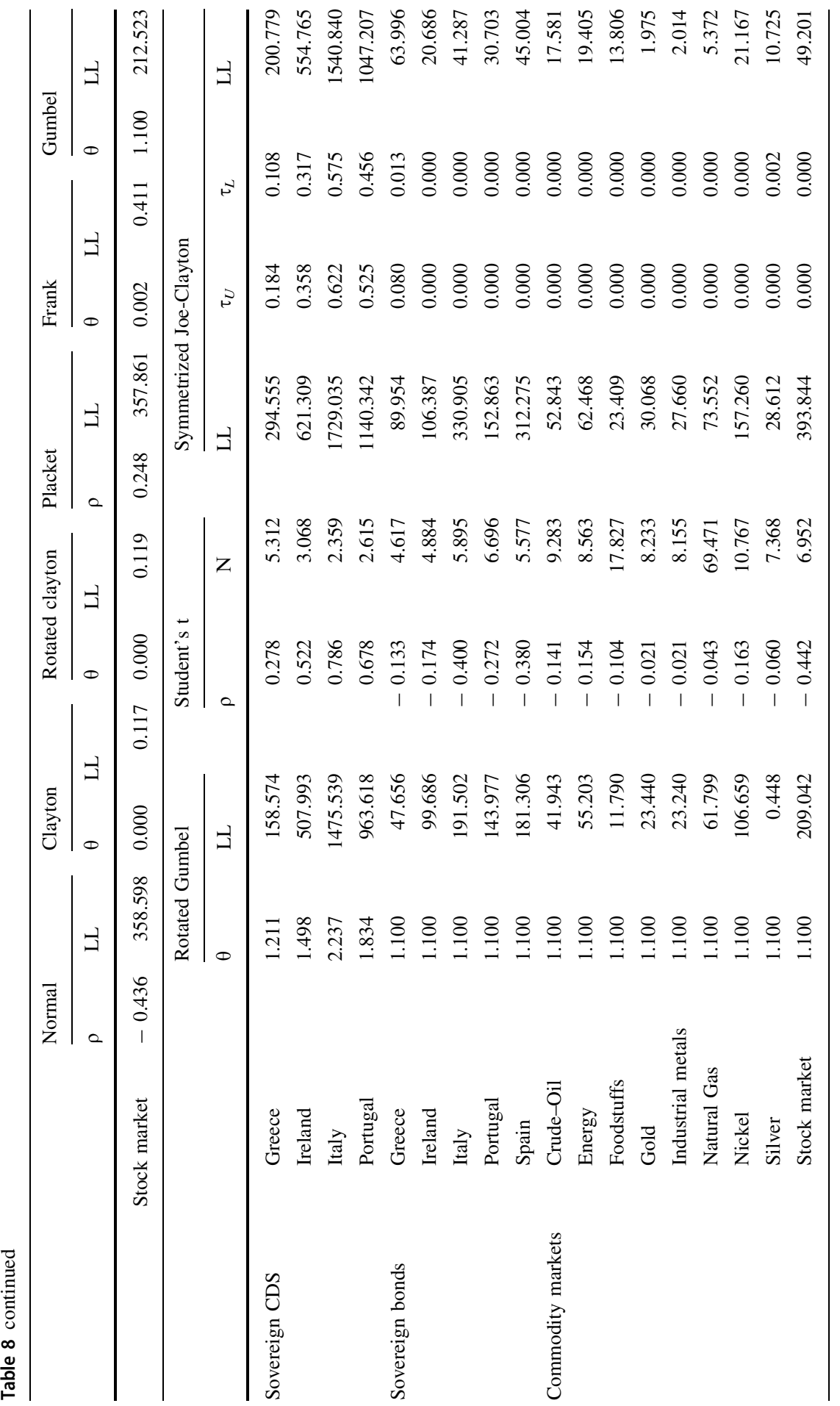




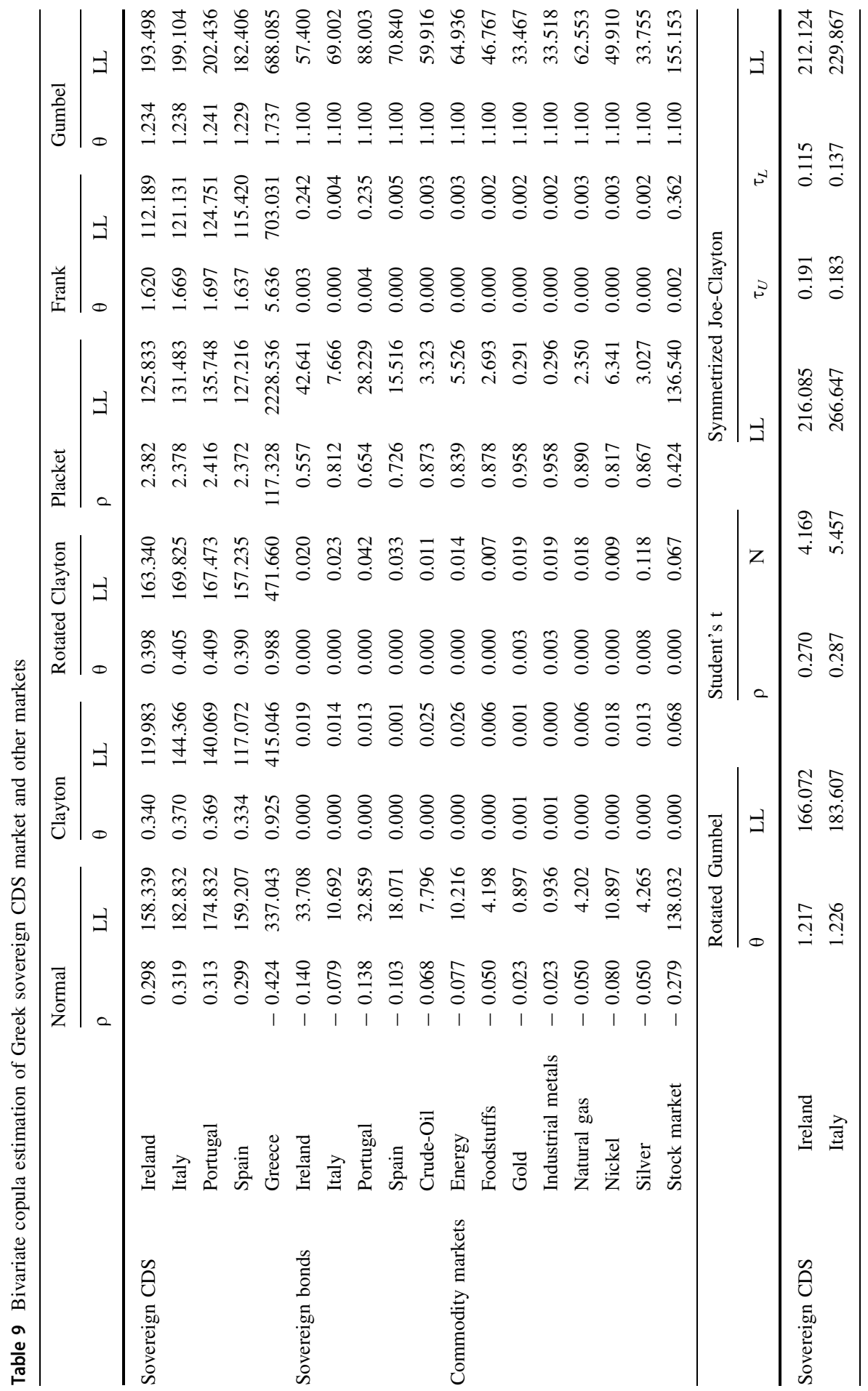




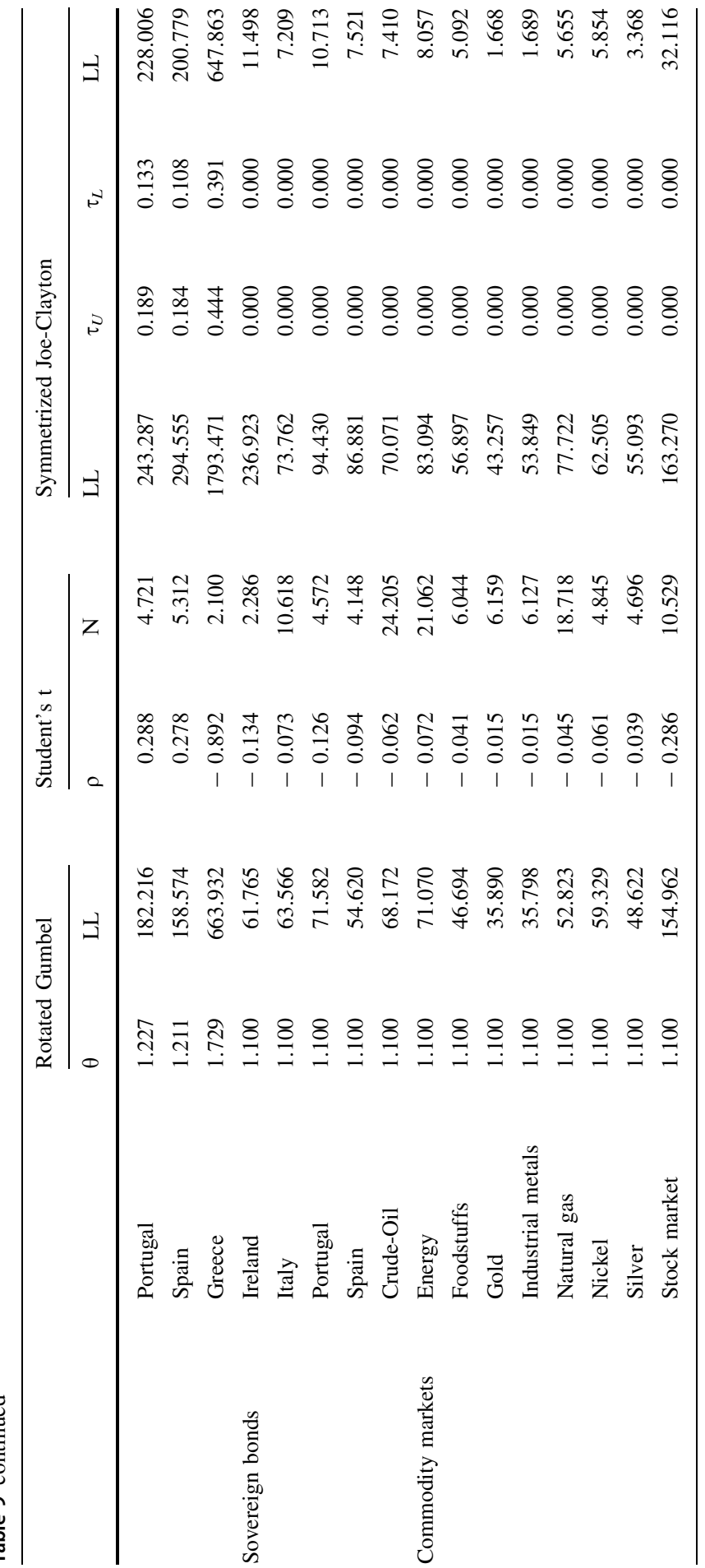




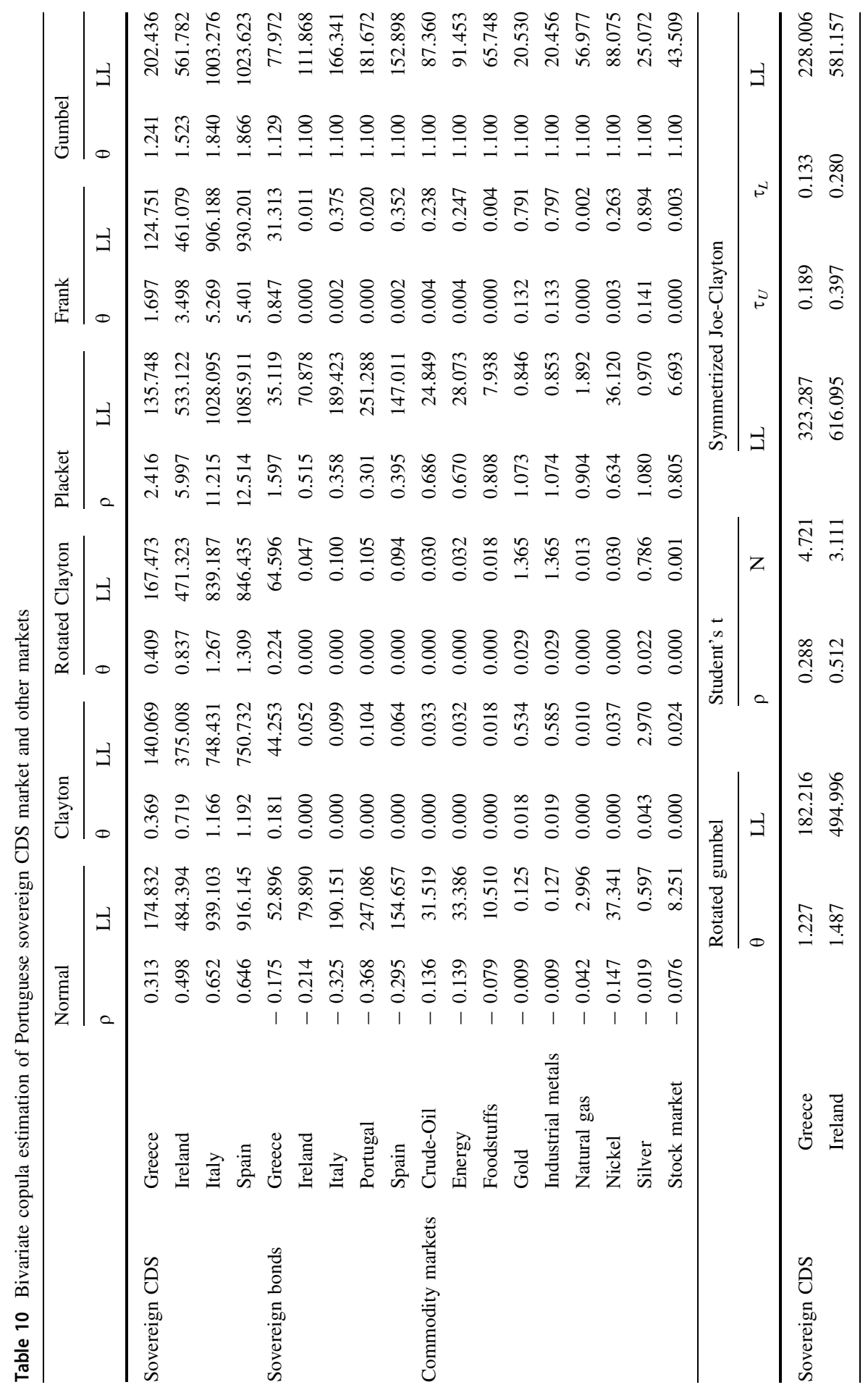




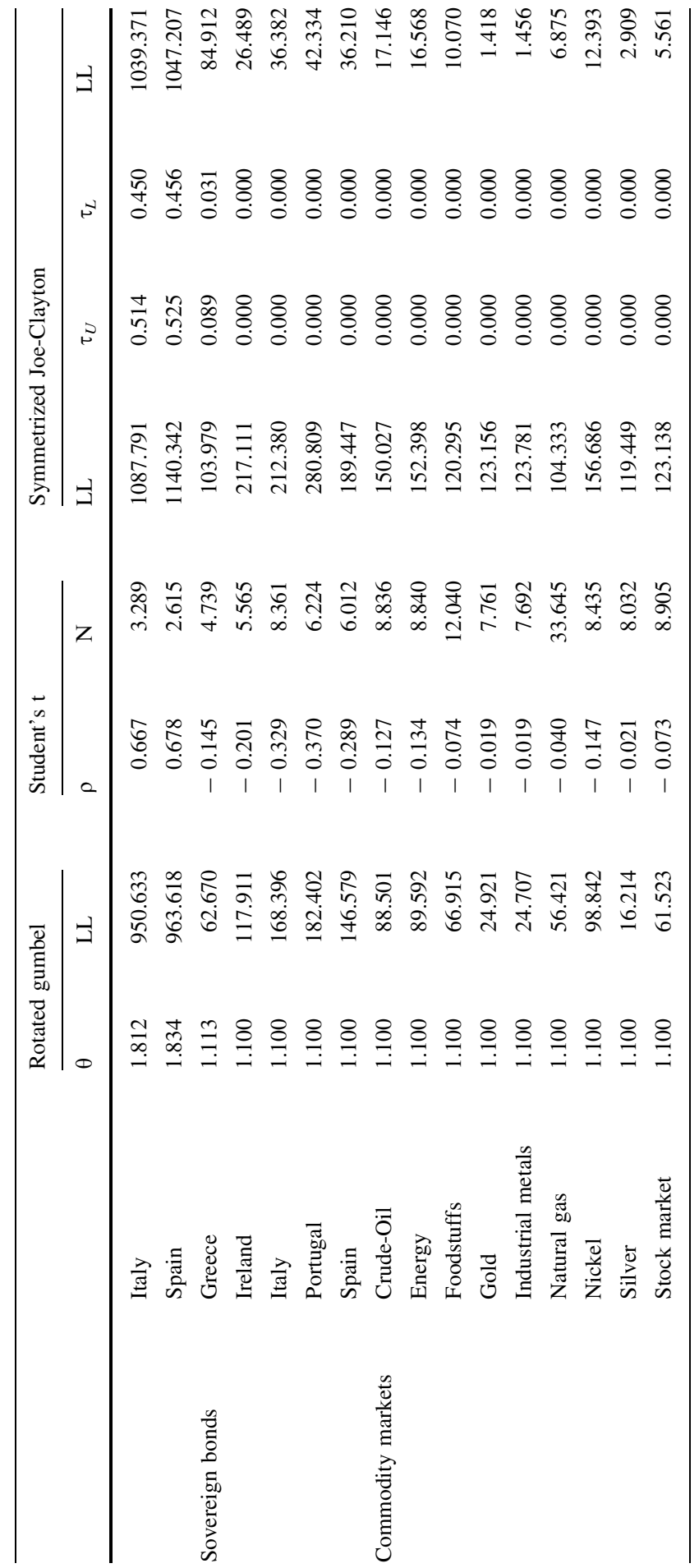




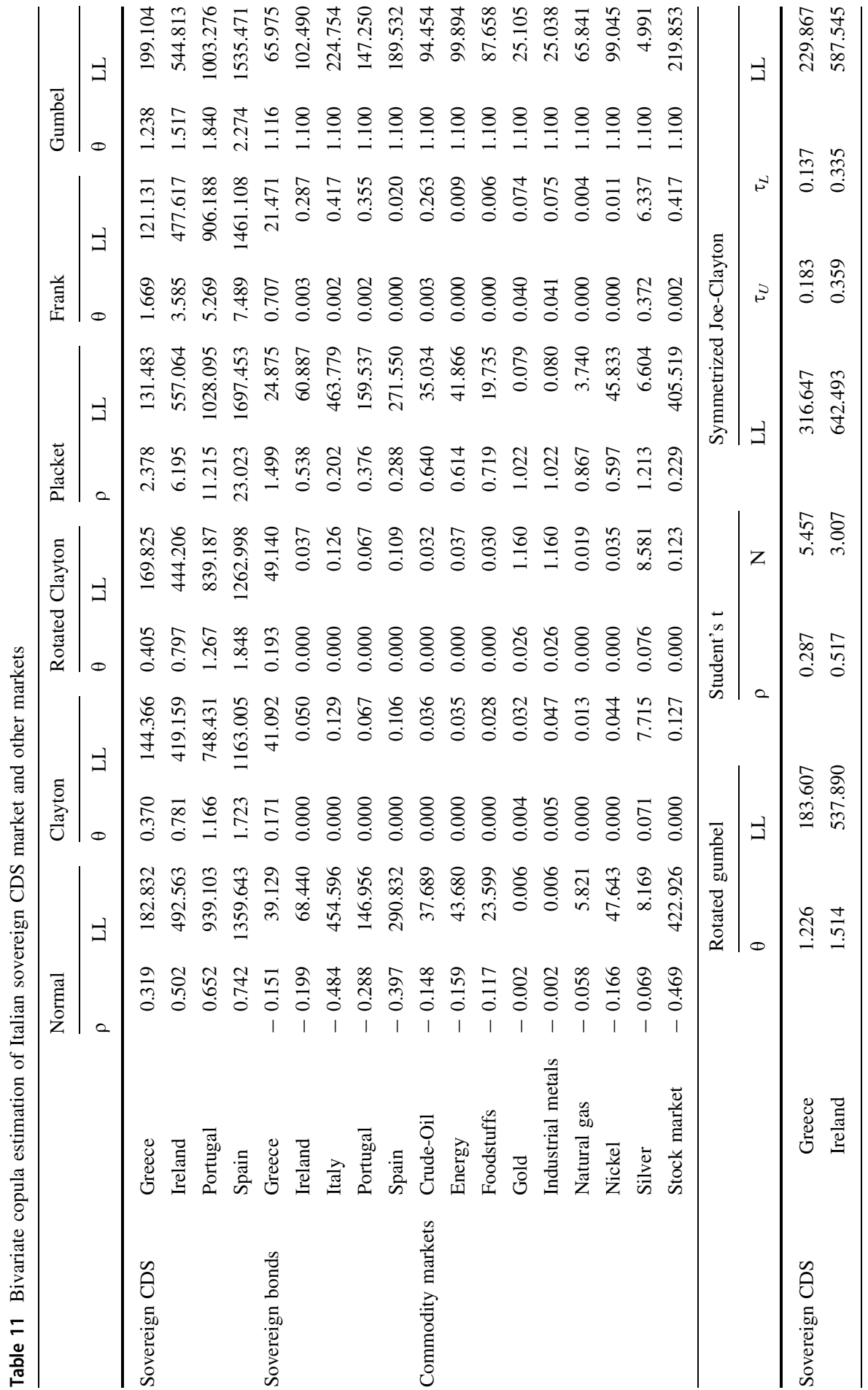




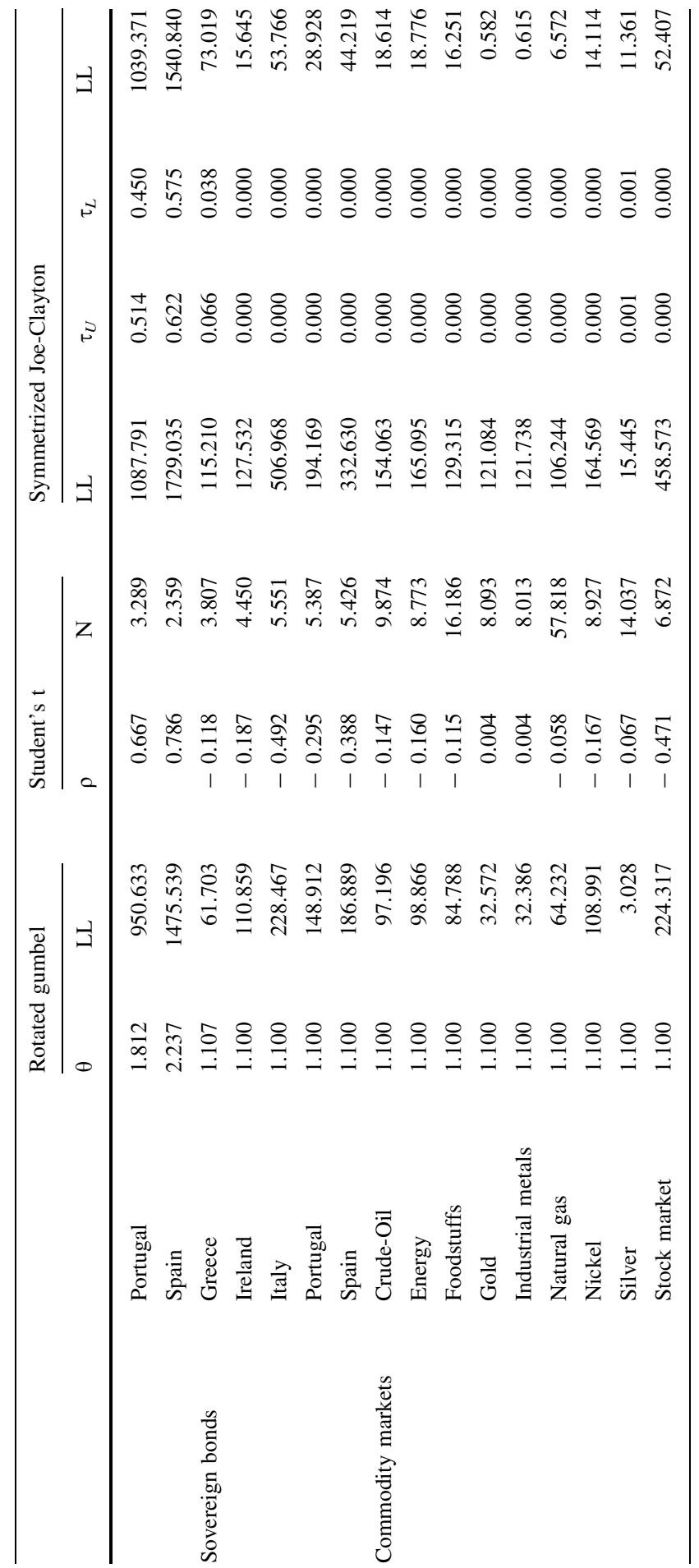




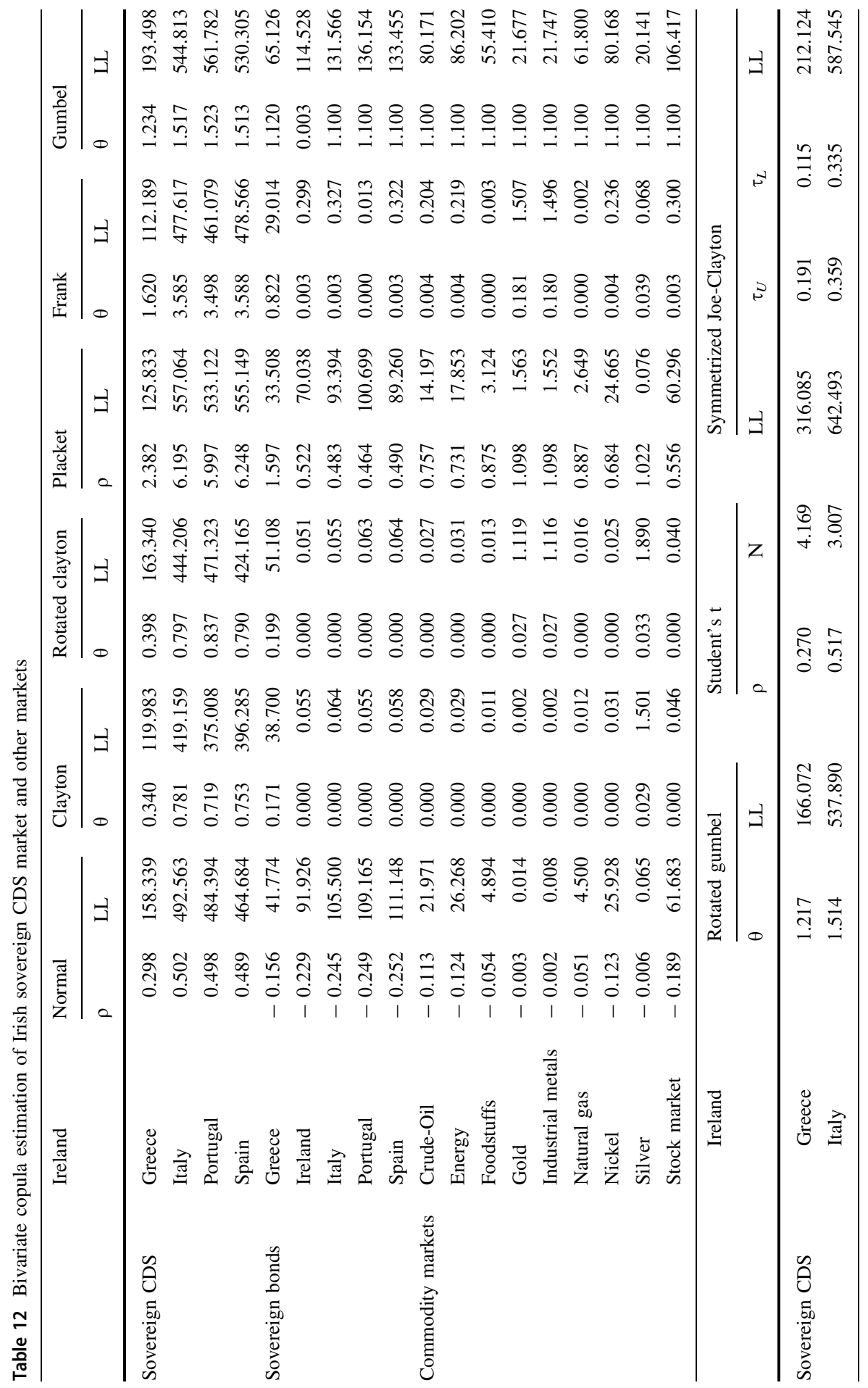




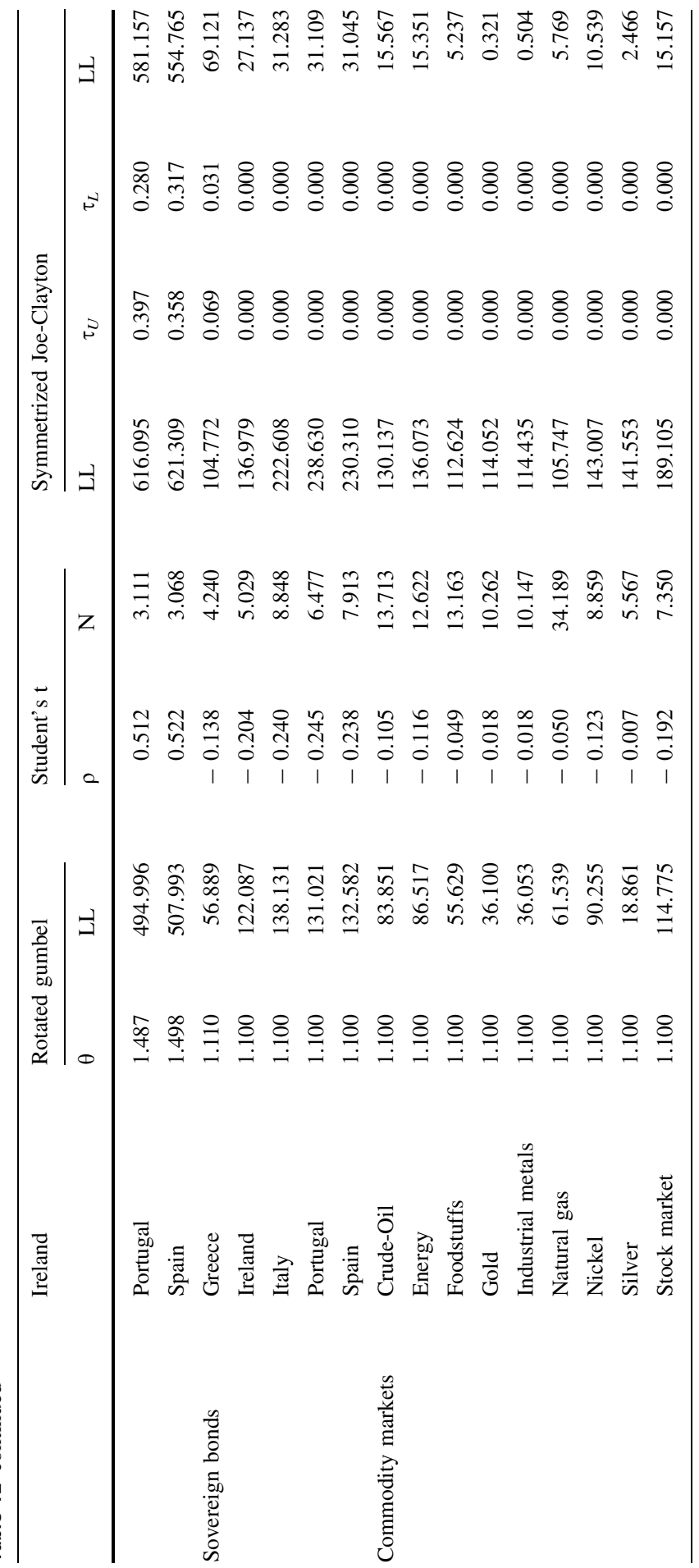




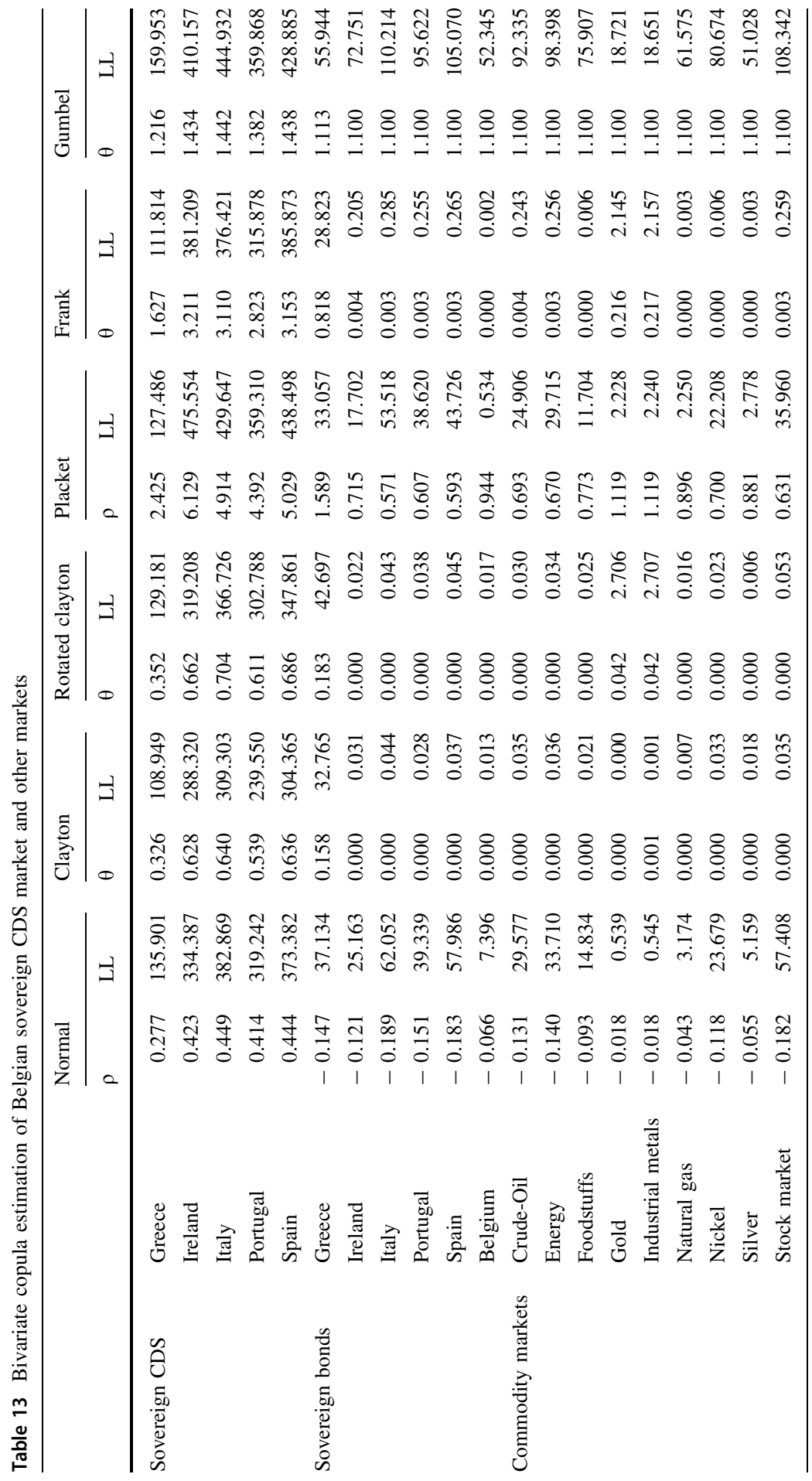




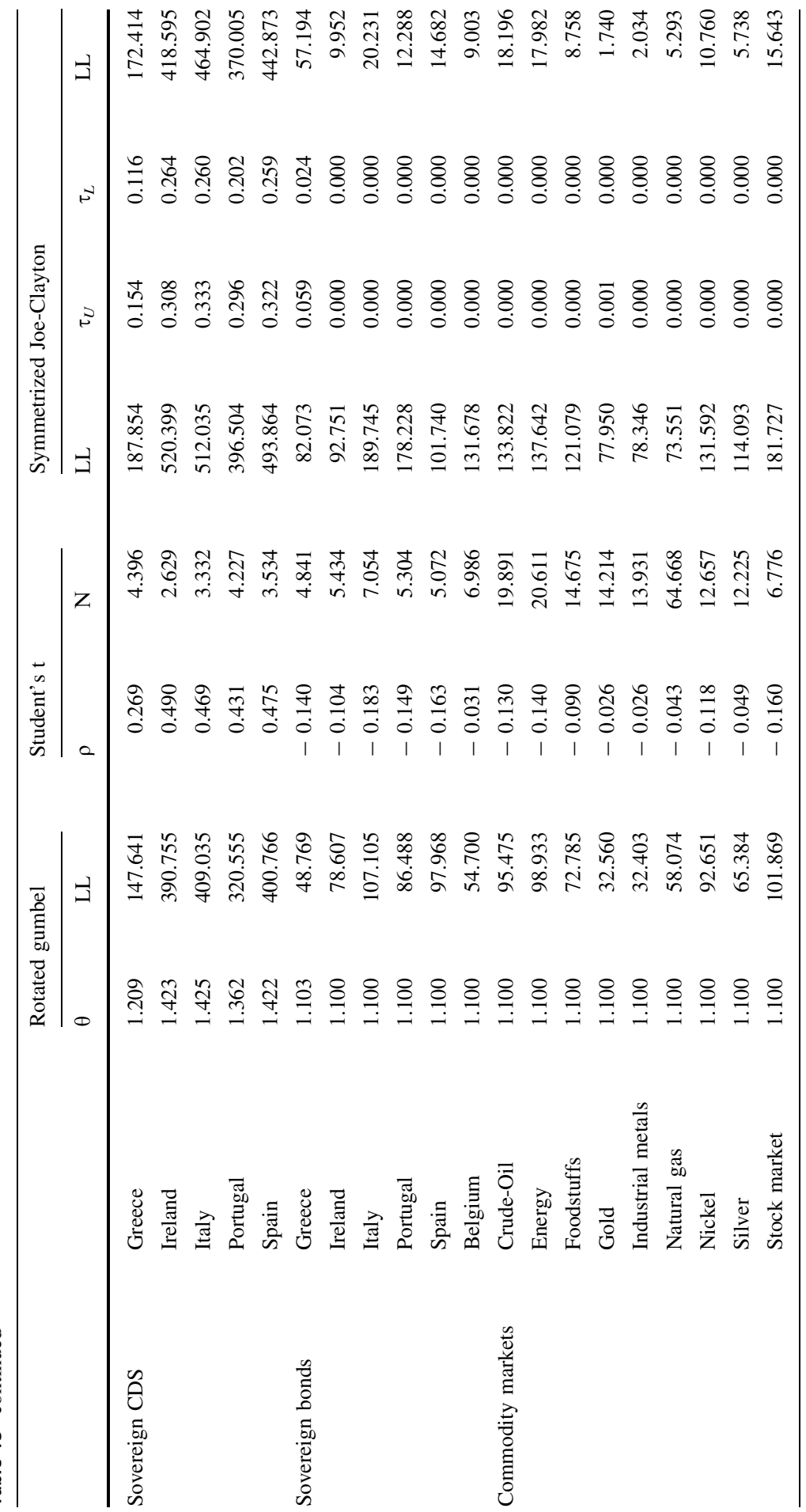




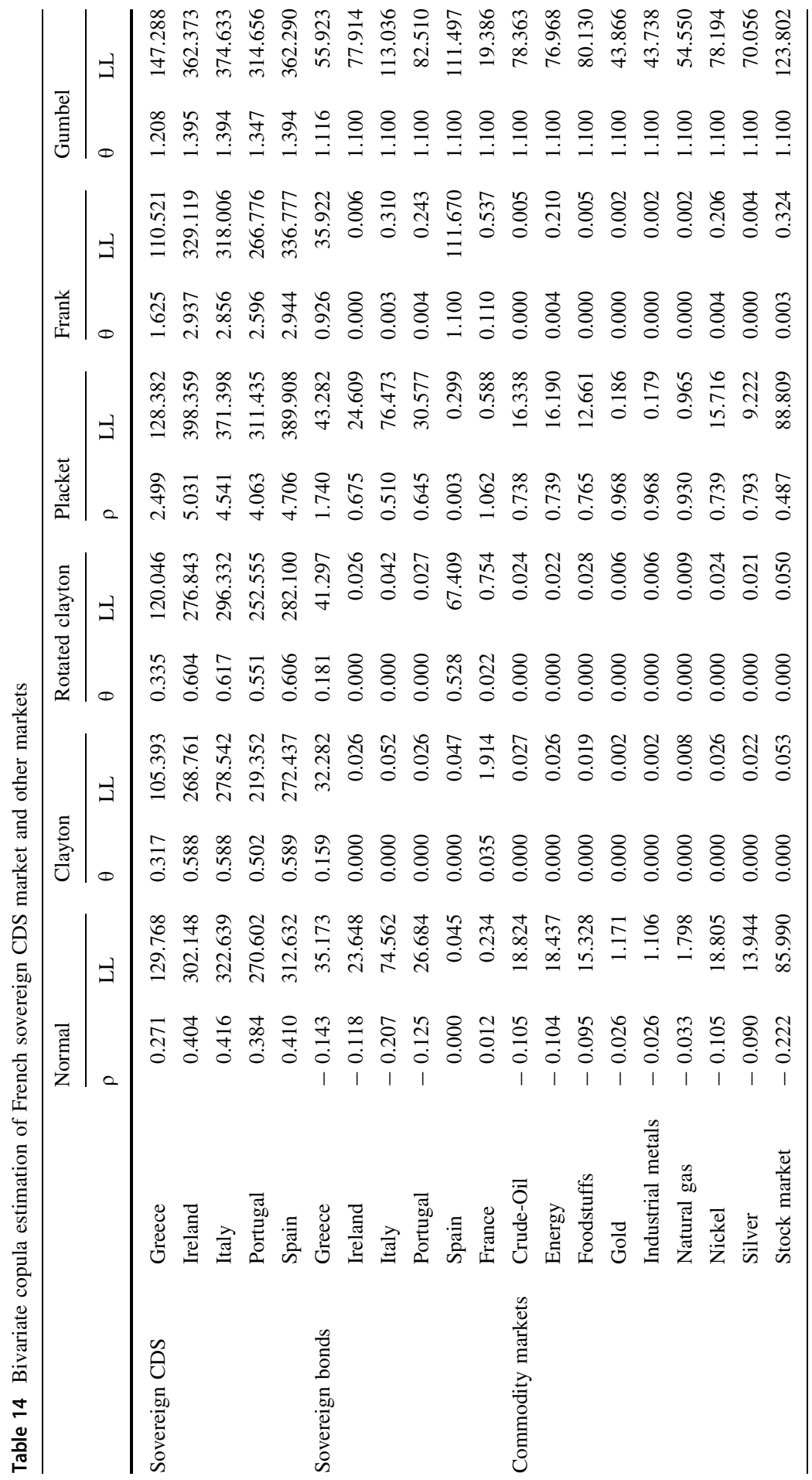




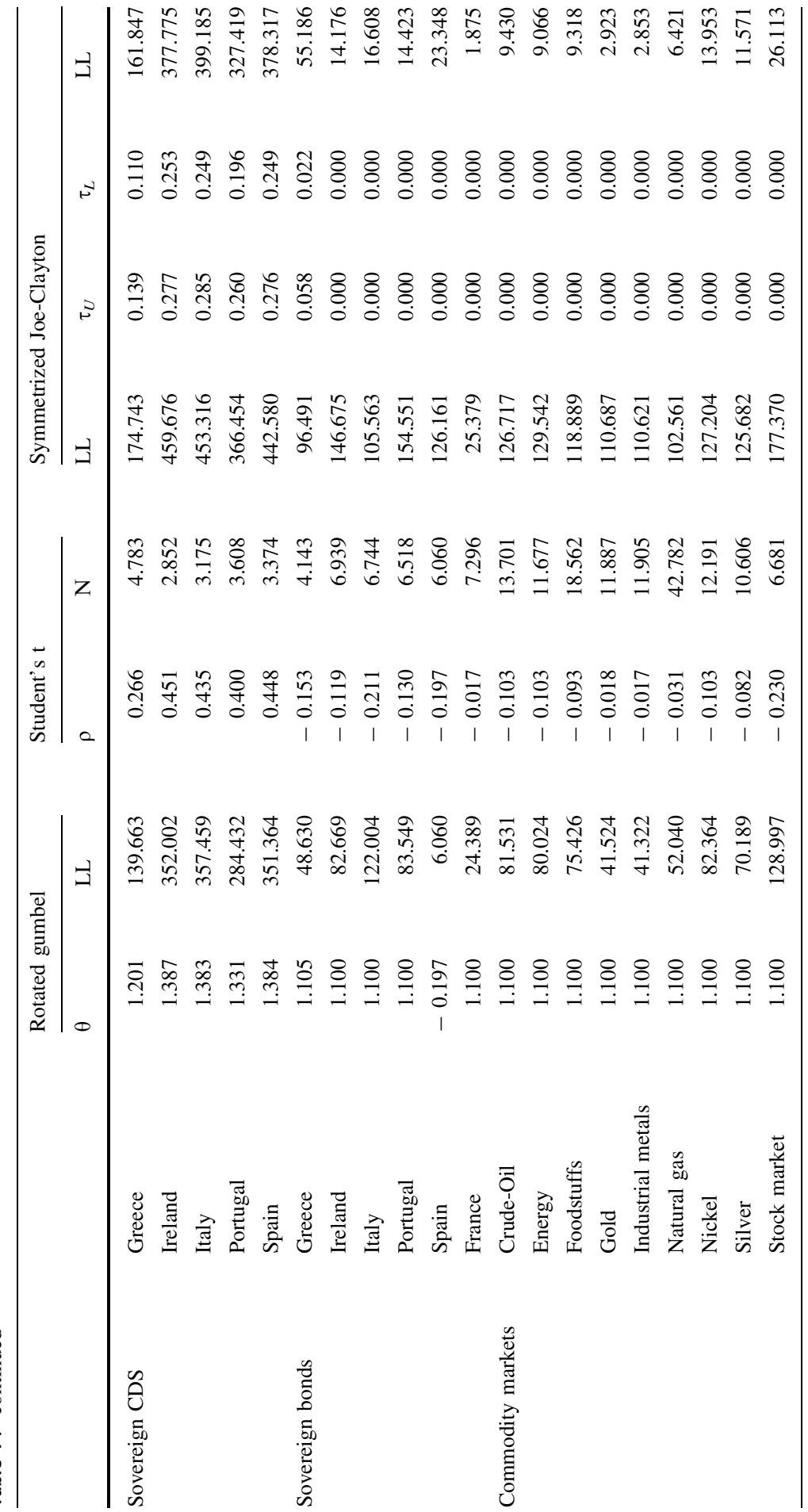




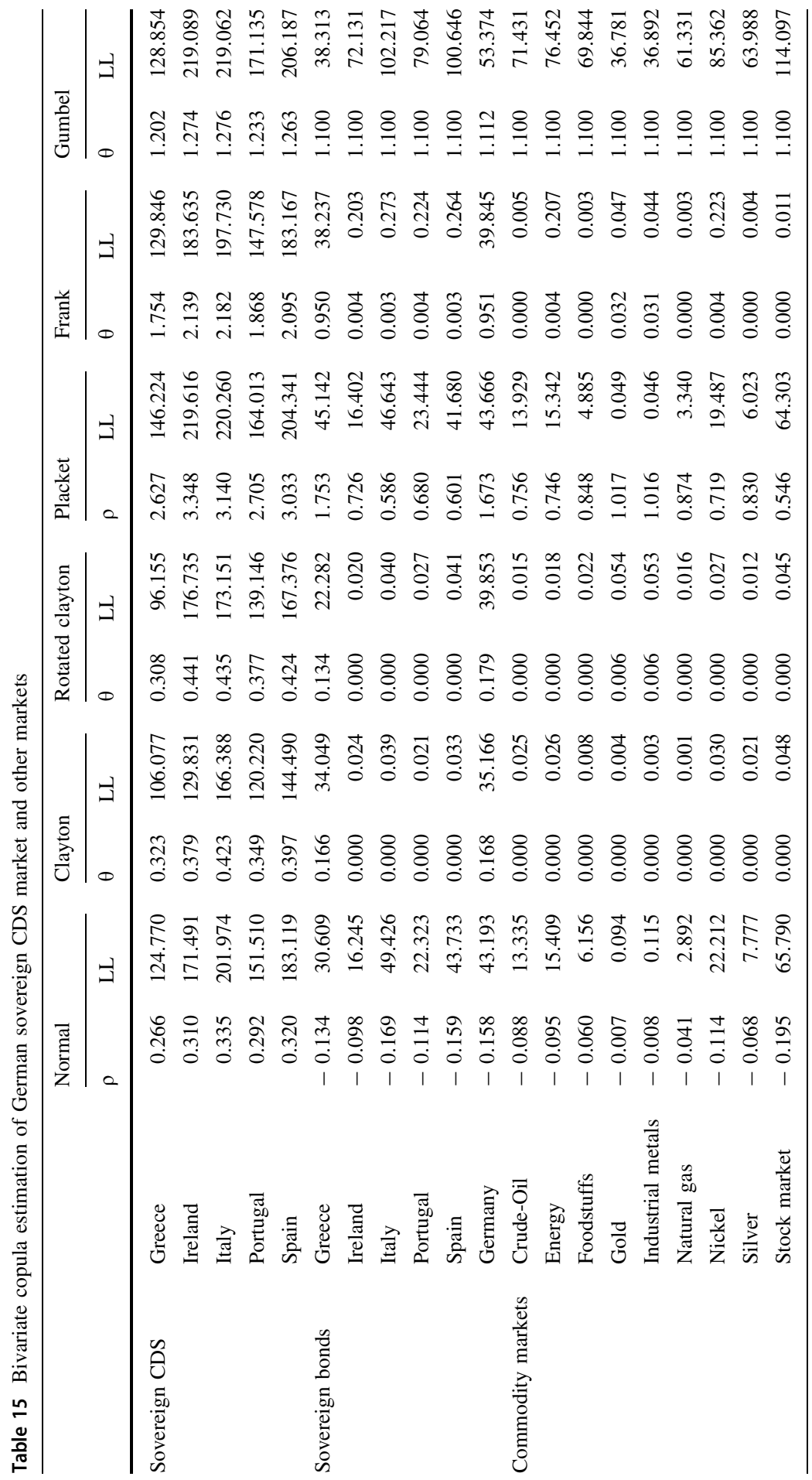




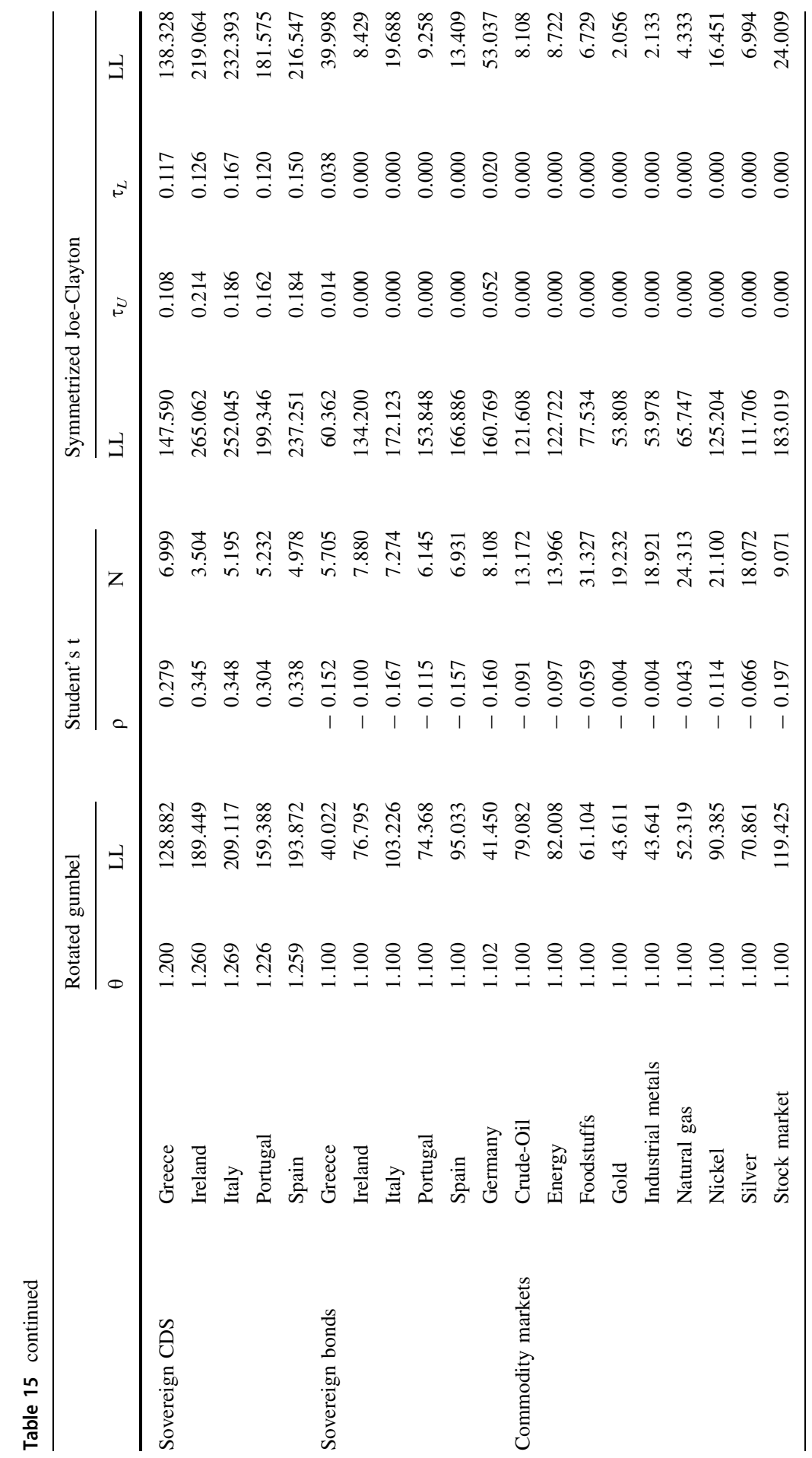




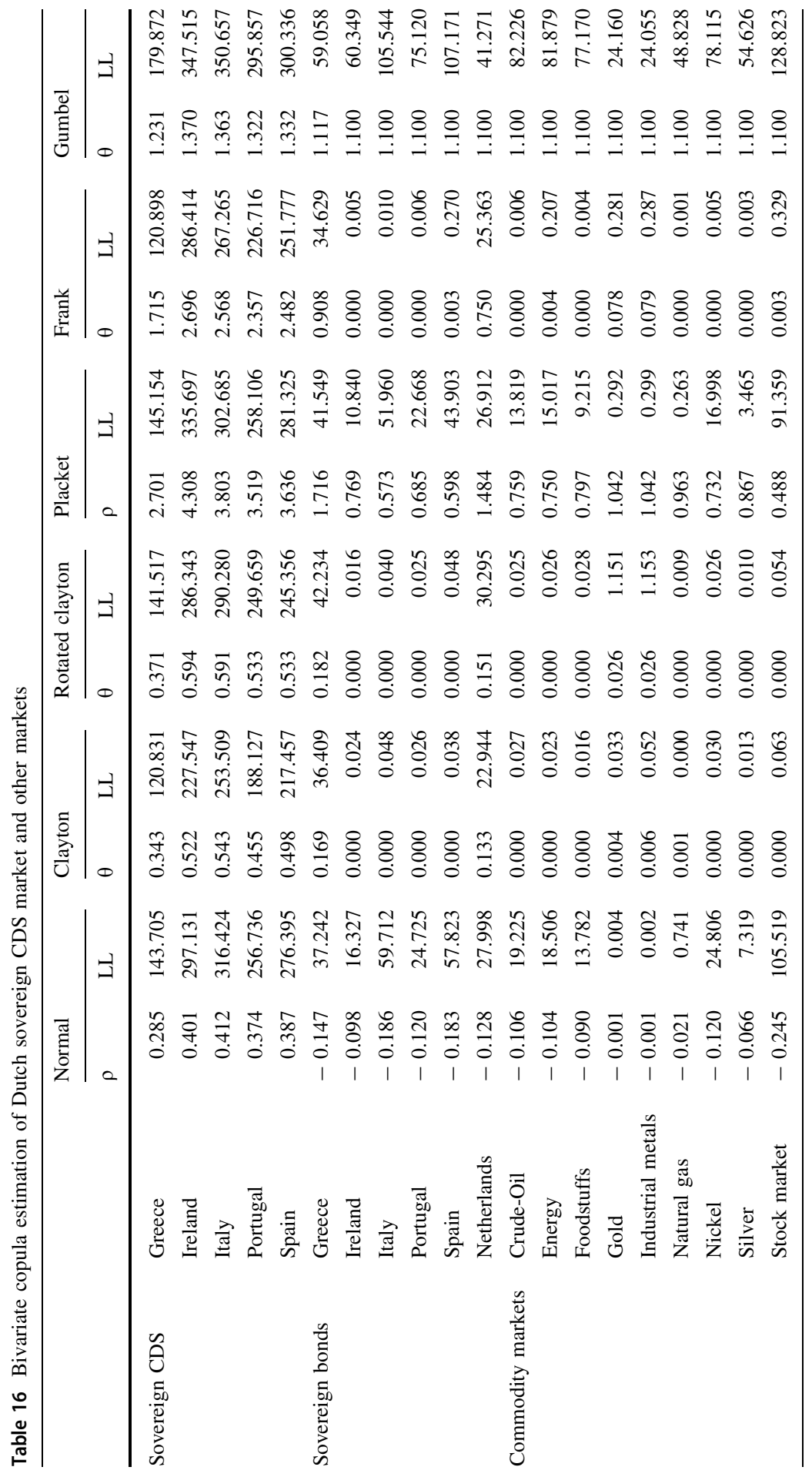




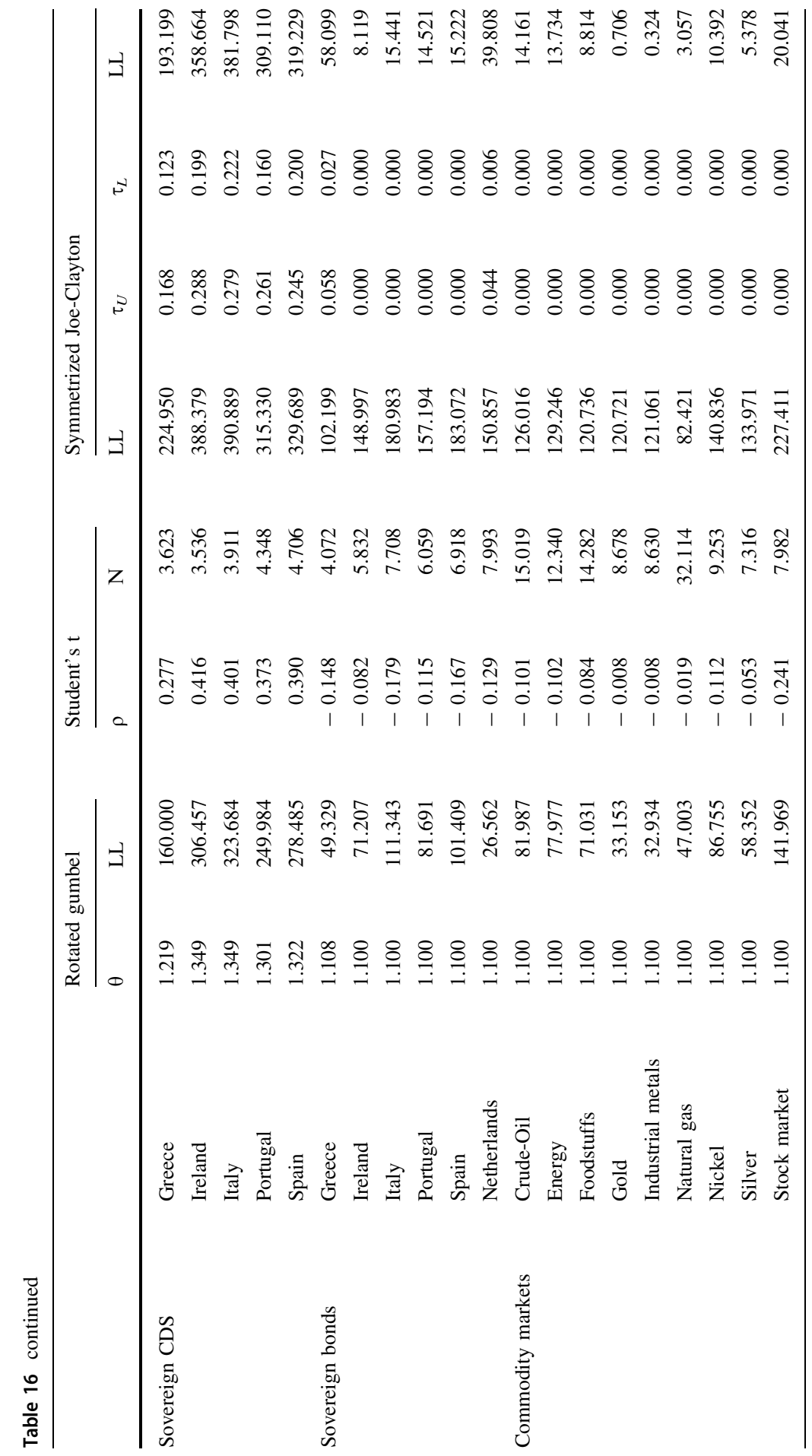




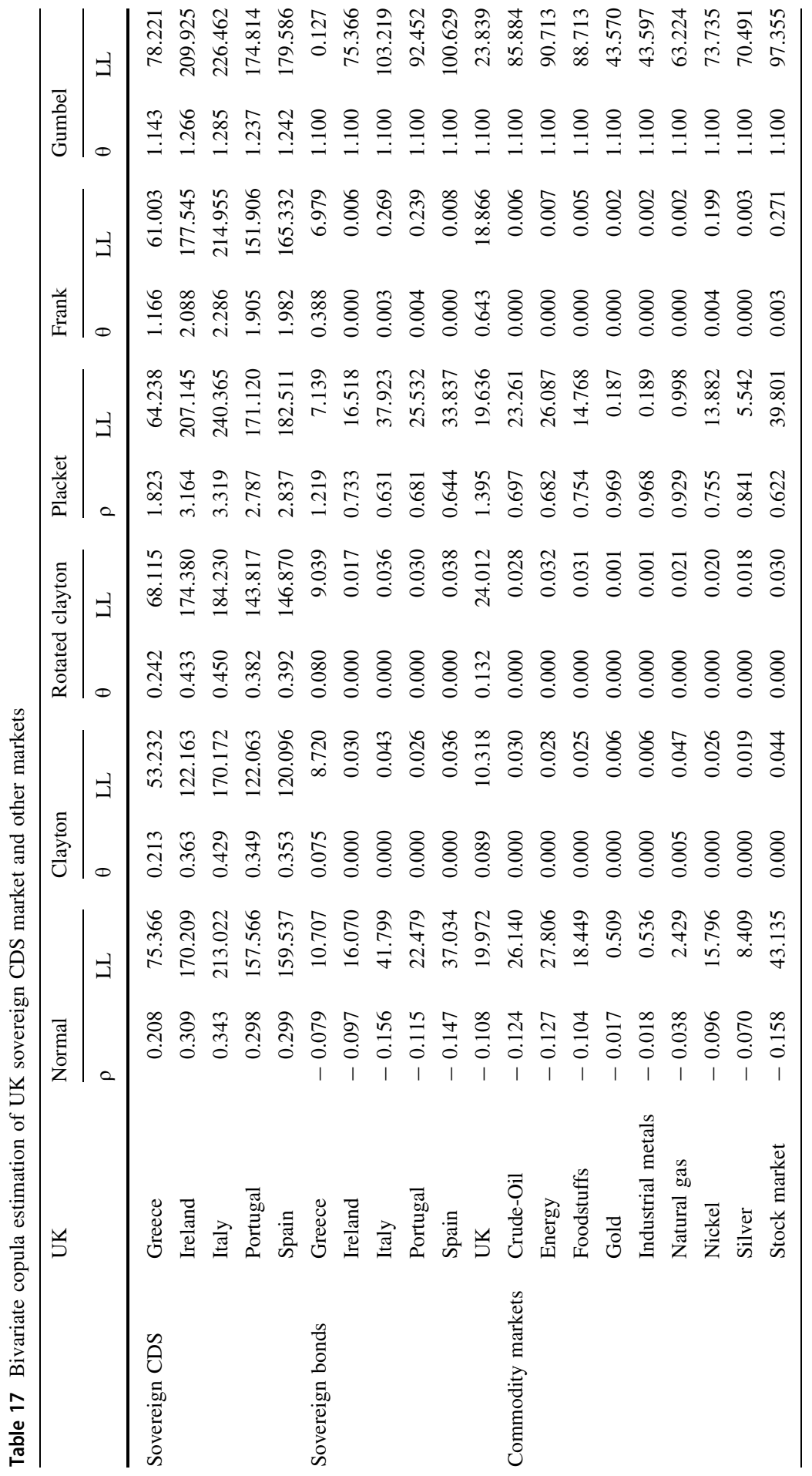




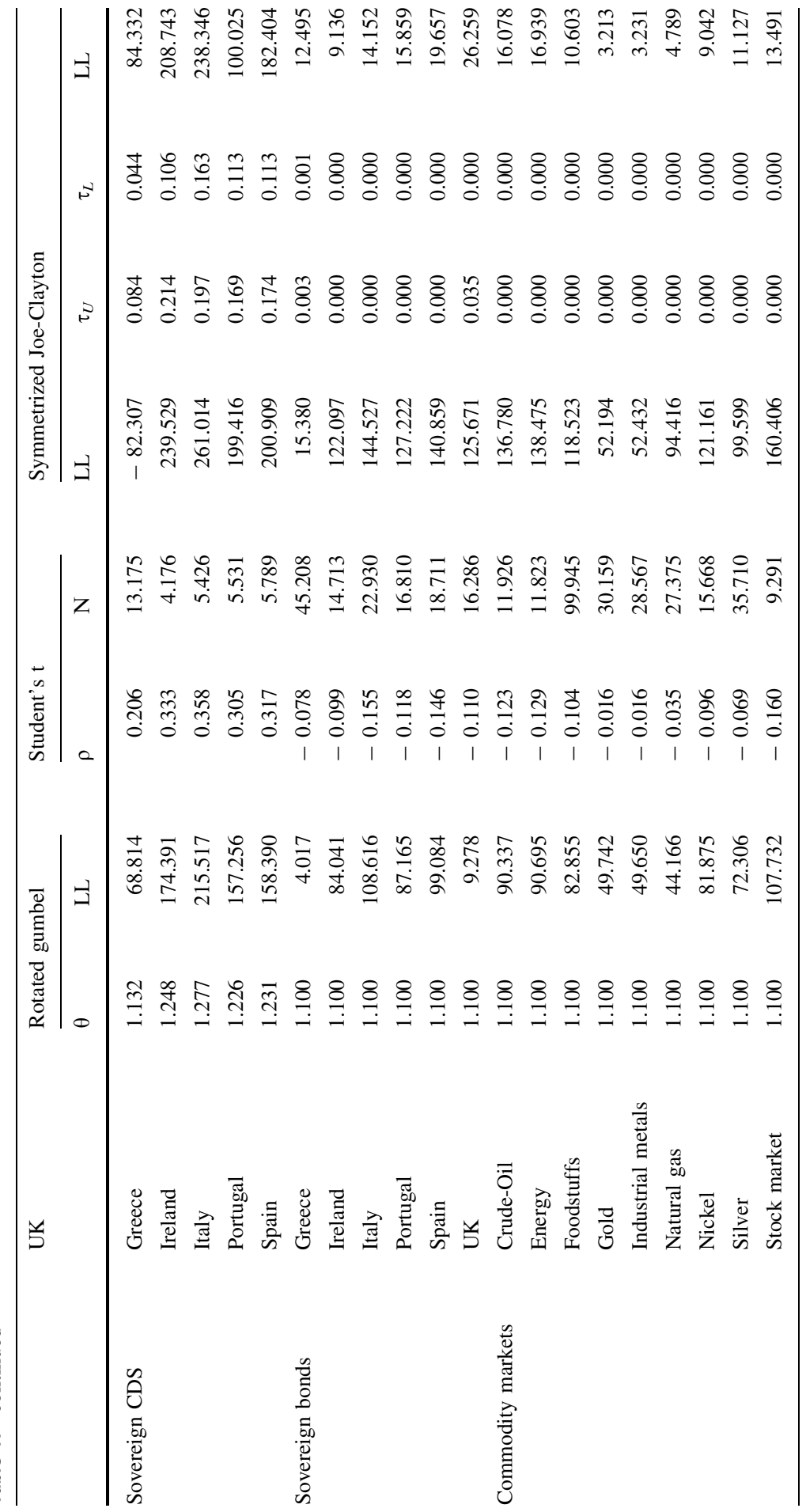




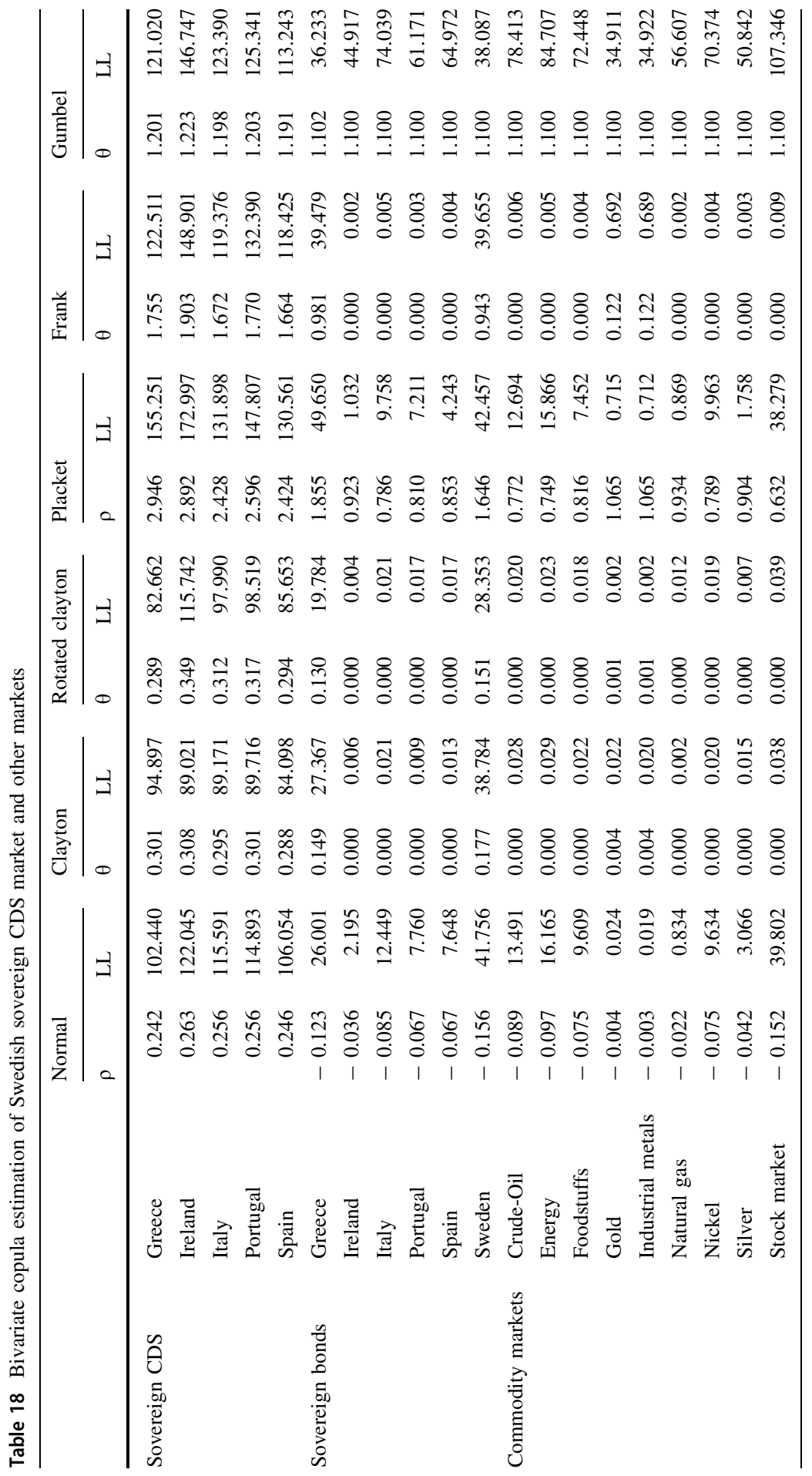




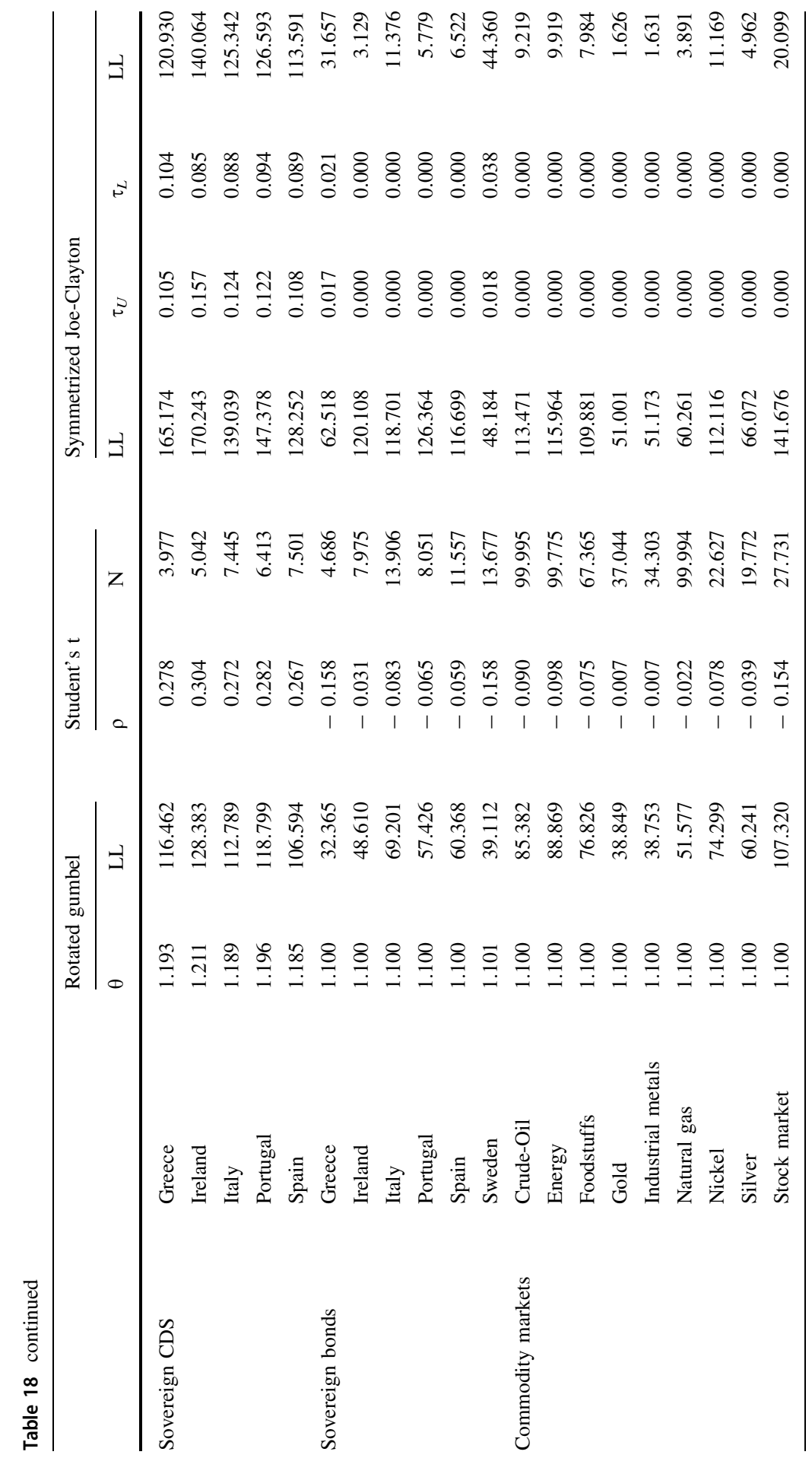




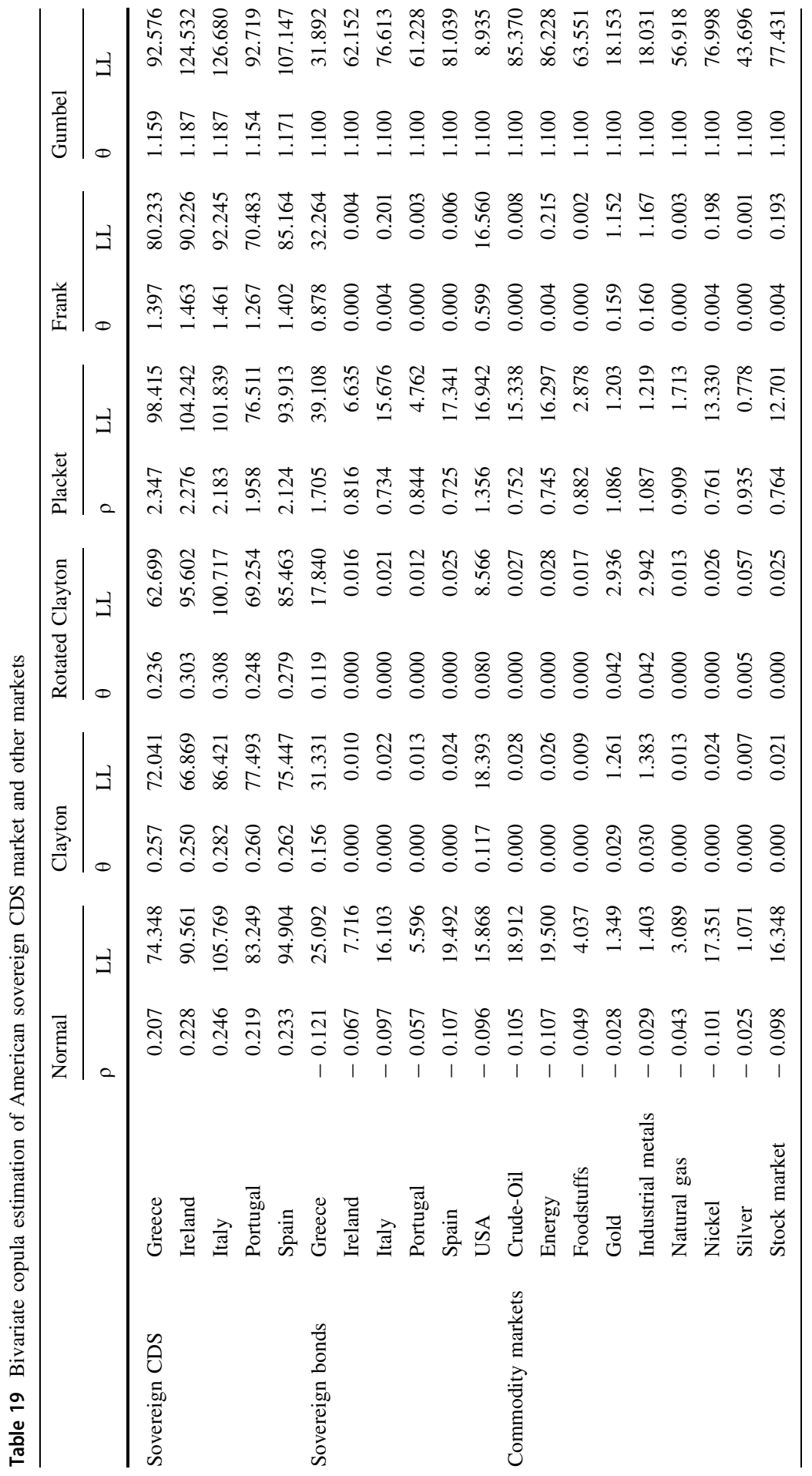




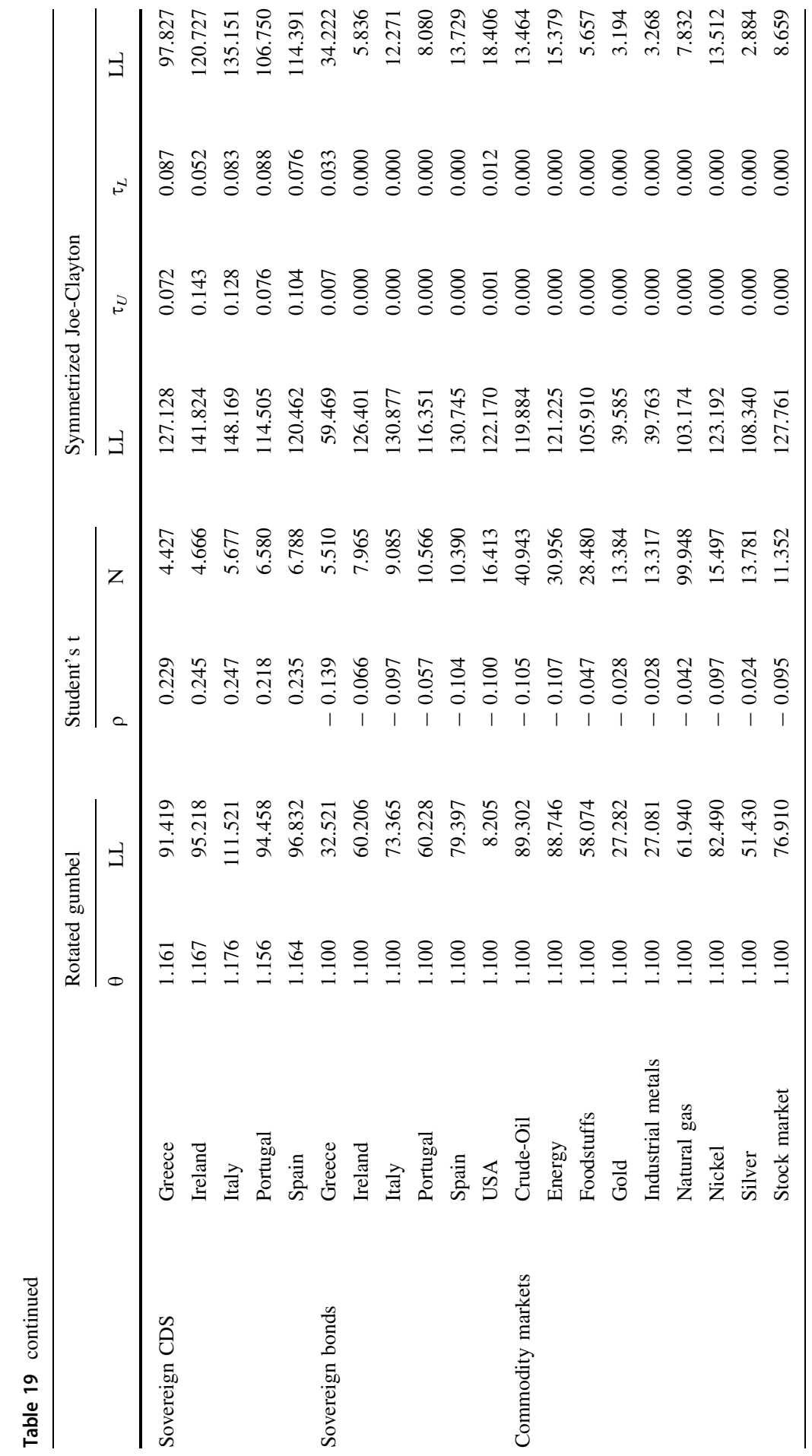




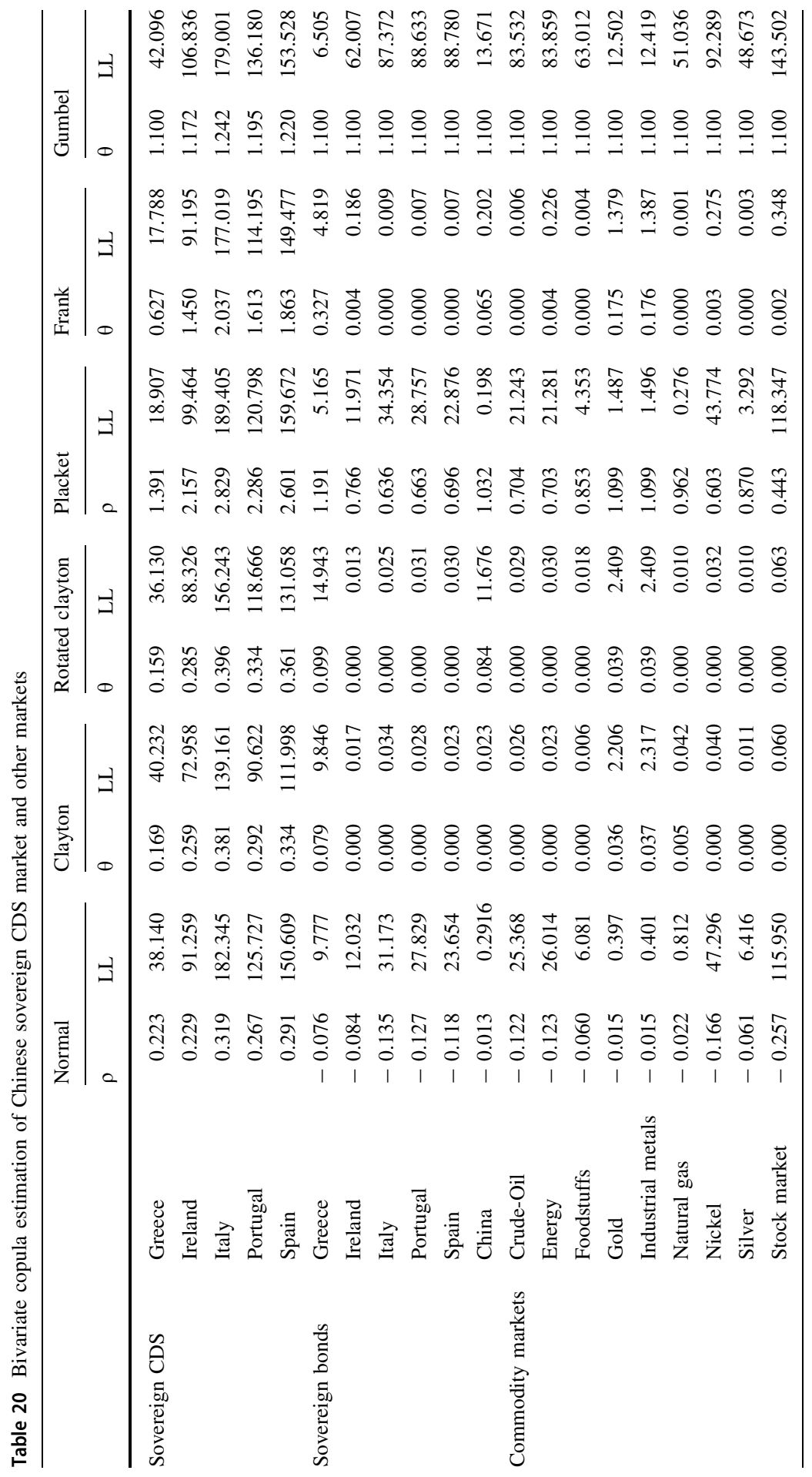




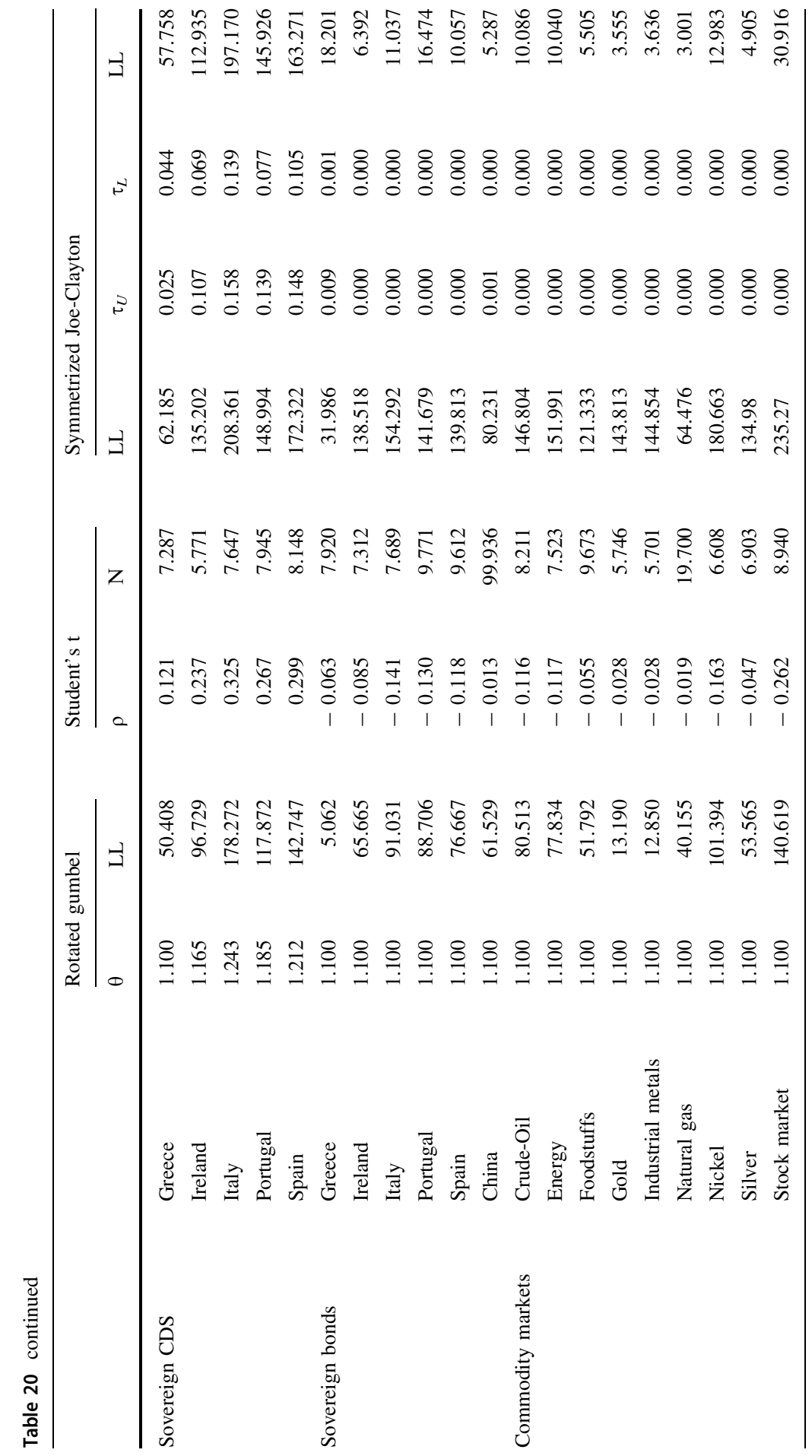




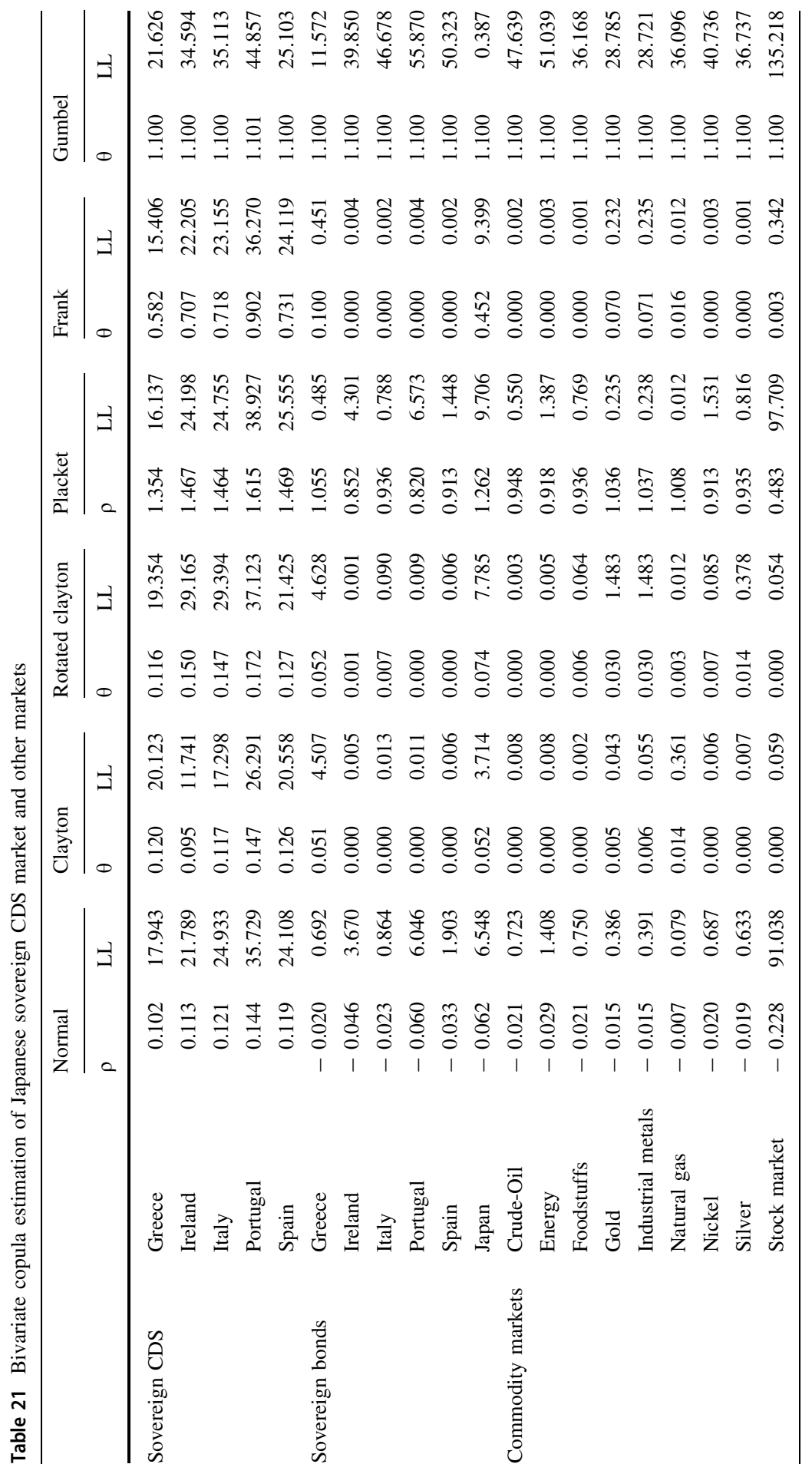




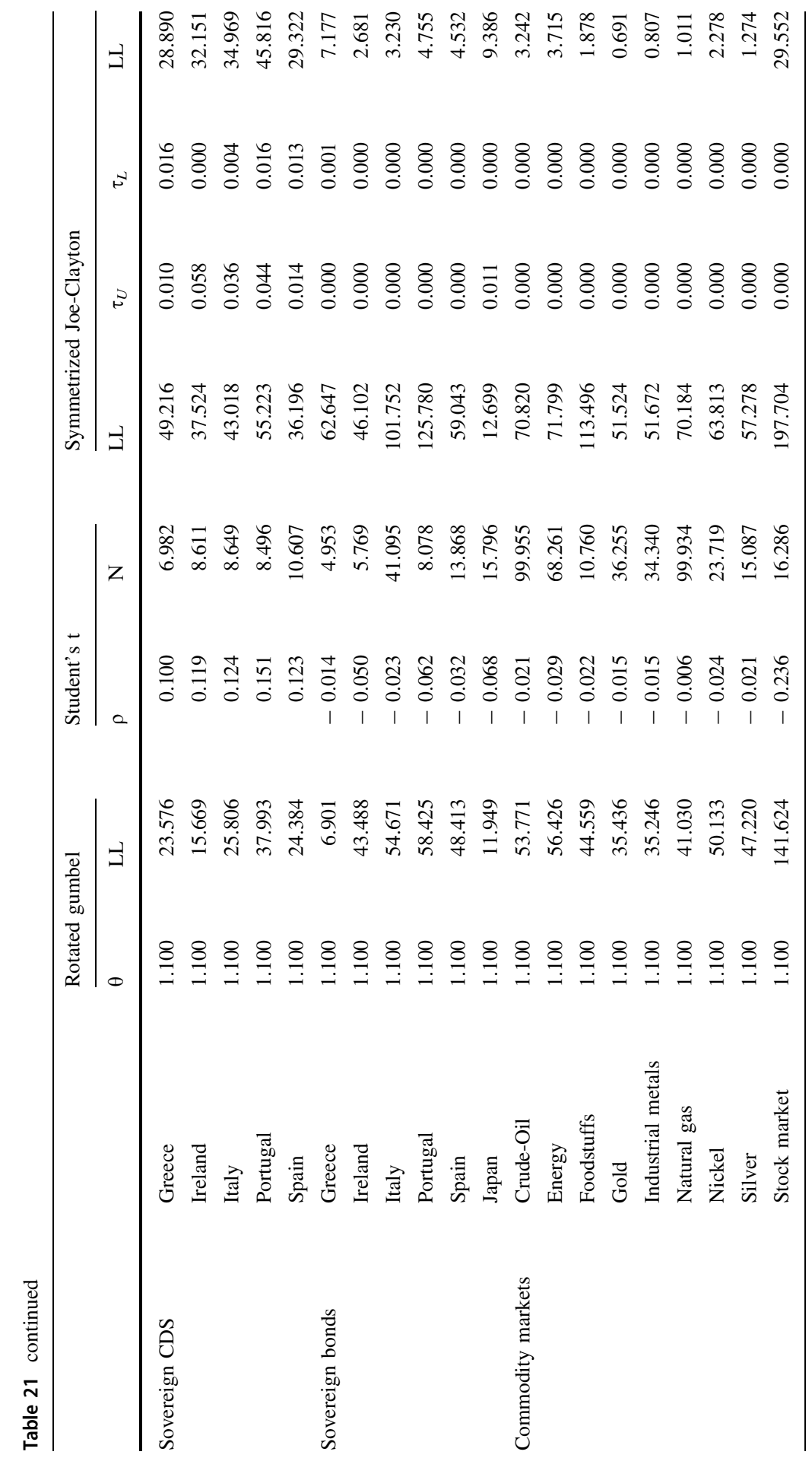




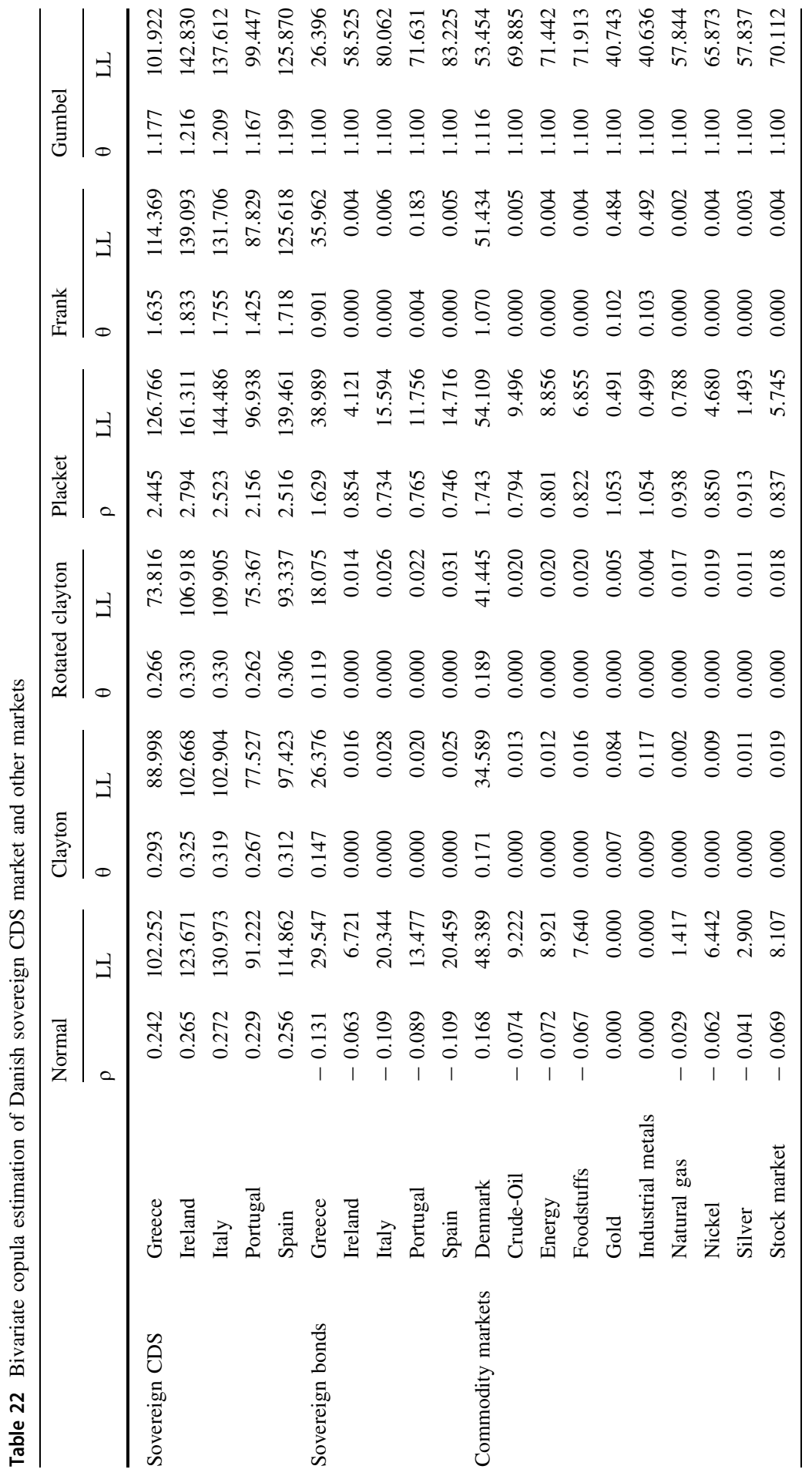




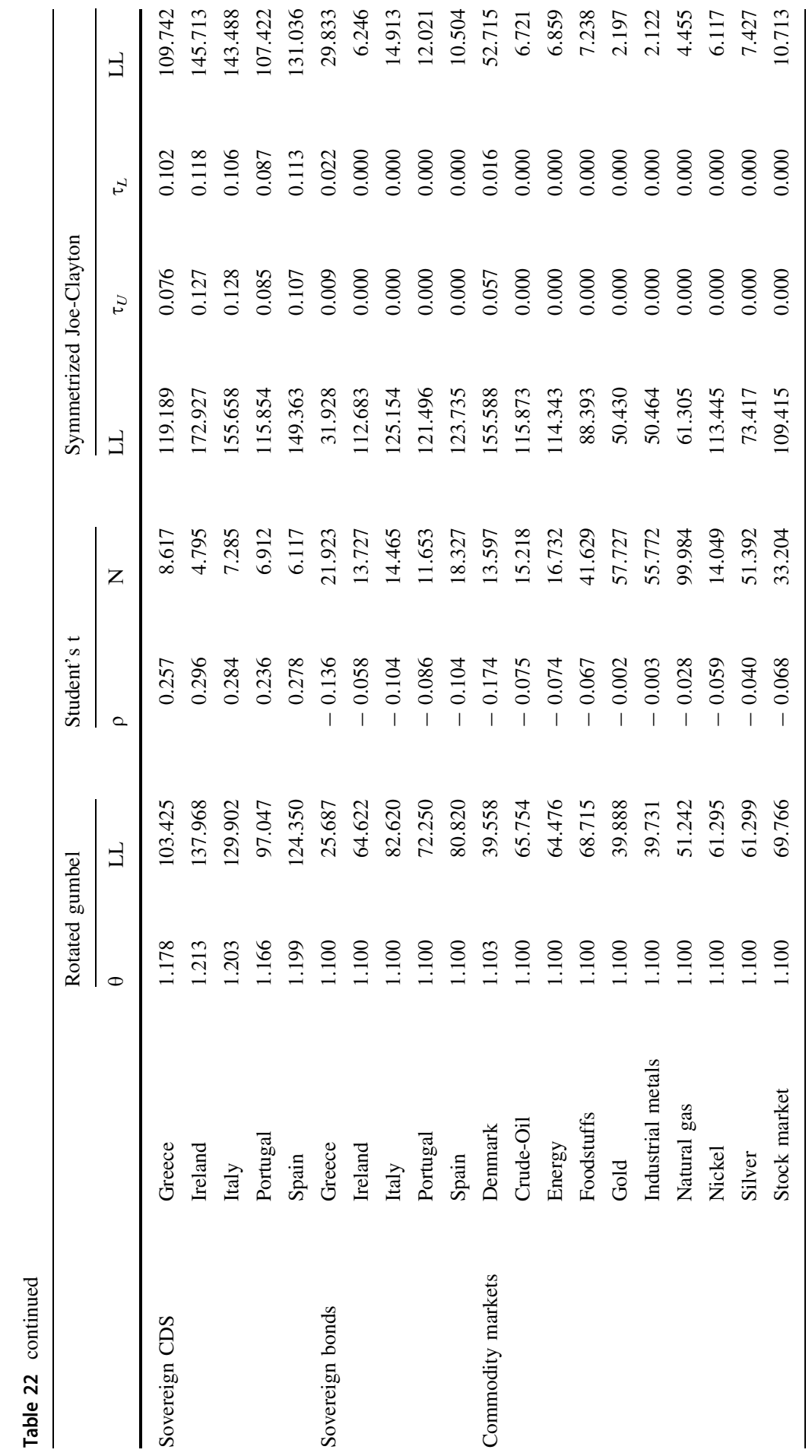




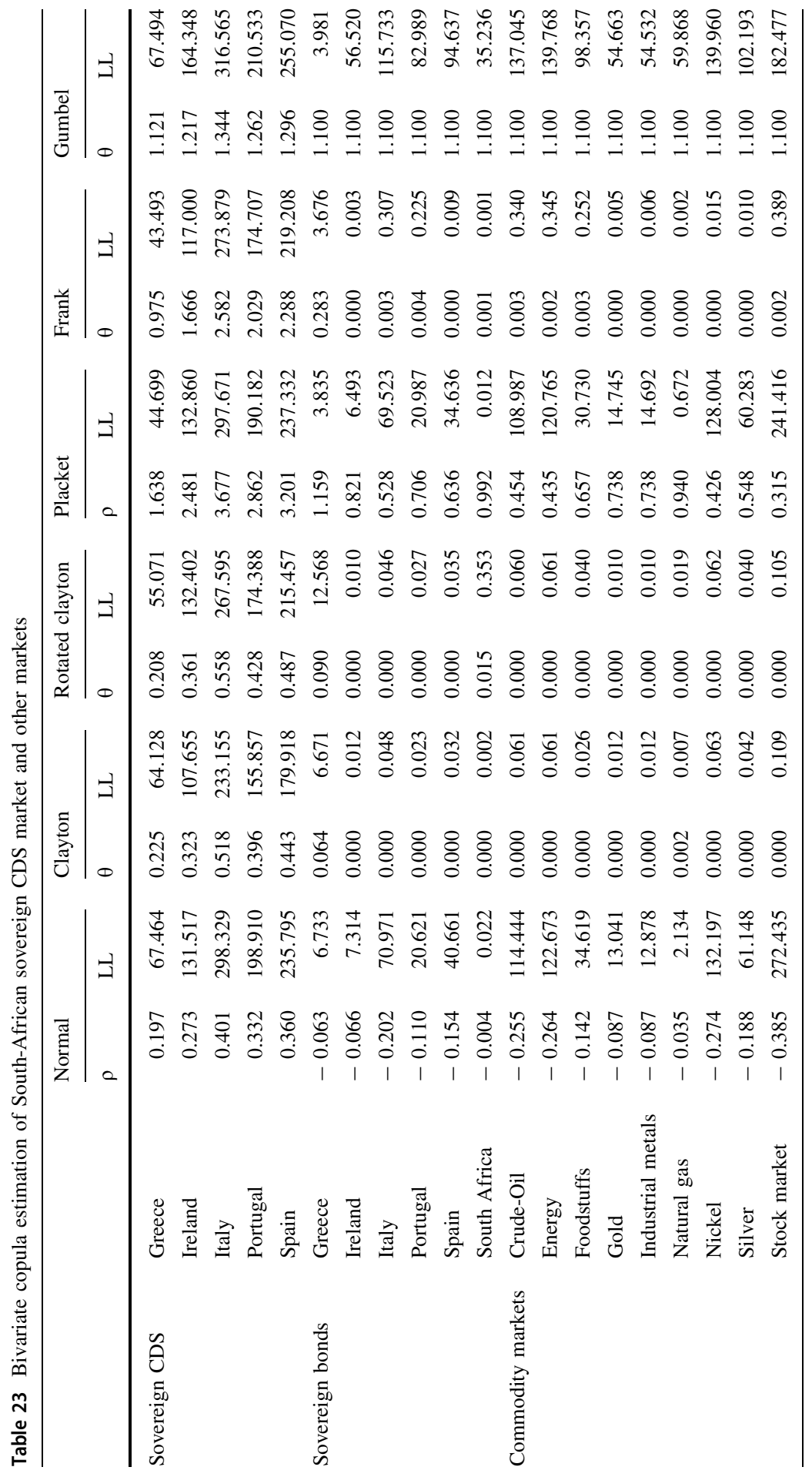




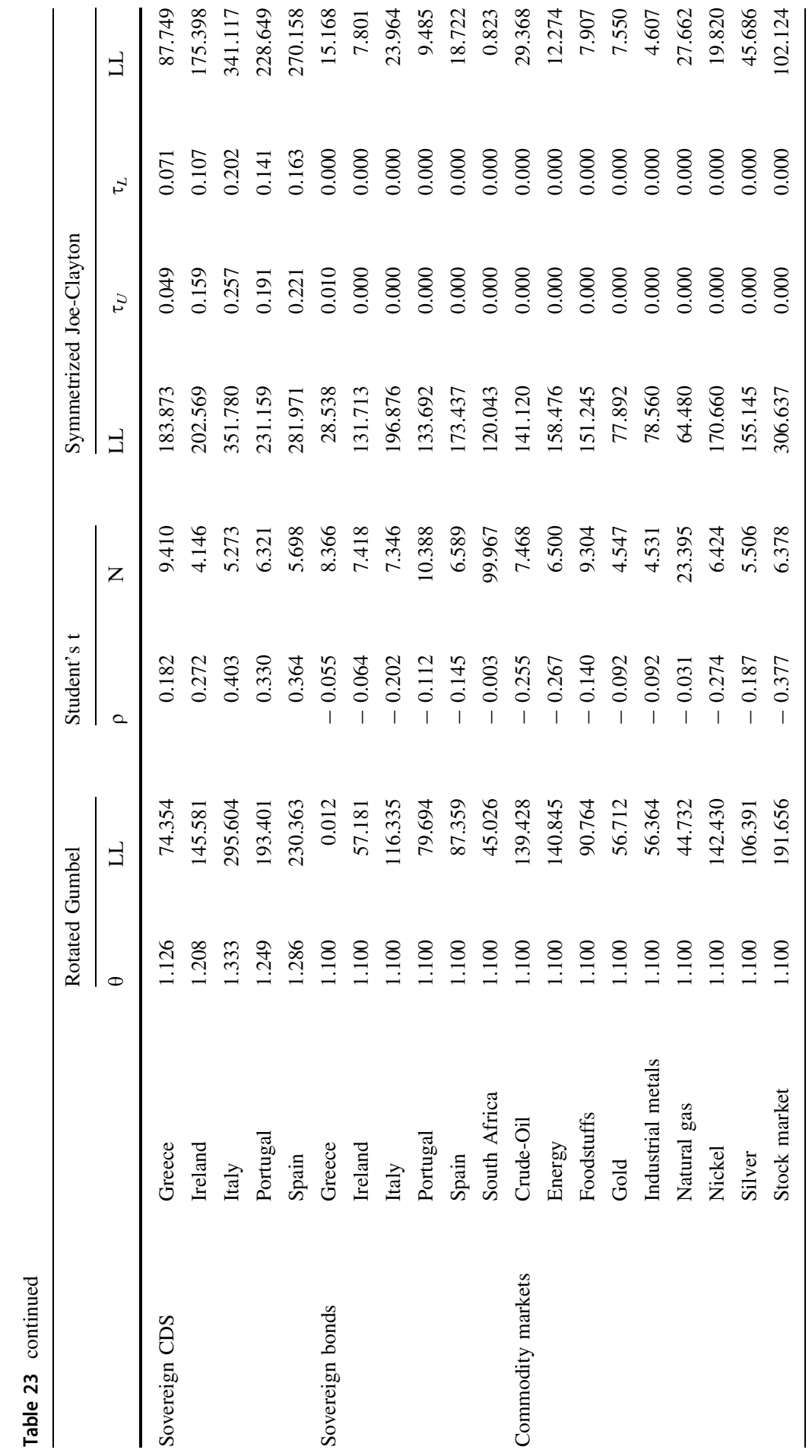




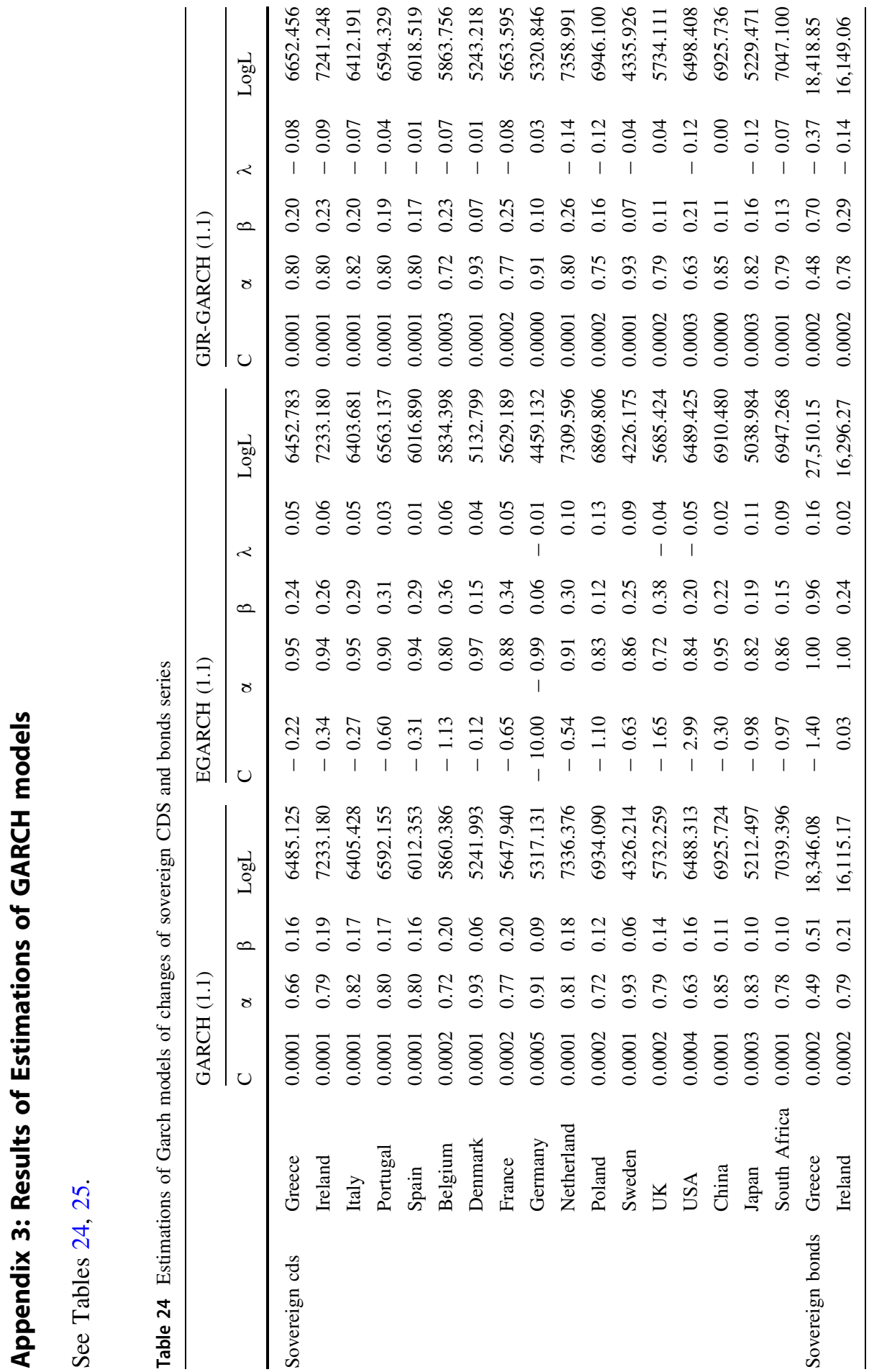




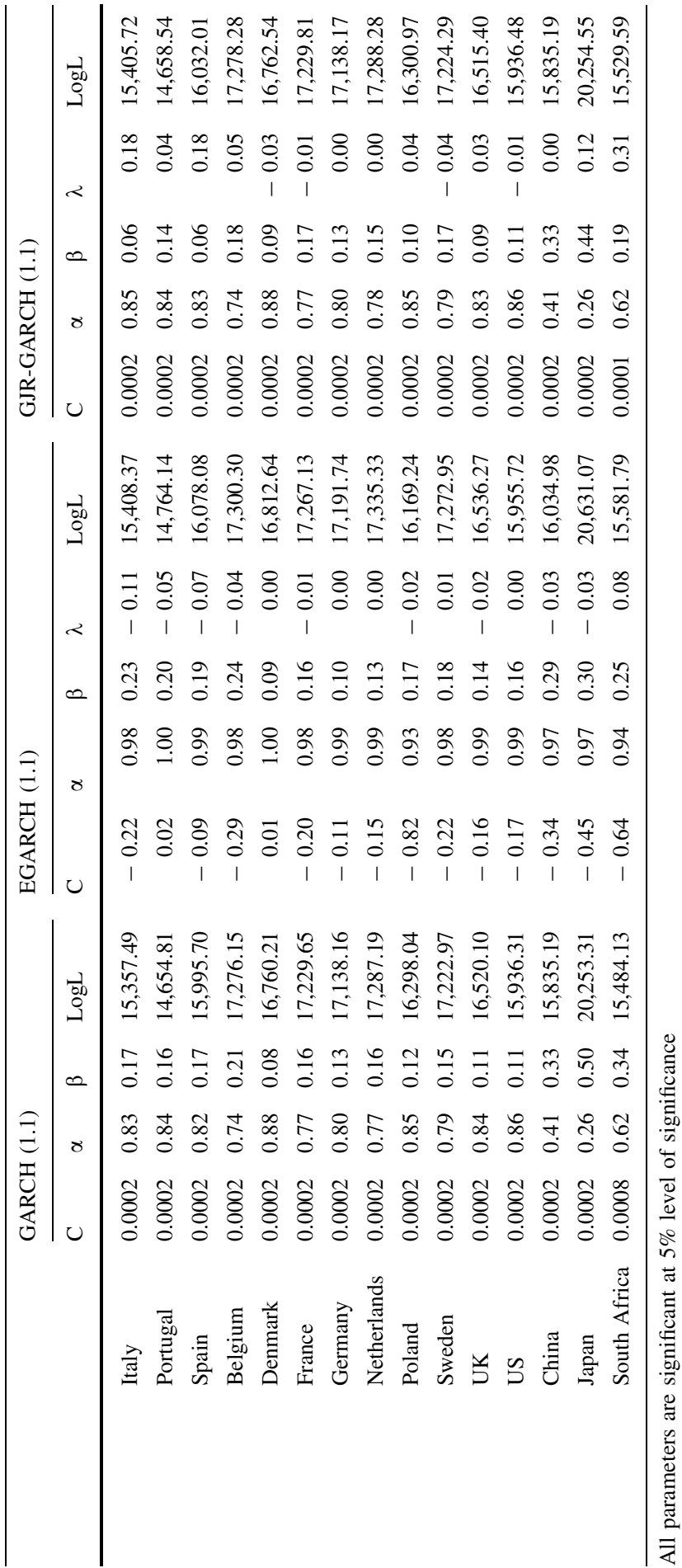




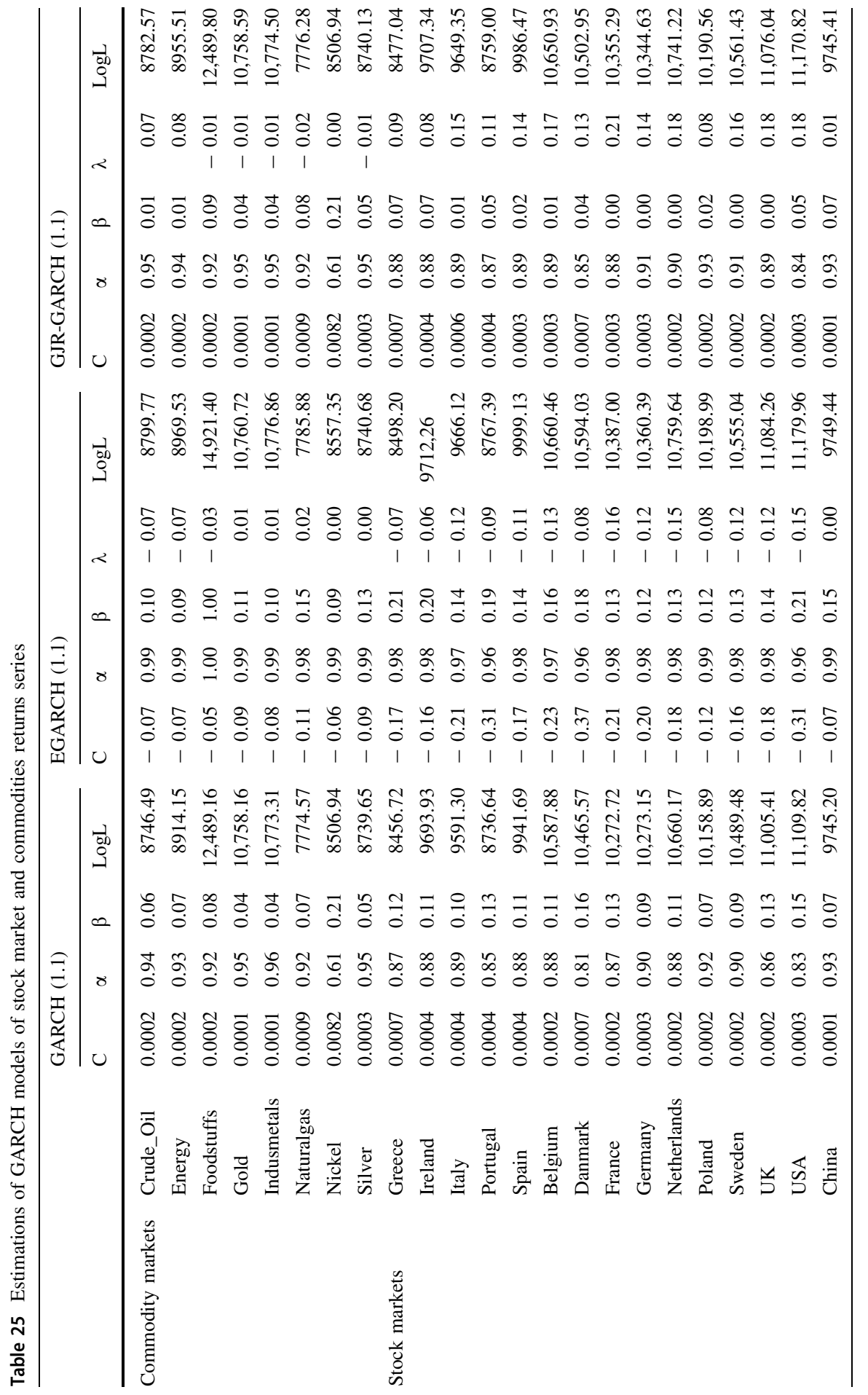




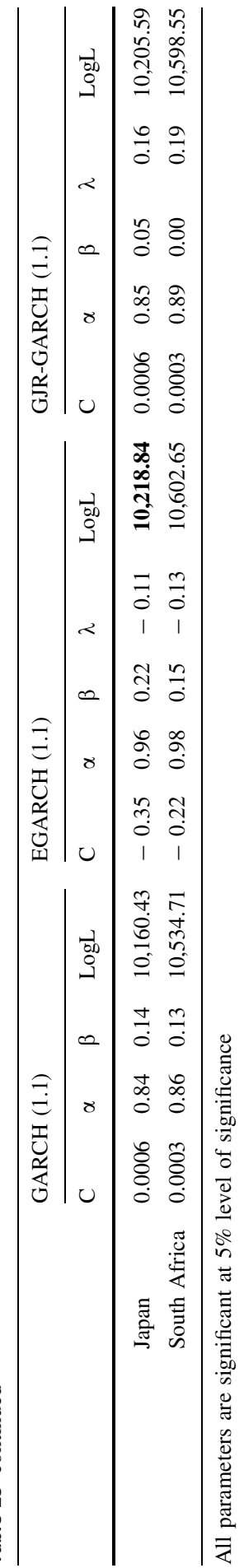




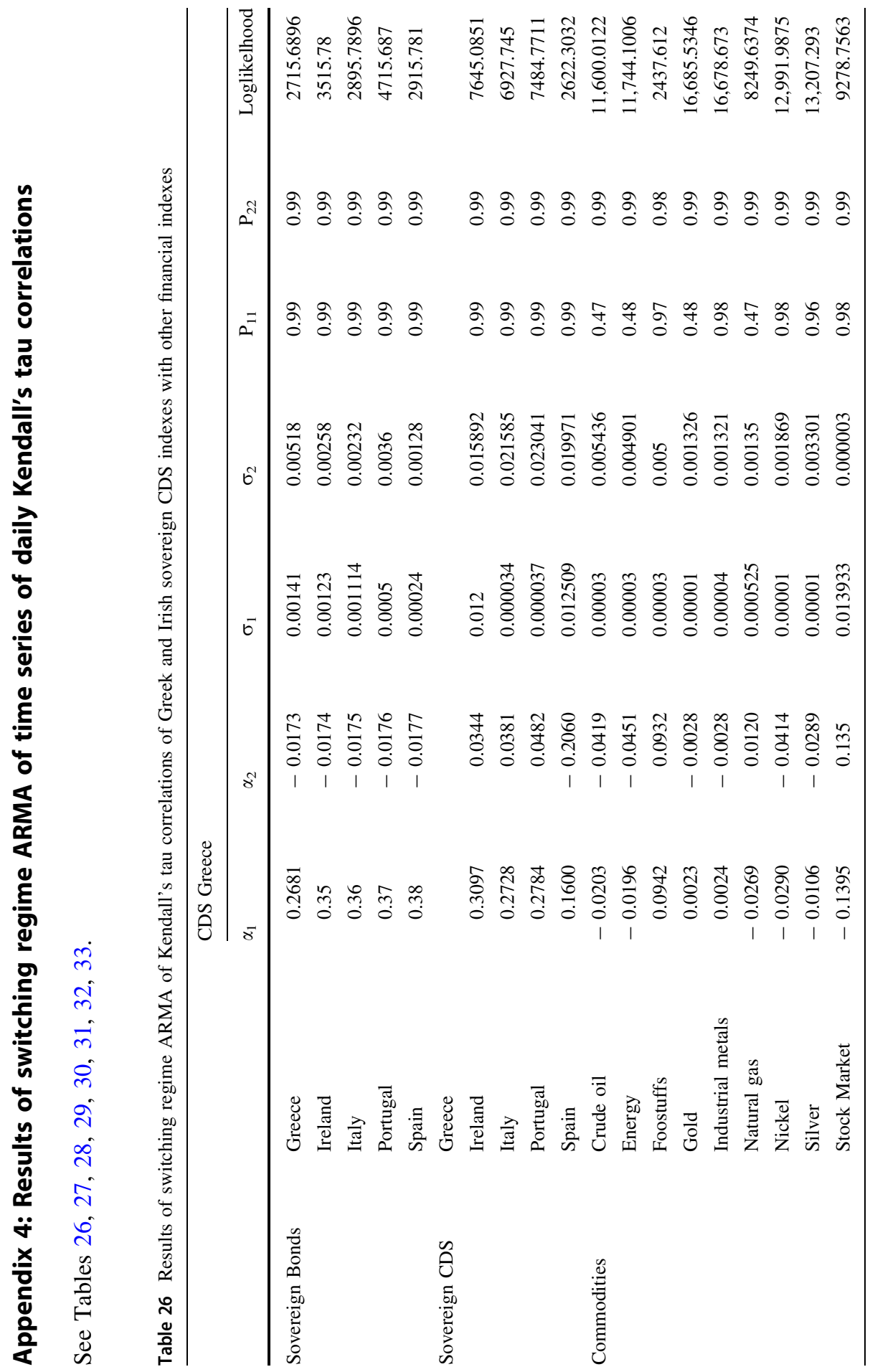




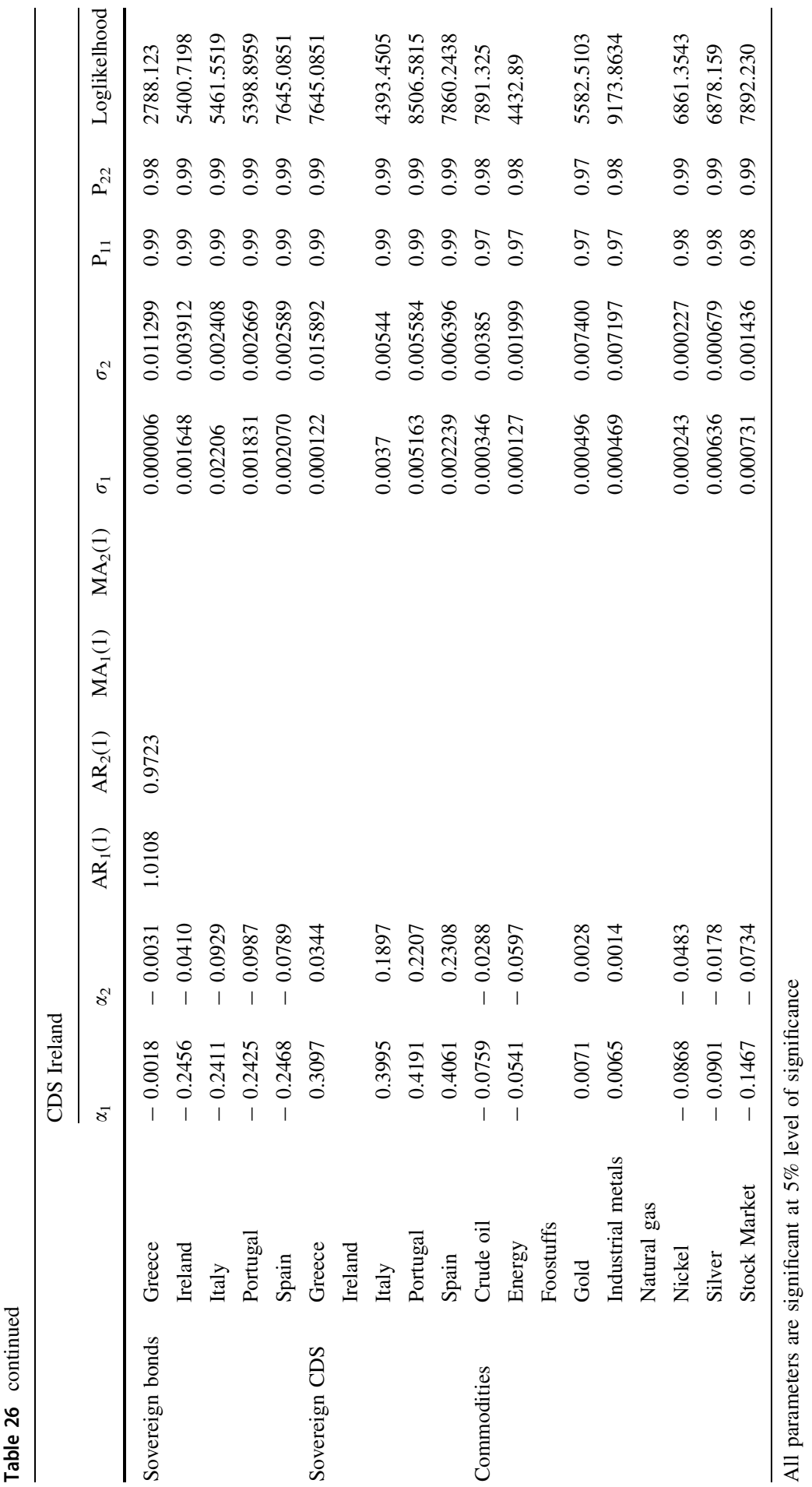




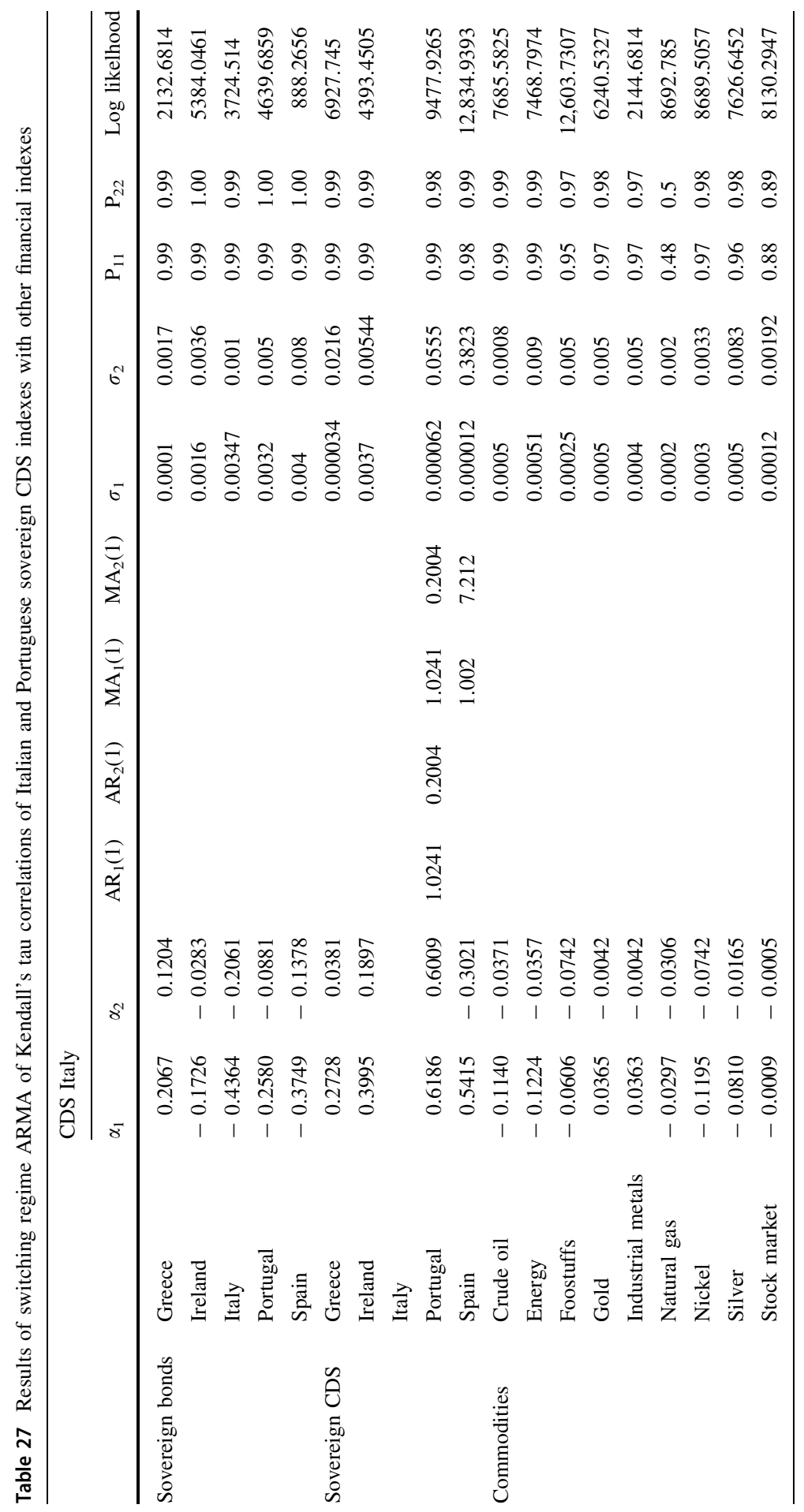




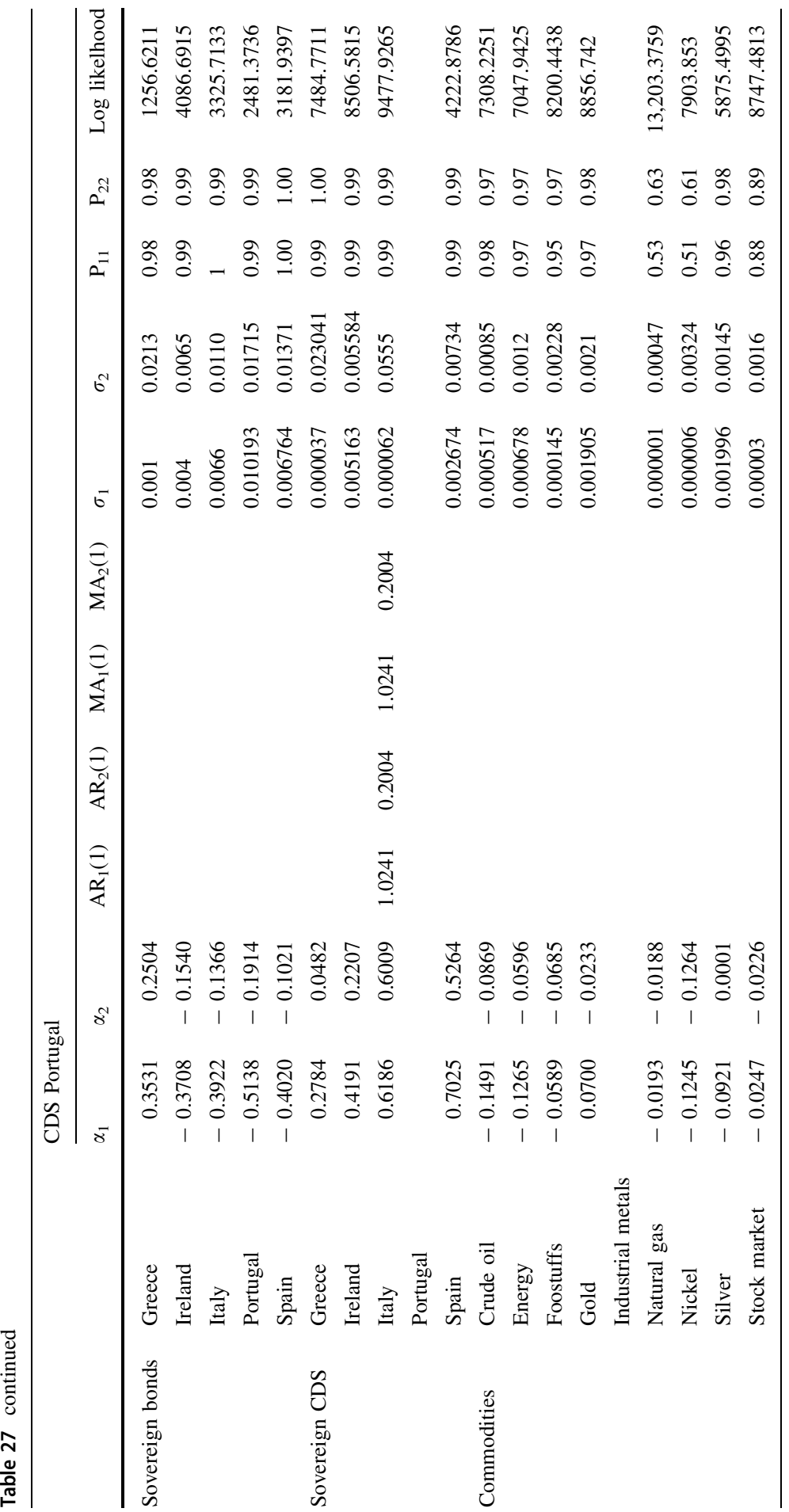




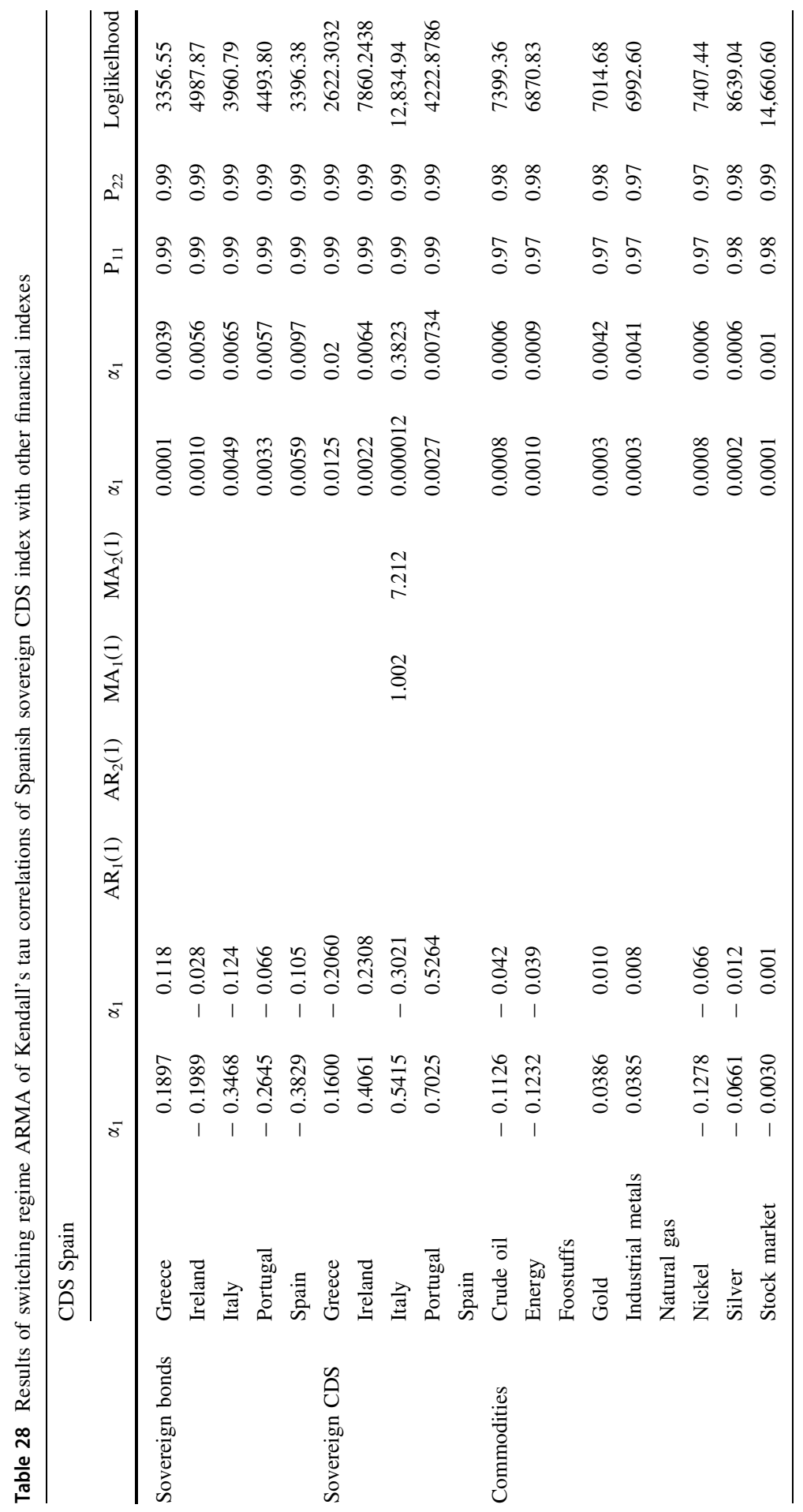




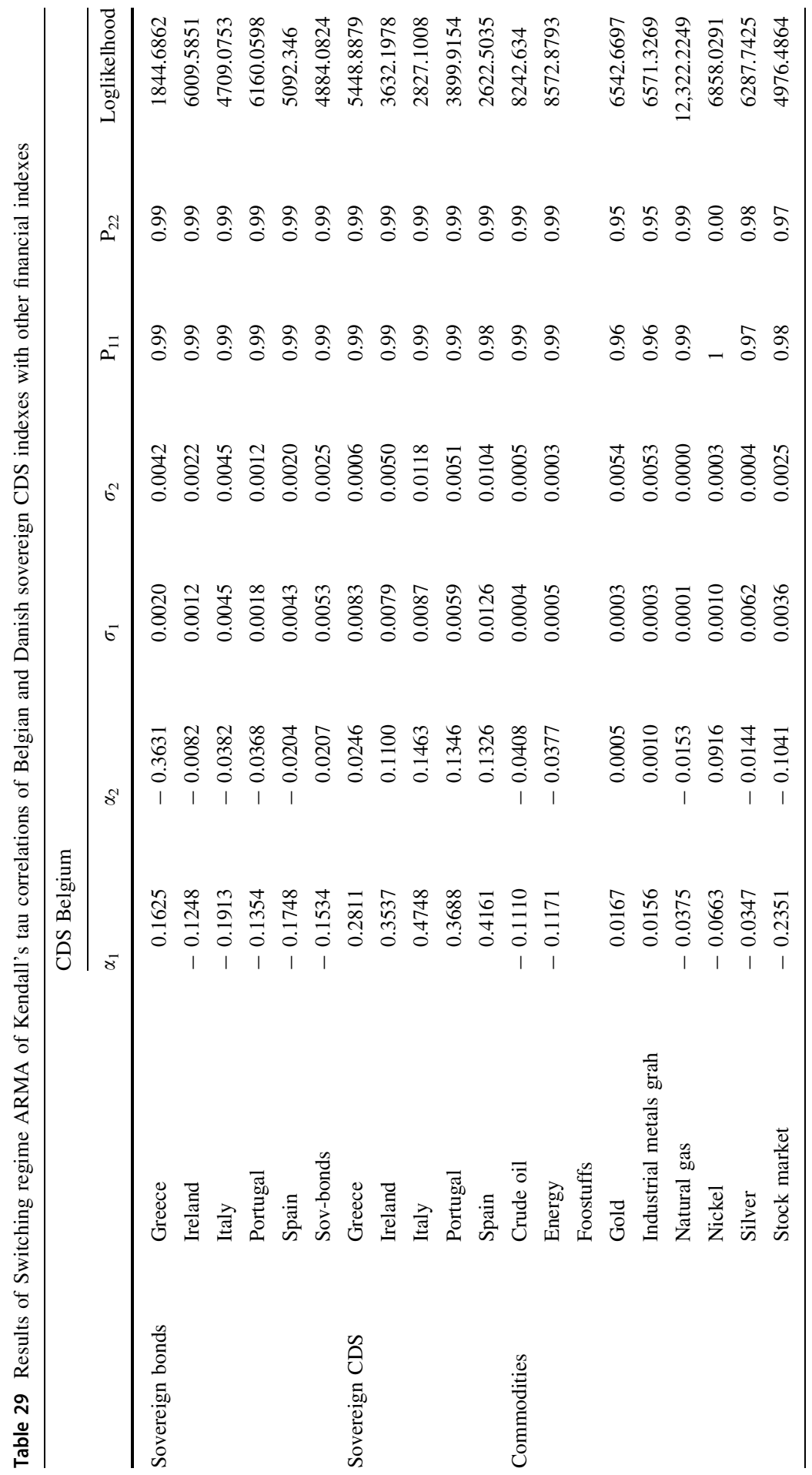




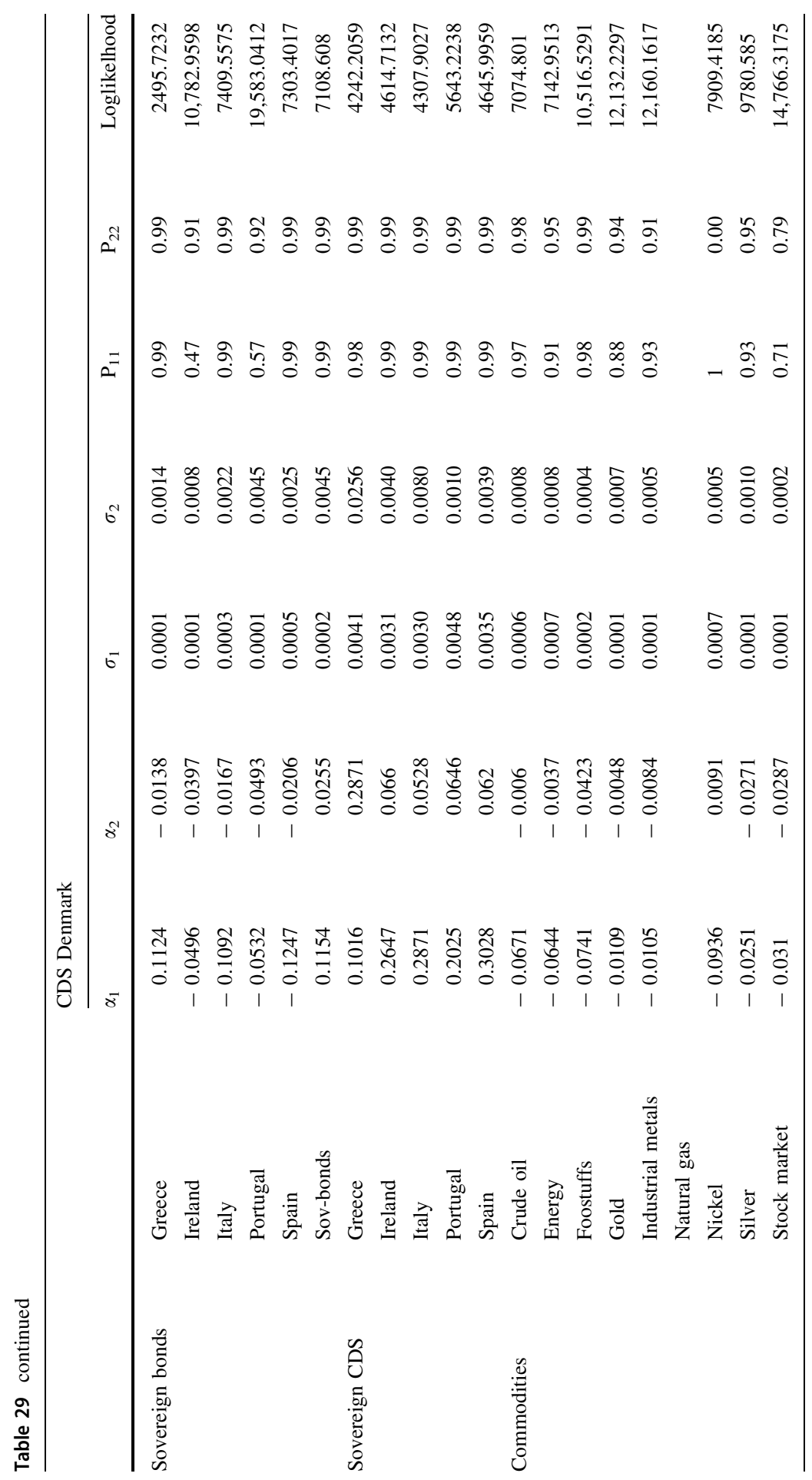




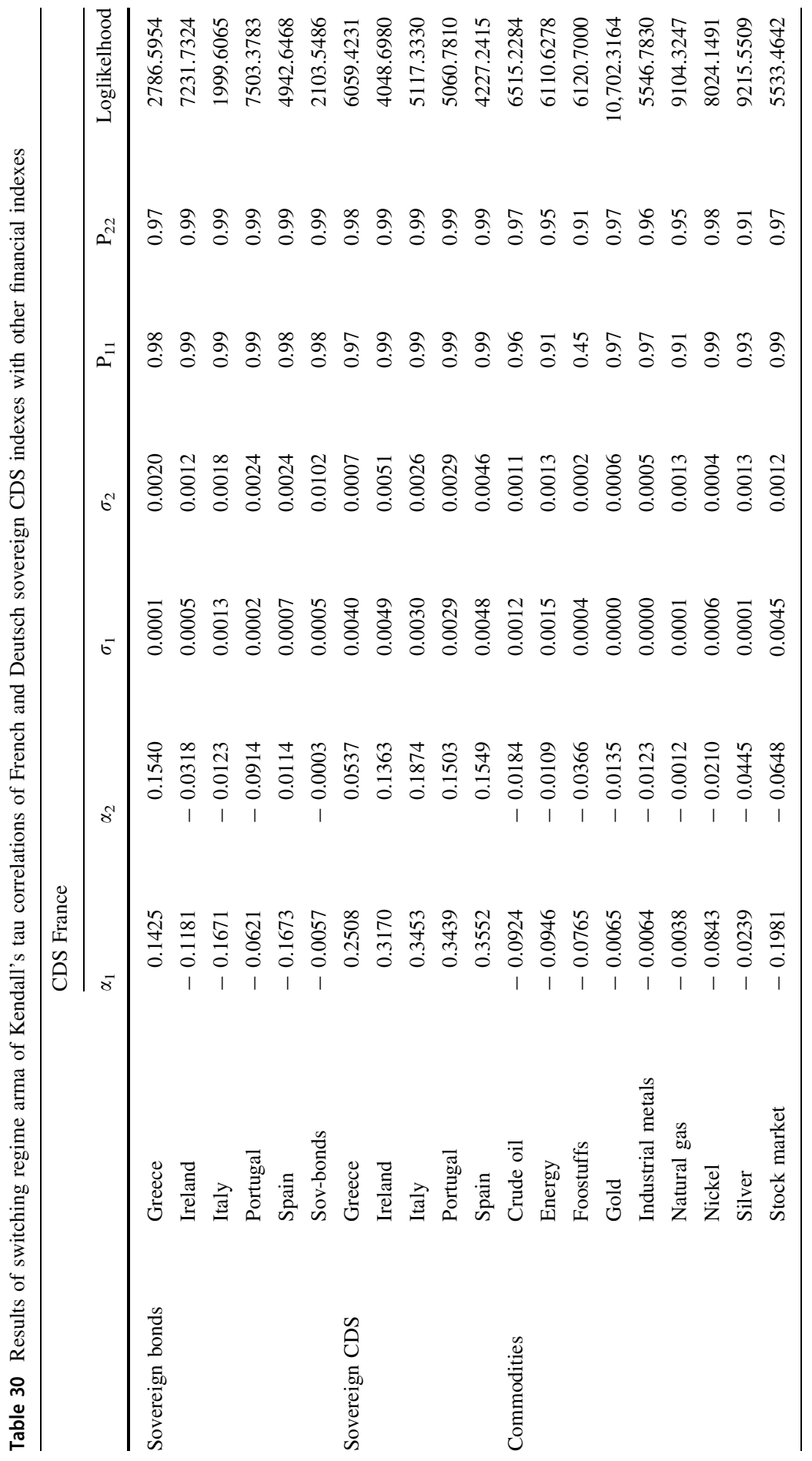




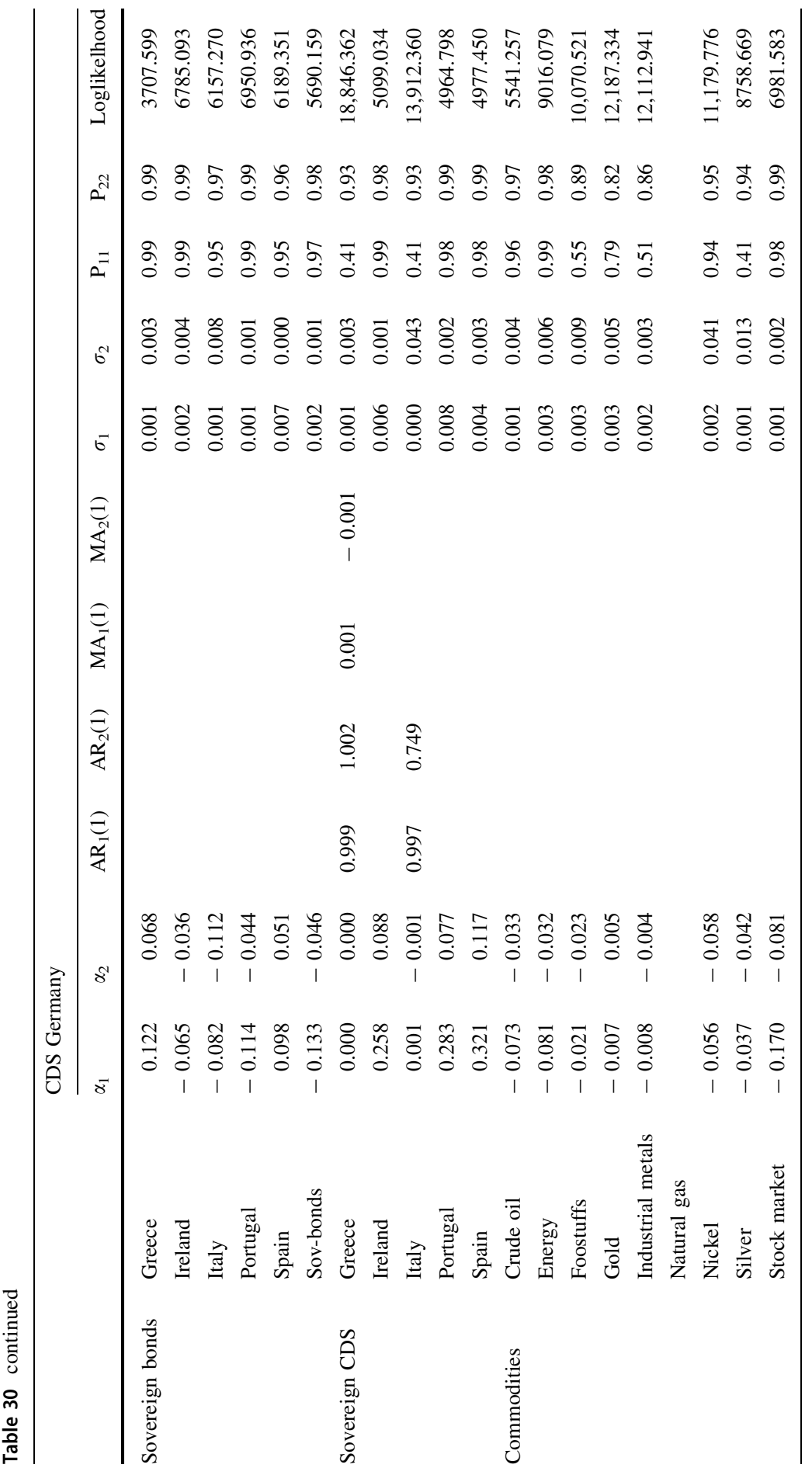




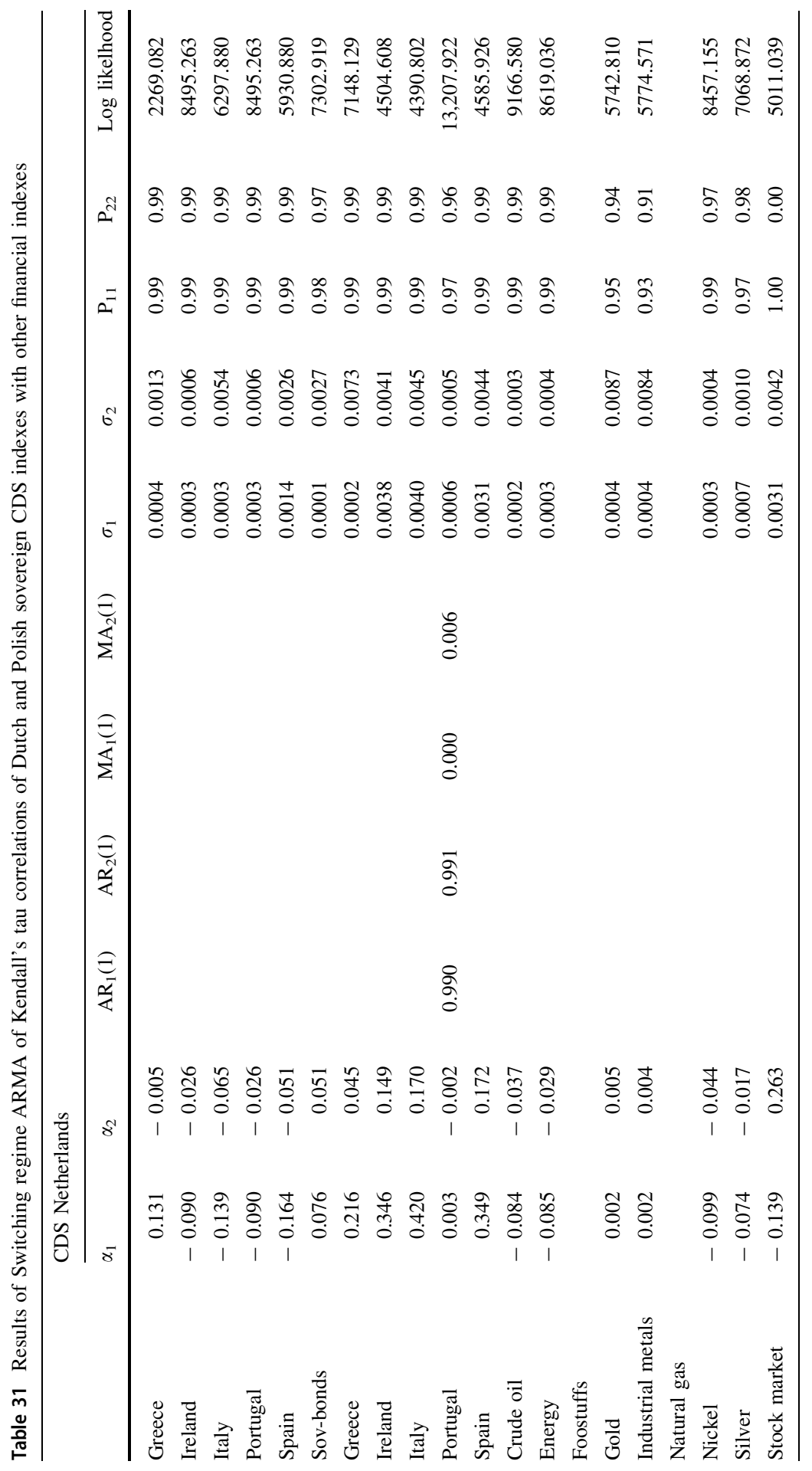




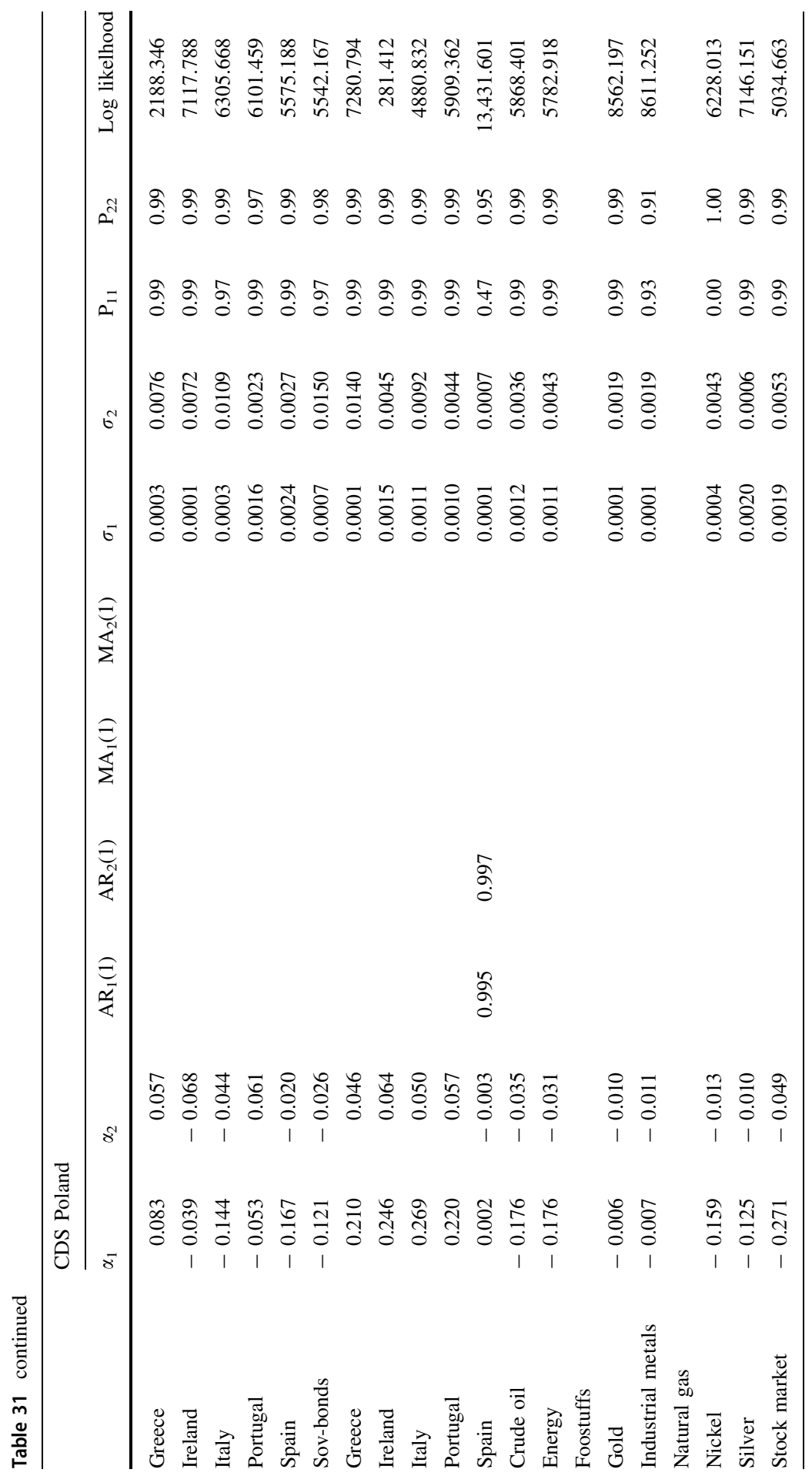




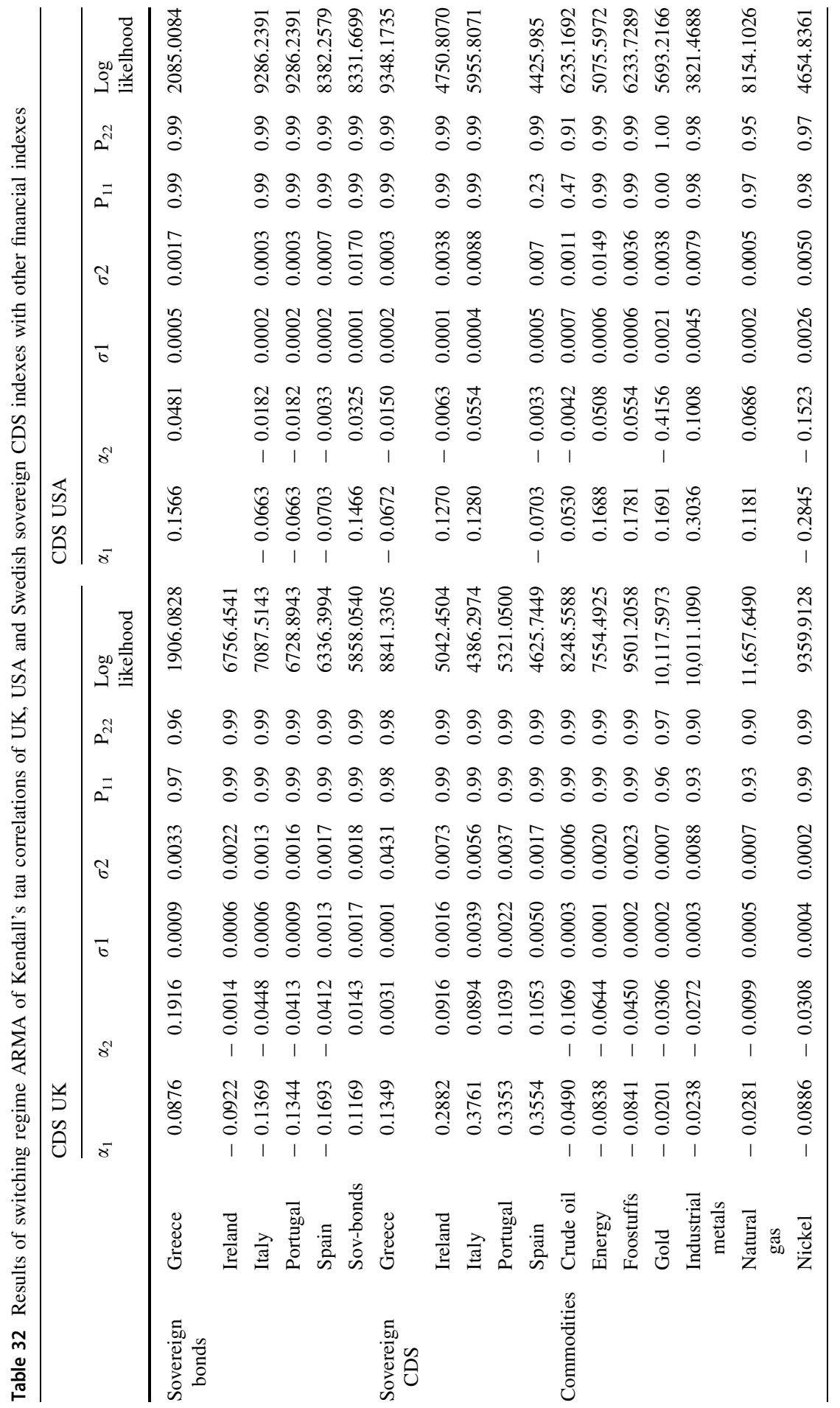




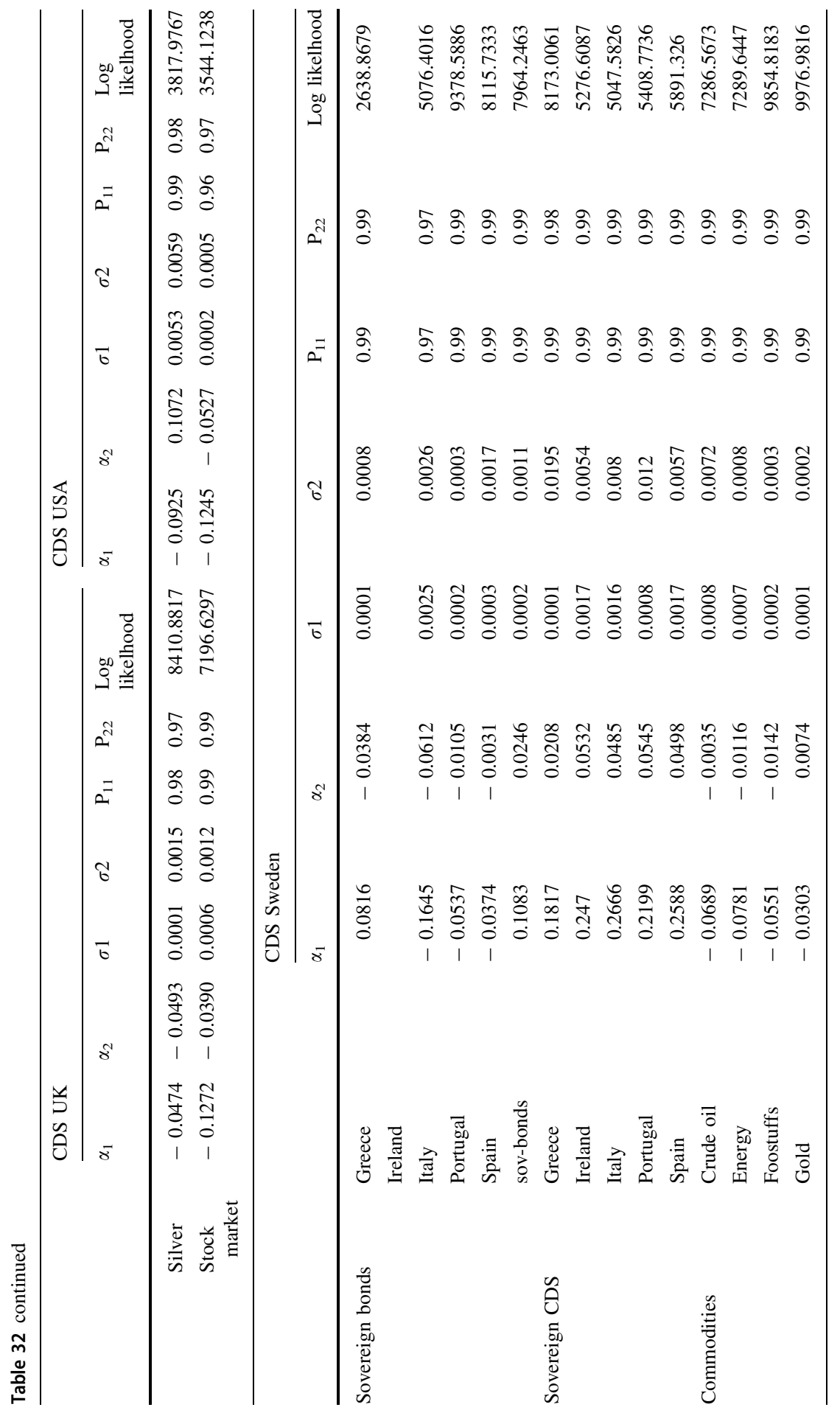




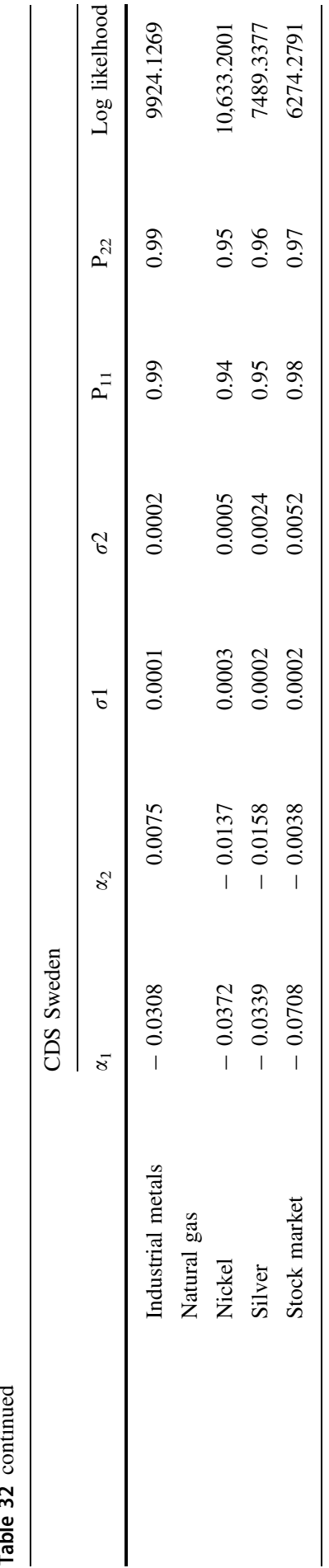




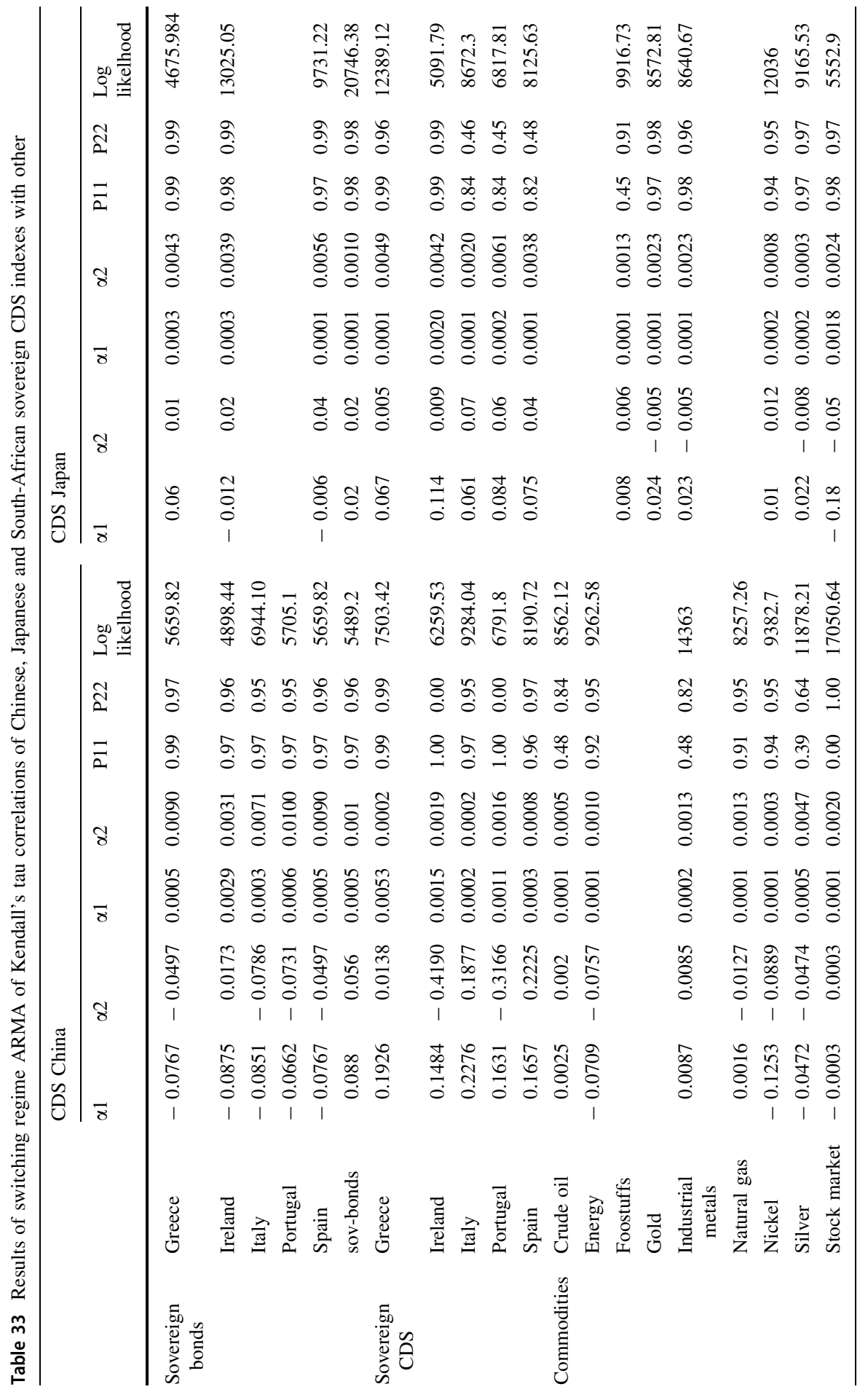




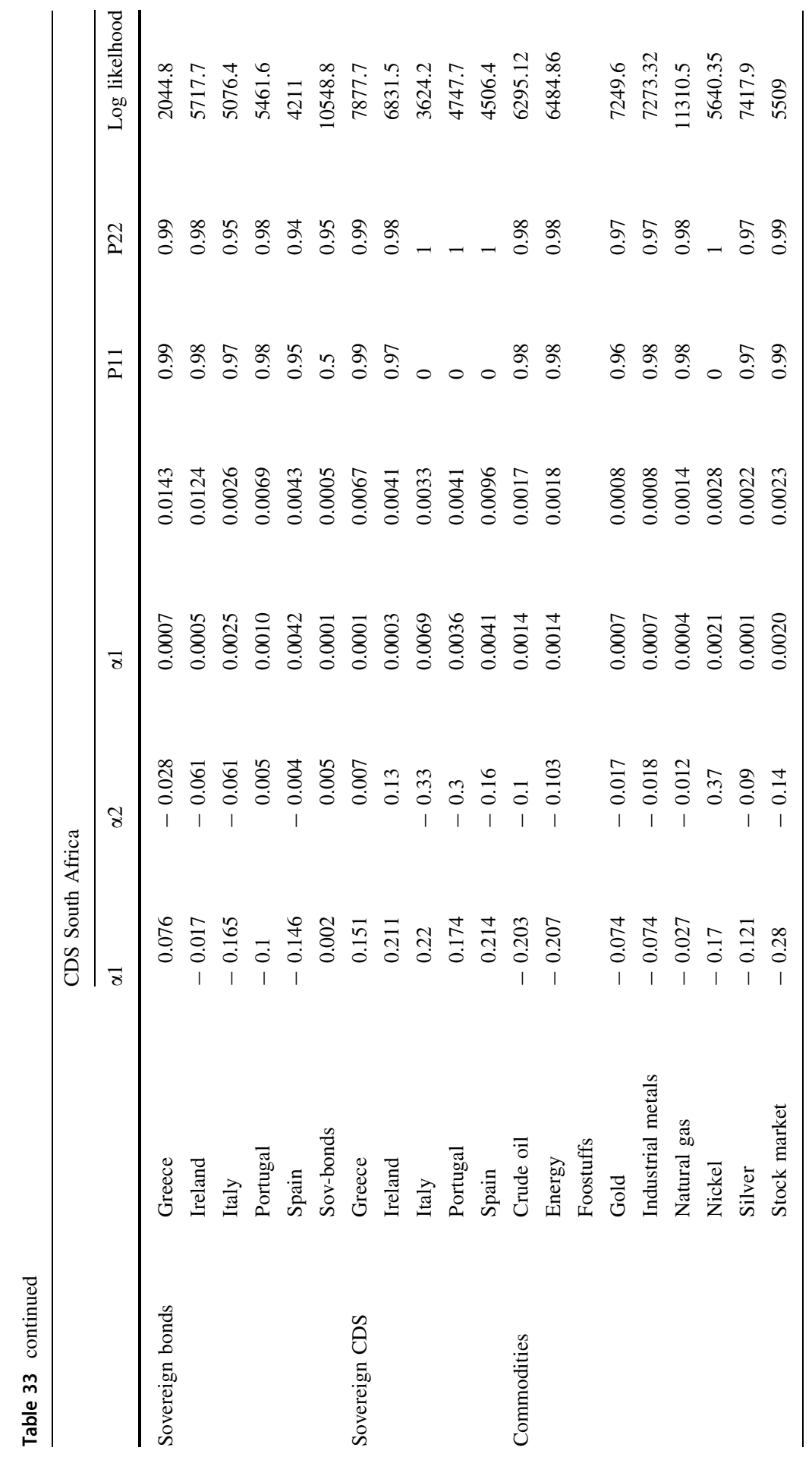




\section{References}

Allen, F., \& Gale, D. (2000). Financial contagion. Journal of Political Economy, 108, 1-33.

Alotaibi, A., \& Mishra, A. V. (2015). Global and regional volatility spillovers to GCC stock markets. Economic Modelling, 45(2), 38-49.

Aloui, C., \& Hkiri, B. (2014). Co-movements of GCC emerging stock markets: New evidence from wavelet coherence analysis. Economic Modelling, 36(1), 421-431.

Alter, A., \& Beyer, A. (2014). The dynamics of spillover effects during the European sovereign debt turmoil. Journal of Banking and Finance, 42, 134-153.

Alter, A., Schüler, Y.S. (2012). Credit spread interdependencies of European states and banks during the financial crisis. Journal of Banking \& Finance, 36(12), 3444-3468.

Apostolakis, G., \& Papadopoulos, A. P. (2015). Financial stress spillovers across the banking, securities and foreign exchange markets. Journal of Financial Stability, 19, 1-21.

Arezki, R., Bertrand, C., Amadou, S. (2011). Spillover Effects from the Munis, forthcoming IMF Working Paper (Washington: International Monetary Fund).

Barberis, N., Shleifer, A., \& Wurgler, J. (2005). Comovement. Journal of Financial Economic, 75, 283-317.

Bekaert, G., \& Hodrick, R. J. (1992). Characterizing predictable components in excess returns on equity and foreign exchange markets. The Journal of Finance, 47(2), 467-509.

Bekaert, G., \& Wu, G. (2000). Asymmetric volatility and risk in equity markets. Review of Financial Studies, 13(1), 1-42.

Black, F. (1976). Studies of stock price volatility changes. In Proceedings of the 1976 Meeting of the Business and Economic Statistics Section, American Statistical Association, Washington DC, 177-181.

Bollerslev, T. (1986). General autoregressive conditional heteroscedasticity. Journal of Econometrics, 31, 307-327.

Bollerslev, T., Chou, R. Y., \& Kroner, K. (1992). ARCH modeling in finance: A review of the theory and empirical evidence. Journal of Econometrics, 52, 5-59.

Bradley, B. O., \& Taqqu, M. S. (2005). How to estimate spatial contagion between financial markets. Finance Letters, 3(1), 64-76.

Brutti, F., Sauré, P. (2015). Repatriation of debt in the euro crisis: Evidence for the secondar market theory. Journal of the European Economic Association, forthcoming.

Chen, W., Ho, K.-C., \& Yang, L. (2020). Network structures and idiosyncratic contagion in the European sovereign credit default swap market. International Review of Financial Analysis, 72, 101594.

Christie, A. (1982). The stochastic behavior of common stock variances: Value, leverage, and interest rate effects. Journal of Financial Economics, 10, 407-432.

Clayton, D. G. (1978). A model for association in bivariate life tables and its application in epidemiological studies of familial tendency in chronic disease incidence. Biometrika, 65, 141-151.

Daehler, T. B., Aizenman, J., \& Jinjarak, Y. (2021). Emerging markets sovereign CDS spreads during COVID-19: Economics versus epidemiology news. Economic Modelling, 100, 105504.

De Bruyckere, V., Gerhardt, M., Schepens, G., \& Vander Vennet, R. (2013). Bank/sovereign risk spillovers in the European debt crisis. Journal of Banking \& Finance, 37(12), 4793-4809.

Diebold, F. X., \& Yilmaz, K. (2012). Better to give than to receive: Predictive directional measurement of volatility spillovers. International Journal of Forecasting, 28, 57-66.

Diebold, F. X., \& Yilmaz, K. (2014). On the network topology of variance decompositions: Measuring the connectedness of financial firms. Journal of Econometrics, 182, 119-134.

Dornbusch, R., Park, Y. C., Claessens, S. (2000). Contagion: Understanding how it spreads. The World Bank Research Observer, 15(2), 177-197.

Dueker, M. J. (1997). Markov switching in GARCH processes and mean-reverting stock market volatility. Journal of Business \& Economic Statistics, 15(1), 26-34.

Dungey, M., Fry-McKibbin, R., González-Hermosillo, B., \& Martin, V. L. (2006). Contagion in international bond markets during the Russian and the LTCM crises. Journal of Financial Stability, 2(1), 1-27.

Durante, F., \& Jaworski, P. (2010). Spatial contagion between financial markets: A copula-based approach. Applied Stochastic Models in Business and Industry, 26(9), 551-564.

Engle, R. F., Ito, T., \& Lin, W. L. (1990). Meteor showers or heat waves? Heteroskedastic intra-daily volatility in the foreign exchange market. Econometrica, 58, 525-542. 
Forbes, K., \& Rigobon, R. (2002). No contagion, only interdependence: Measuring stock market comovements. The Journal of Finance, 57, 2223-2261.

Frank, M. J. (1979). On the simultaneous associativity of $\mathrm{F}(\mathrm{x}, \mathrm{y})$ and $\mathrm{x}+\mathrm{y}-\mathrm{F}(\mathrm{x}, \mathrm{y})$. Aequationes Mathematicae, 19, 194-226.

Fratzscher, M., Lo Duca, M., \& Straub, R. (2016). ECB unconventional monetary policy: Market impact and international spillovers. IMF Economic Review, 64(1), 36-74.

Fry-McKibbin, R., Hsiao, C.Y.-L., \& Martin, V. L. (2021). Measuring financial interdependence in asset markets with an application to eurozone equities. Journal of Banking and Finance, 122, 105985.

Glosten, L. R., Jagannathan, R., \& Runkle, D. (1993). On the relation between the expected value and the volatility of the nominal excess return on stocks. Journal of Finance, 48, 1779-1801.

Grammatikos, T., \& Vermeulen, R. (2012). Transmission of the financial and sovereign debt crises to the EMU: Stock prices, CDS spreads and exchange rates. Journal of International Money and Finance, 31(3), 517-533.

Granger, C. W. J. (1969). Investigating causal relations by econometric models and cross-spectral methods. Econometrica, 37(3), 424-438.

Grubel, H. G., \& Fadner, K. (1971). The interdependence of international equity markets. Journal of Finance, 26(1), 89-94.

Gumbel, E. J. (1960). Distributions des valeurs extrêmes en plusieurs dimensions. Publications De L'institut De Statistique De L'université De Paris, 9, 171-173.

Hamilton, J. D. (1989). A new approach to the economic analysis of nonstationary time series and the business cycle. Econometrica, 57(2), 357-384.

Hamilton, J. D., \& Susmel, R. (1994). Autoregressive conditional heteroskedasticity and changes in regime. Journal of Econometrics, 64, 307-333.

Hryckiewicz, A. (2014). What do we know about the impact of government interventions in the banking sector? An assessment of various bailout programs on bank behavior. Journal of Banking and Finance, 46, 246-265.

Hwang, E. H., Min, H. G., Kim, B. H., \& Kim, H. (2013). Determinants of stock market co movements among US and emerging economies during the US financial crisis. Economic Modelling, 35(9), 338-348.

Ji, Q., Bouri, E., \& Roubaud, D. (2018a). Dynamic network of implied volatility transmission among US equities, strategic commodities, and BRICS equities. International Review of Financial Analysis, 57, $1-12$.

Ji, Q., Bouri, E., Gupta, R., \& Roubaud, D. (2018b). Network causality structures among Bitcoin and other financial assets: A directed acyclic graph approach. The Quarterly Review of Economics and Finance, 70, 203-213.

Ji, Q., Marfatia, H., \& Gupta, R. (2018c). Information spillover across international real estate investment trusts: Evidence from an entropy-based network analysis. North American Journal of Economics and Finance, 46, 103-113.

King, M., \& Wadhwani, S. (1990). Transmission of volatility between stock markets. Review of Financial Studies, 3, 5-33.

Kizys, R., Paltalidis, N., \& Vergos, K. (2016). The quest for banking stability in the euro area: The role of government interventions. Journal of International Financial Markets, Institutions and Money, 40, 111-133.

Kohonen, A. (2014). Transmission of government default risk in the eurozone. Journal of International Money and Finance, 47, 71-85.

Lamoureux, C. G., \& Lastrapes, W. D. (1990). Persistence in variance, structural change, and the GARCH model. Journal of Business \& Economic Statistics, 8(2), 225-234.

Louzis, D. P. (2015). Measuring spillover effects in euro area financial markets: A disaggregate approach. Empirical Economics, 49, 1367-1400.

Masson, P. (1999a). Contagion: Macroeconomic models with multiple equilibria. Journal of International Money and Finance, 18, 587-602.

Masson, P. (1999b). Contagion: Monsoonal effects, spillovers, and jumps between multiple equilibria. IMF Working Paper 142.

Masson, P. (1999c). Multiple equilibria, contagion and the emerging market crises. IMF Working Paper 164.

Nelson, D. B. (1991). Conditional heteroskedasticity in asset returns: A new approach. Econometrica, 59(2), 347-370. 
Patton, A. J. (2004). On the out-of-sample importance of skewness and asymmetric dependence for asset allocation. Journal of Financial Econometrics, 2(1), 130-168.

Pericoli, M., \& Sbracia, M. (2003). A primer on financial contagion. Journal of Economic Surveys, 17(4), 571-608.

Plackett, R. L. (1965). A class of bivariate distributions. Journal of the American Statistical Association, $60,516-522$.

Sachs, J. D., Tornell, A., \& Velasco, A. (1996). The Mexican peso crisis: Sudden death or death foretold? Journal of International Economics, 41(3-4), 265-283.

Sharpe, W. F. (1964). Capital asset prices: A theory of market equilibrium under conditions of risk. Journal of Finance, 19(3), 425-442.

Sklar, A. (1959). Fonctions de répartition à n dimensions et leurs marges. Publications De L'institut De Statistique De L'université De Paris, 8, 229-231.

Sun, X., Wang, J., Yao, Y., Li, J., \& Li, J. (2020). Spillovers among sovereign CDS, stock and commodity markets: A correlation network perspective. International Review of Financial Analysis, 68, 101271.

Schweitzer, F., Fagiolo, G., Sornette, D., Vega-Redondo, F., Vespignani, A., \& White, D. R. (2009). Economic networks: The new challenges. Science, 325, 422-425.

Sharma, S. S., \& Thuraisamy, K. (2013). Oil price uncertainty and sovereign risk: Evidence from Asian economies. Journal of Asian Economics, 28, 51-57.

Sun, E., Tenengauzer, D., Bastani, A., \& Rezania, O. (2011). Identification of driving factors for emerging markets sovereign spreads. Economics Bulletin, 31(3), 2584-2592.

Tabak, B. M., de Castro Miranda, R., \& da Silva Medeiros, M. (2016). Contagion in CDS, banking and equity markets. Economic Systems, 40, 120-134.

Wang, A. T. (2018). The information transmissions between the European sovereign CDS and the sovereign debt markets of emerging countries Asia Pacific. Management Review, 24, 2.

Zhang, B., Zhou, H., \& Zhu, H. (2009). Explaining credit default swap spreads with the equity volatility and jump risks of individual firms. Review of Financial Studies, 22(12), 5099-5131.

Zhang, W., Zhang, G., Helwege, J. (2021). Cross country linkages and transmission of sovereign risk: Evidence from China's credit default swaps. Journal of Financial Stability. https://doi.org/10.1016/ j.jfs.2020.100838

Publisher's Note Springer Nature remains neutral with regard to jurisdictional claims in published maps and institutional affiliations. 